$$
\begin{aligned}
& \text { Hith the len ciomplimests } \\
& \text { or As C/divoin }
\end{aligned}
$$

BOTANISCHEN MUSEUM OER EIDGENÖSS. TECHNISCHEN HOCHSCHULE

\title{
MONOGRAPHISCHE STUDIEN AM ZUGERSEE
}

\section{VON DER \\ EIDGENÖSSISCHEN \\ TECHNISCHEN HOCHSCHULE IN ZÜRICH \\ ZUR ERLANGUNG DER \\ WÜRDE EINES DOKTORS DER \\ :: NATURWISSENSCHAFTEN :: \\ GENEHMIGTE \\ PROMOTIONSARBEIT}

VORGELEGT VON

ADOLF BRUTSCHY,

DIPL. FACHLEHRER IN NATURWISSENSCHAFTEN

AUS RHEINFELDEN

REFERENT: HERR PROF. DR. C. SCHRÖTER

KORREFERENT: HERR PROF. DR. P. JACCARD

STUTTGART 1912

E. SCHWEIZERBARTSCHE VERLAGSBUCHHANDLUNG NÄGELE \& DR. SPROESSER 


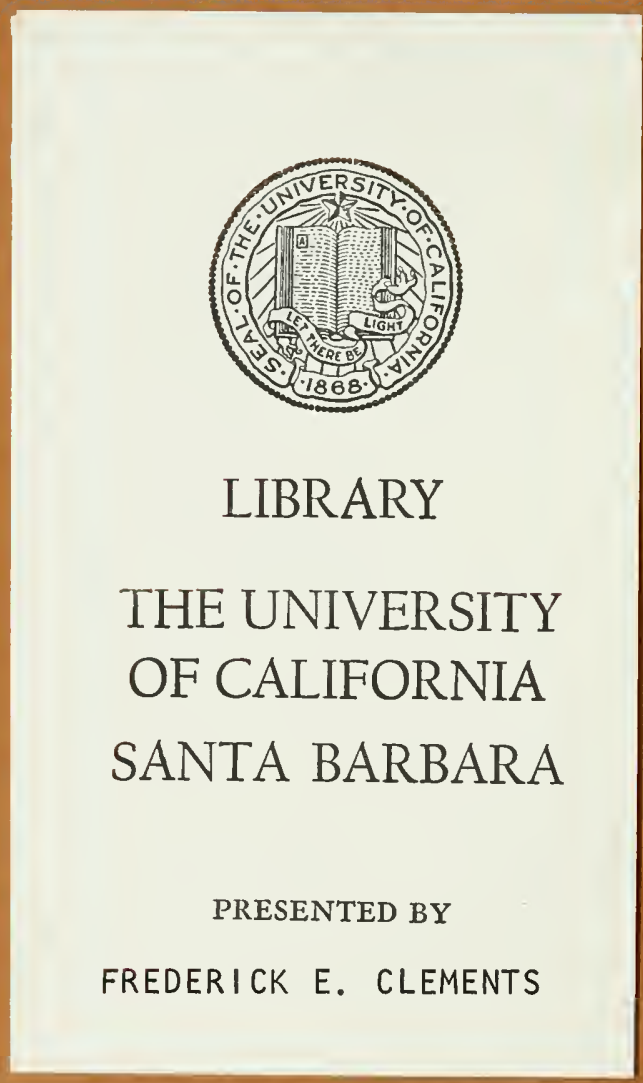




\title{
MONOGRAPHISCHE STUDIEN AM ZUGERSEE
}

\begin{abstract}
VON DER
EIDGENÖSSISCHEN

TECHNISCHEN HOCHSCHULE IN ZÜRICH
\end{abstract}

ZUR ERLANGUNG DER

WÜRDE EINES DOKTORS DER

:: NATURWISSENSCHAFTEN ::

GENEHMIGTE

PROMOTIONSARBEIT

VORGELEGT VON

ADOLF BRUTSCHY,

DIPL. FACHLEHRER IN NATURWISSENSCHAFTEN

AUS RHEINFELDEN

REFERENT: HERR PROF. DR. C. SCHRÖTER

KORREFERENT: HERR PROF. DR. P. JACCARD

STUTTGART 1912

E. SCHWEIZERBARTSCHE VERLAGSBUCHHANDLUNG

NÄGELE \& DR. SPROESSER 



\section{Vorwort.}

Vorliegende Arbeit wurde im April 1906 auf Anraten von Herrn Professor Schröter in Angriff genommen. Unter seiner Leitung besuchte ich den Zugersee zunächst monatlich 2 mal von Zürich aus. Von 1908 an mußte ich mich teils infolge der umständlicheren Verkehrsverhältnisse von meinem Wohnort Seon aus, teils infolge weitgehender Inanspruchnahme dureh mein Lehramt auf nur einen monatlichen Besuch beschränken.

Herr Professor Schröter war stets bemüht, mir alle Neuerscheinungen der Fachliteratur zukommen zu lassen. Dieser Freundlichkeit habe ich es zu verdanken, daß ich meine Arbeit neben meiner Berufstätigkeit vollenden konnte, ohne diese unterbrechen zu müssen. Es ist mir deshalb eine angenehme Pflicht, meinem hochverehrten Lehrer und freundlichen Berater an dieser Stelle meinen wärmsten Dank auszusprechen.

Mein Dank gebührt auch den Herren Professoren Früı, Heim und Heuscher in Zürich, Prof. Bieler in Zug, Prof. BachMANx in Luzern und Secundarlehrer MeIster in Horgen für ihre bereitwilligst erteilten Auskünfte, sowie der Direktion der Seetalbahn für die weitgehendste Vergünstigung bei Benützung ihrer Strecke.

S e o n, im Juli 1911.

Der Verfasser. 



\title{
Monographische Studien am Zuger- see.
}

\author{
Von ADOLF BRUTSCHY (Rheinfelden).
}

(Mit Taf. I (Fig. 1), 13 T xtfiguren und 12 Tabellen.)

\section{Physische Verhältnisse.}

\section{Das Seebecken.}

\section{A. Lage und morphologische Verhältnisse.}

Die Mitte der Längsachse des Zugersees liegt bei $47^{\circ} 0^{4}$ nördl. Breite und $8^{0} 29^{6}$ östl. Länge von Greenwich im Gebiete der schweizerischen Kantone Zug, Schwyz und Luzern. Er gehört zur Reihe der cisalpinen Randseen.

In seinem Süden erhebt sich steil und trotzig die Rigi (1800 m), die aus nach Süden fallenden, wechsellagernden Schichten ron Molasse-Nagelfluh und -Mergel aufgebaut ist. Im Osten begleiten ihn der geologisch gleich gebaute Roßberg (1684 m) und der breite, nur wenig gegliederte Rücken des Zugerberges (975 m), ein Rest

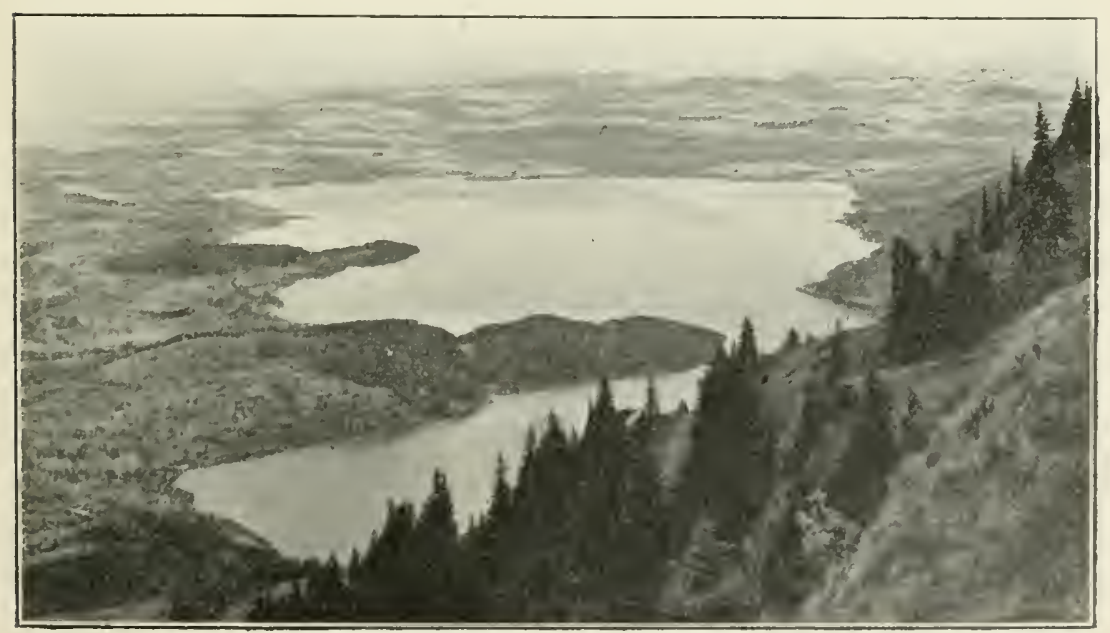

Fig. 2. Zugersee von Rigi-Irulm aus.

Phot. Gebr. Wehrli A.-G. Kilchberg. 
der präglacialen Landoberfläche (Lit. 62 1, pag. 471) zwischen Jura und Alpen, in die durch Erosion die heutigen Täler eingeschnitten worden sind. Das Westufer ist stark gebuchtet. Zwei Halbinseln, der Kiemen (605 m) und der Kirchberg von Risch (534 m), beide aus erosionsresistenten Nagelfluhschichten bestehend (Lit. 41), ragen in den See hinaus vor und lassen sich auch noch unter Wasser verfolgen. Zwischen den beiden Erhebungen liegen die flachen Riedwiesen von Böschenrot (Lit. 24). Das Nordwestund Nordufer, die Strecken von Buonas über Cham nach Zug werden ebenfalls durch breite Gürtel von Ried- und Sumpfwiesen gebildet.

Der Kiemen teilt den Zugersee, der hier bloß $800 \mathrm{~m}$ breit ist, in 2 auch morphologisch verschiedene Teile. Der südliche Teil, der ,Obersee", zeichnet sich aus durch die steilen Ufer, die jäh abfallen und so Raum gewähren für einen ,Schweb" von $3,5 \mathrm{~km}$ Länge und 1,9 km Breite, in dessen Mitte die tiefste Stelle des ganzen Sees 198 m unter dem Seespiegel liegt. Von dieser Stelle an steigt die Sohle allmählig gegen den nördlich gelegenen ,Untersee" an und geht in die flachen Ufer desselben über.

Die einzige, nur wenige $\mathrm{m}^{2}$ große Insel „Eiele“ (= Inselchen) liegt in der Nähe des Ostufers und ist der höchste Punkt einer Nagelfluhbank, die vom Nordufer des Kiemen herüberstreicht, jedoch in der Mitte der Erosion nicht hat widerstehen können.

Die Gesamtlänge des Zugersees beträgt $13,5 \mathrm{~km}$, wovon auf den Obersee 6, auf den Untersee 7,5 km entfallen. Der Obersee ist 3, der Untersee 4,5 km breit. Die Oberfläche liegt 416,72 m über Meer und bedeckt ein Areal von $38,236 \mathrm{~km}^{2}$.

\section{B. Entstehung.}

Der Zugersee liegt eingebettet in die autochthonen Schichten der Molasse. Im Süden fallen dieselben nach Süden ab, stehen bei Immensee nahezu senkrecht und gehen dann über in die Antiklinale, die sich in der Richtung S.O.-N.E. parallel zu den Alpen durch die ganze Schweiz hinzieht (Lit.41). Im Norden liegen die Schichten nahezu horizontal.

Das Seebecken durchschneidet die Falten, ist also ein Quertal. Wer nun dasselbe geschaffen hat, ob Reußfluß oder Reußgletscher, diese Frage ist heute noch nicht endgültig gelöst.

${ }^{1}$ ) Lit. = „L tes aturverzeichnis No." . . 
Heım (Lit. 29) schreibt die Entstehung der Täler der erodierenden Tätigkeit der Flüsse zu. Nach ihm wäre das Zugerseetal dureh die Reuß gebildet, naehträglich allerdings von ihr verlassen worden.

Aeppli (Lit. 1) stellt fest, daß sowohl die Molasse-Landoberfläche, wie die Deckenschotter Gefälle talaufwärts haben; dieselbe Beobachtung macht auch HEıм (Lit. 29) an rückläufigen Terrassen, am Zürichsee. Diese Rückläufigkeit und zugleich die Entstehung der alpinen Randseen werden von ihm wie folgt erklärt:

„,Die Alpen sind nach der Ausbildung der großen Erosionstäler (Flußerosion!) als starres Ganzes eingesunken und haben die Randzonen der ungestörten Molasse mit heruntergezogen, während die äußeren, entfernteren Teile der Molasse stehen geblieben sind. So ist der obere Teil der Täler in den Randzonen von rückläufigem Gefälle geworden und unter Wasser gesunken."

Im Gegensatz zu dieser Auffassung stehen Pench und Brǘcher, welehe die Hauptarbeit der Erosion nieht den Flüssen, sondern der Energie der Gletseher und dem am Grunde derselben initgleitenden Schutt zuschreiben.

Brückner bestreitet die Rüekläufigkeit des Gefälles der Landoberfläehe und schreibt darüber folgendes (Lit. 62, pag. $537 \mathrm{ff}$.$) :$

„Entstehung des Vierwaldstätter- und Zugersees durch Übertiefung. Der Vierwaldstätter- wie der Zugersee sind sowohl in den präglacialen, als aueh in den interglacialen Talboden eingesenkt. Dabei sind die Becken in festem Gestein, wie am Vierwaldstättersee (Tiefe $214 \mathrm{~m}$ ) bei Luzern und Küßnach direkt zu sehen ist. Am Zugersee (Tiefe 198 m) muß man darauf schließen, da sein Boden in $219 \mathrm{~m}$ Meereshöhe und damit $120 \mathrm{~m}$ unter dem Niveau der Felsschwelle liegt, über die die Reuß bei Birmensdorf einen Ausläufer des Jura passiert.

„Wenn irgend ein See am Fuße der Alpen durch seine Form ein ertrunkenes Talsystem im Sinne von A. Herm darstellt, so wäre das der Vierwaldstättersee mit seinen mannigfachen Zipfeln. Es ist daher von besonderer Bedeutung, daß auch für ihn sich die Abwesenheit einer Rücksenkung der Alpen seit der Entstehung der präglacialen Landoberfläehe nachweisen läßt. Die letzlere hat nämlich von Flüelen bis zum Zugerherg und weiterhin bis zum Jurafuß stets ein Gefälle von den Alpen fort; nirgends auf der ganzen Strecke sind Spuren einer Rückläufigkeit zu treffen. Die 
Annahme der Entstehung der Seen durch eine Rücksenkung des alpinen Teils des Reußtales gegenüber dem im Vorland gelegenen ist daher ausgeschlossen. Die Existenz der Seen kann nicht auf eine Dislokation, sondern nur auf Erosion zurückgeführt werden. Auch der Zugersee und der Vierwaldstättersee sind durch glaciale Erosion entstanden und zwar in der Quartärperiode. Alpnacherund Küßnacherbucht sind nicht ertrunkene Seitentäler, sondern glaciale Zungenbecken, die dem Streichen der Schichten folgen."

Dieselbe Ansicht vertritt auch Frey (Lit. 23, pag. 169).

Nach der Bildung der Hohlform hat die Lorze mit Unterstützung der übrigen Zuflüsse das Becken angefüllt. Noch waren die Molasseanhöhen im Norden nicht durchschnitten. Das Niveau des Sees muß also unmittelbar nach seiner Entstehung höher gelegen haben als heute. Das geht hervor aus dem Delta, das etwa $4 \mathrm{~km}$ nördlich Zug in der Nähe von Blickensdorf über $500 \mathrm{~m}$ ü. M., also etwa $100 \mathrm{~m}$ über dem heutigen Seeniveau liegt (Lit. 1, pag. 88; 41, pag. 412; 23, pag. 167). Östlich Baar finden sich 450-500 m ü. M. Ablagerungen von Seekreide, die nur aus dem ehemaligen Zugersee stammen können, der höher lag und größer war als der heutige (Lit. 1, pag 88; 23, pag. 168).

Nach und nach sägte sich der Abfluß im weichen Molassefels ein (Lit. 23, pag. 167), und der See wurde auf sein heutiges Niveau herabgesetzt, wodureh natürlich auch die Oberfläche verkleinert wurde.

Aber auch andere Faktoren wirkten und wirken noch heute bei der Verkleinerung des Seebeckens mit. Es sind dies die Sehilfrohrbestände, die unter Bildung von Torf (Lit. 41, pag. 439) das Westufer seewärts verschoben haben, und die Lorze, die mit ihrem Geschiebe ein mächtiges Delta in den See hinaus getragen hat.

Diese Ablagerungen der Lorze waren nicht immer gleich beschaffen. Wenn in der Schuttzufuhr Unterbrechungen eintraten, setzte sich aus dem See Sehlamm nieder. So entstanden wechselnde Schichten von seewärts fallenden, festen Kiesbänken und von losem, sehlüpfrigem Mergel (Lit. 31).

Diese Schichtung hat zu einigen Katastrophen getührt, die für die Anwohner von Zug sehr verhängnisvoll geworden sind. In den Jahren 1435, 1594 und 1887 kamen die über den Mergelschichten ruhenden Geröllmassen ins Gleiten und stürzten in den See, jedesmal ganze Häuserreihen und eine Anzahl Menschen mit sich reißend. 
Wie das Gesamtbecken eines jeden Sees einem allmählichen Werdegang unterworfen ist, so sind auch seine Ufer nicht immer gleich gewesen, sondern dureh versehiedene Faktoren nach und nach in ihrer heutigen Gestalt modelliert worden. Zwei derselben sind schon genannt worden, nämlich die Deltabildung durch die Lorze und selbstrerständlich auch durch die übrigen Zuflüsse, jedoch nirgends in so großem Maßstabe, und die verlandende Wirkung der Schilfzonen am Flachufer des Untersees.

Ein ebenso wichtiger Falitor für die Nodellierung des Ufers ist die Energie des am Zugersee oft heftig brandenden Wellenschlages, der die ursprüngliche Uferwand mechanisch erodiert hat und diese Arbeit noeh immer fortsetzt.

Aber nieht überall hat die erodierende Energie des Wellenschlages denselben Erfolg davongetragen. Die harten Felsen am Kiemen und an anderen Orten des Obersees haben ihr Widerstand geleistet und sieh wenigstens zum Teil noch in ihrer ursprüngliehen Gestalt erhalten, so daß z. B. noch heute an verschiedenen Stellen die von den Gletschern glatt gesehliffenen Flächen zu sehen sind.

Der Form der Ufer nach steht der Zugersee im geologischen Reifealter (Lit. 22, pag. 43).

\section{Das Wasser.}

\section{A. Hydrometrische Verhältnisse.}

Der Zugersee, im Flußgebiet der Reuß gelegen, bezieht seine Wasser aus einem Sammelgebiet von 246,278 km² Fläehe. Sein wichtigster Zufluß ist die Lorze. Sie sammelt sieh aus den Wassern des Aegerisees (726 m ï. II.) und des Aegeritales, eilt durch das in diluviale Ablagerungen und horizontale Molassesandsteinschichten eingeschnittene Lorzetobel (Lit. 1) in die Tiefe, umfließt in weitem Bogen Baar und Zug und mündet $2 \mathrm{~km}$ östlich von Cham in den See.

Außer der Lorze verzeichnet die Siegfriedkarte (1:25000) ea. 70 meist unbedentende Zuflüsse. Der Lotenbach entwässert den südlichen Zugerberg und mündet beim gleichnamigen Weiler in die Kiemenenge. In steilen Furehen fallen die Rigiaa und der Ghürschbach von der Rigi herunter in den Obersee.

Der Abfluß, durch im Dienste von Fabriken stehende Schleusen 
geregelt, heißt wie der Hauptzufluß Lorze und verläßt den See bei Cham, nur $2 \mathrm{~km}$ vom Einfluß entfernt, um dureh das postglacial gebildete Tal (Lit. 23, pag. 507) der Reuß zuzueilen.

Der Pegelstand, im Mittel 416,72 m ü. M., ist nur geringen Schwankungen unterworfen. Die mittleren Sommermaxima und Winterminima wichen seit Aufnahme der regelmäßigen Pegelbeobachtungen (1867) nur um je $8 \mathrm{~cm}$ vom Mittelstand ab. Doch sind auch stärkere Pegelschwankungen nicht ausgesehlossen. Der niedrigste Wasserstand mit $42 \mathrm{~cm}$ unter dem Mittel wurde im Winter 1890/91, kurz bevor der See zugefror, beobachtet, der höchste mit $87 \mathrm{~cm}$ über dem Mittel im Sommer 1897.

\section{B. Thermisches Verhalten.}

Die Temperaturmessungen wurden anfangs an den von HalbFass für die von ihm organisierten internationalen SeenTemperaturbeobachtungen festgesetzten Daten, später bei jedem Besuche ausgeführt. Ich bediente mich dazu eines NegrettiZambra-Thermometers. Die Verkehrsverhältnisse zwischen meinem Wohnort und dem Zugersee zwangen mich, die Beobachtungen auf die tiefste Stelle zu beschränken, die indessen wohl auch die interessantesten Aufschlüsse geboten haben mag. Die dreijährige Beobachtungsperiode mußte leider im Herbst 1907 eine längere Unterbrechung erleiden.

Da die Gesamtresultate der drei einzehnen Jahre nur geringe, durch den allgemeinen Witterungseharakter bedingte Abweichungen voneinander aufzuweisen haben, darf ich mir wohl eine Detailbesprechung aller thermischen Vorgänge erlassen und verweise auf die Tabelle I, was ich mir angesichts der umfangreichen Literatur über dieses Gebiet wohl erlauben darf.

Ich teile das ,thermische Seejahr" ein wie Pfenniger (Lit. 63).

1. Die Periode der $\mathrm{Som}$ e r s t ag $\mathrm{n}$ a $\mathrm{t}$ i o $\mathrm{n}$ beginnt anfangs April und dauert bis zur zweiten Augusthälfte.

2. Die Sommerteilzirkulation setzt zu Ende August ein und findet ihren Abschluß erst in den Tagen größter Winterkälte, etwa in der zweiten Januarhälfte.

3. Die Herbstvollzirkulation ist nur von kurzer Dauer und erstreckt sich auf einige Tage der strengsten Kálteperiode, meist anfangs Februar.

4. Das Stadium der Winterstagnation ist je nach 


\begin{tabular}{|c|c|c|c|}
\hline & \multicolumn{2}{|c|}{ ๗ગృ! $\mathrm{L}$} & 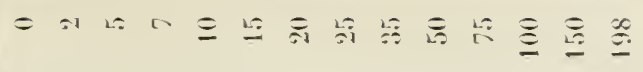 \\
\hline \multirow{14}{*}{\multicolumn{2}{|c|}{ 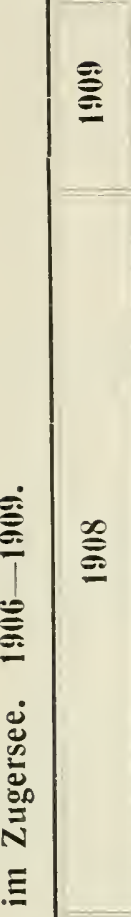 }} & III 9 & 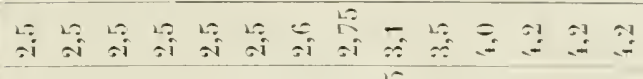 \\
\hline & & II $x^{\prime} \mathrm{I}$ & 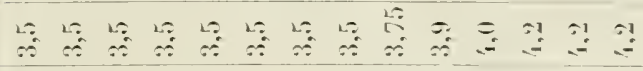 \\
\hline & & I 01 & 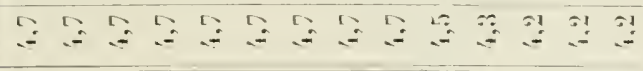 \\
\hline & & $\operatorname{IIx} 0 \overline{6}$ & 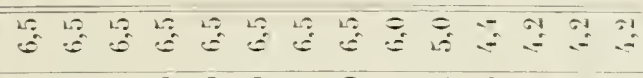 \\
\hline & & IX $\overline{6} \overline{6}$ & 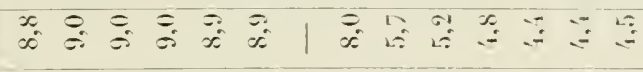 \\
\hline & & $\mathrm{X} \cdot \mathrm{cl}$ & $\begin{array}{l}\because ! \\
=\end{array}=$ \\
\hline & & $\mathrm{XI} \cdot 8 \mathrm{z}$ & 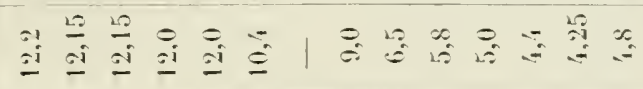 \\
\hline & & IIIAOT & 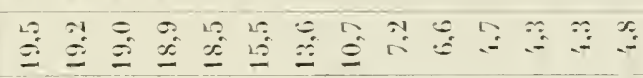 \\
\hline & & I. 211 & 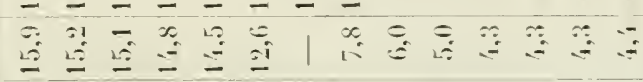 \\
\hline & & $1<\pi$ & 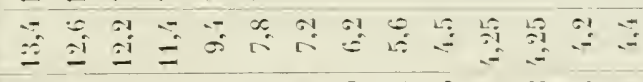 \\
\hline & & $\lambda I \div-6$ & 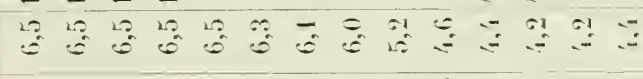 \\
\hline & & 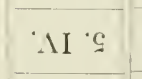 & 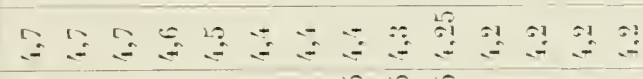 \\
\hline & & III it & 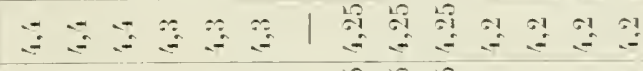 \\
\hline & & II $\%$ & $\because$ \\
\hline \multirow{12}{*}{ 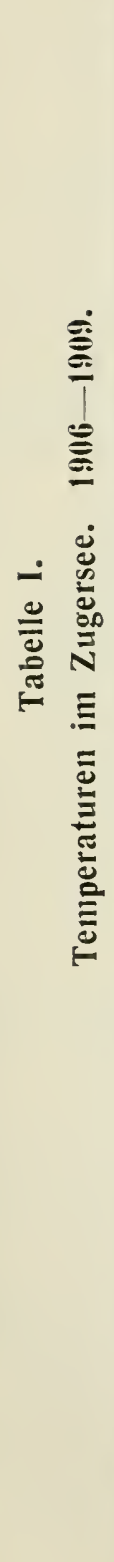 } & \multirow{6}{*}{ 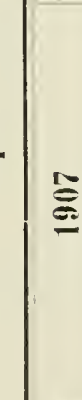 } & IIX 91 & 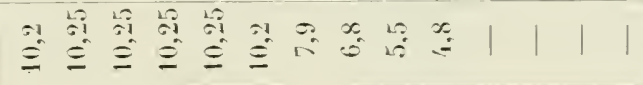 \\
\hline & & $\mathrm{X} \subseteq$ & 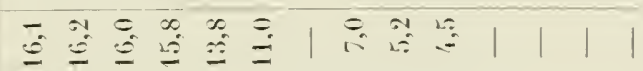 \\
\hline & & $\mathrm{XI} \cdot \overline{6}$ & 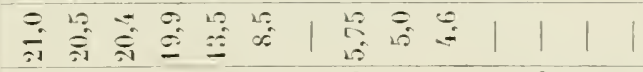 \\
\hline & & II $9 \overline{6}$ & 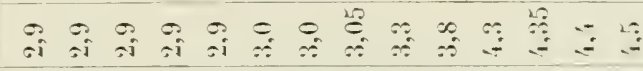 \\
\hline & & II 61 & 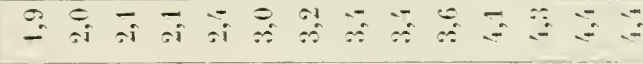 \\
\hline & & $1 \cdot 8$ & 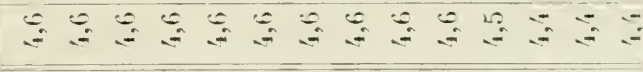 \\
\hline & \multirow{5}{*}{ 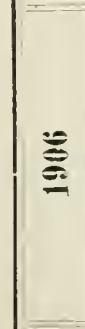 } & $1 \mathrm{x} \cdot 81$ & 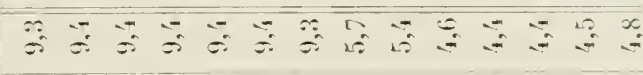 \\
\hline & & 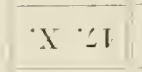 & 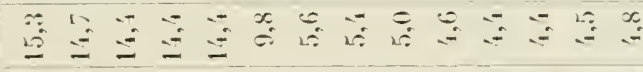 \\
\hline & & III.I. IT: & 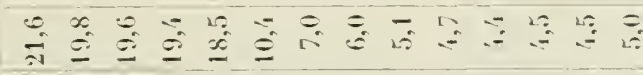 \\
\hline & & $\mathrm{L} A \div \sigma$ & 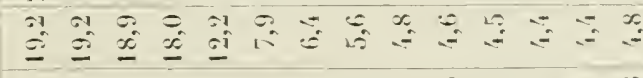 \\
\hline & & $\Lambda \cdot 6$ & 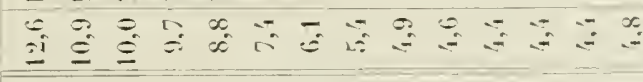 \\
\hline & \multicolumn{2}{|c|}{ иวја!.L } & 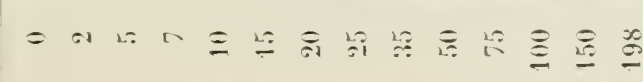 \\
\hline
\end{tabular}

Archiv f. Hydrobiologie. VIII. 

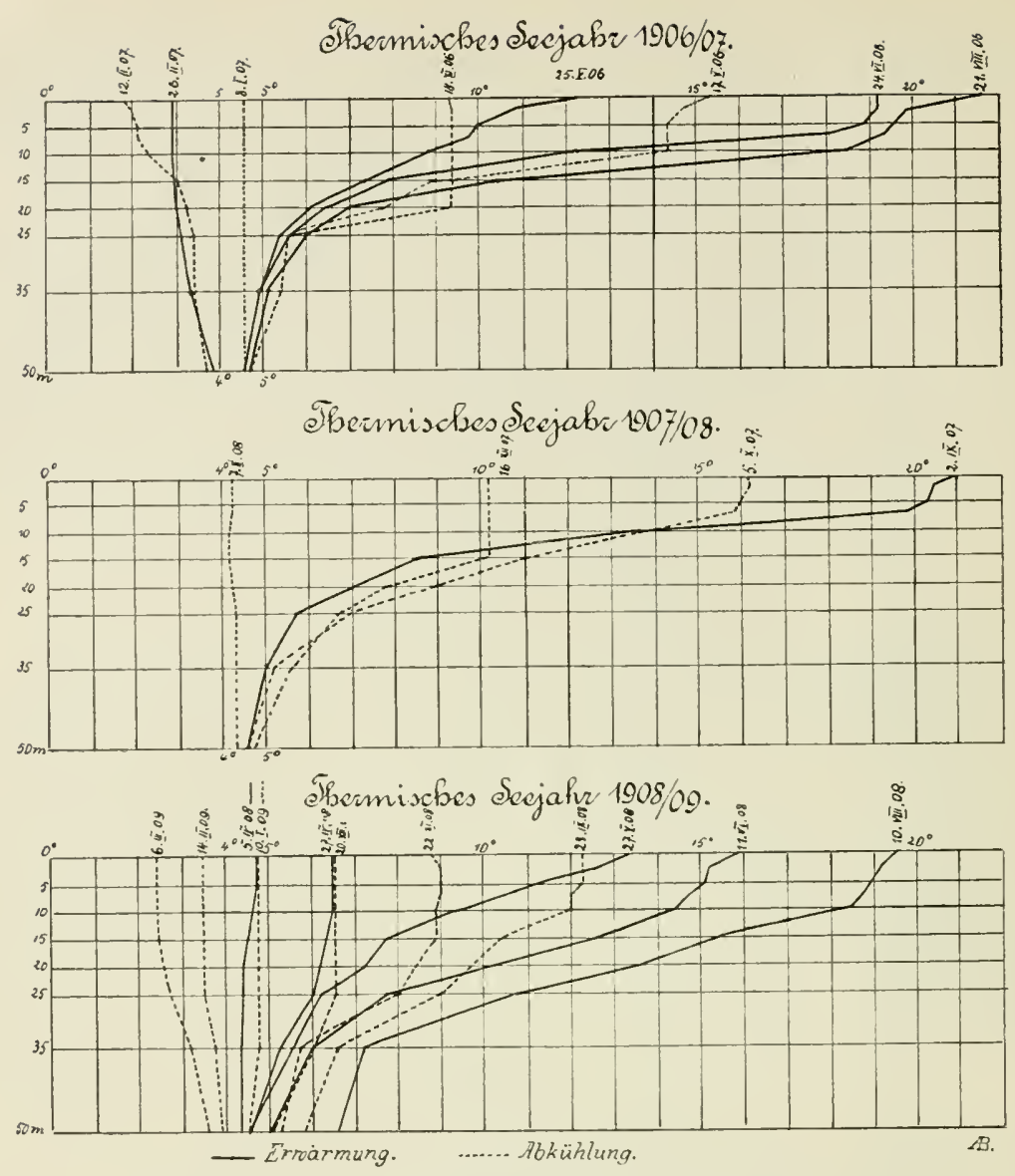

Fig. 3. Graphische Darstellung der Temperaturen.

den Witterungsverhältnissen mehr oder weniger ausgeprägt und dauert bis Ende Februar.

5. Die Winterteilzirkulation und

6. Das nie vollkommen beobachtete Stadium der Fr ühlingsvollzirkulation erstrecken sich über den Monat März.

Je nach den allgemeinen klimatischen Verhältnissen sind starke Verschiebungen in den angegebenen Zeiten möglich. Nach warmen Sommern kann der Wärmevorrat so groß sein, daß das Stadium der Winterstagnation unterdrückt wird und sich die Herbst- und Frühlingsvollzirkulation aneinanderhängen. (Vergl. Frühling 1908.) 


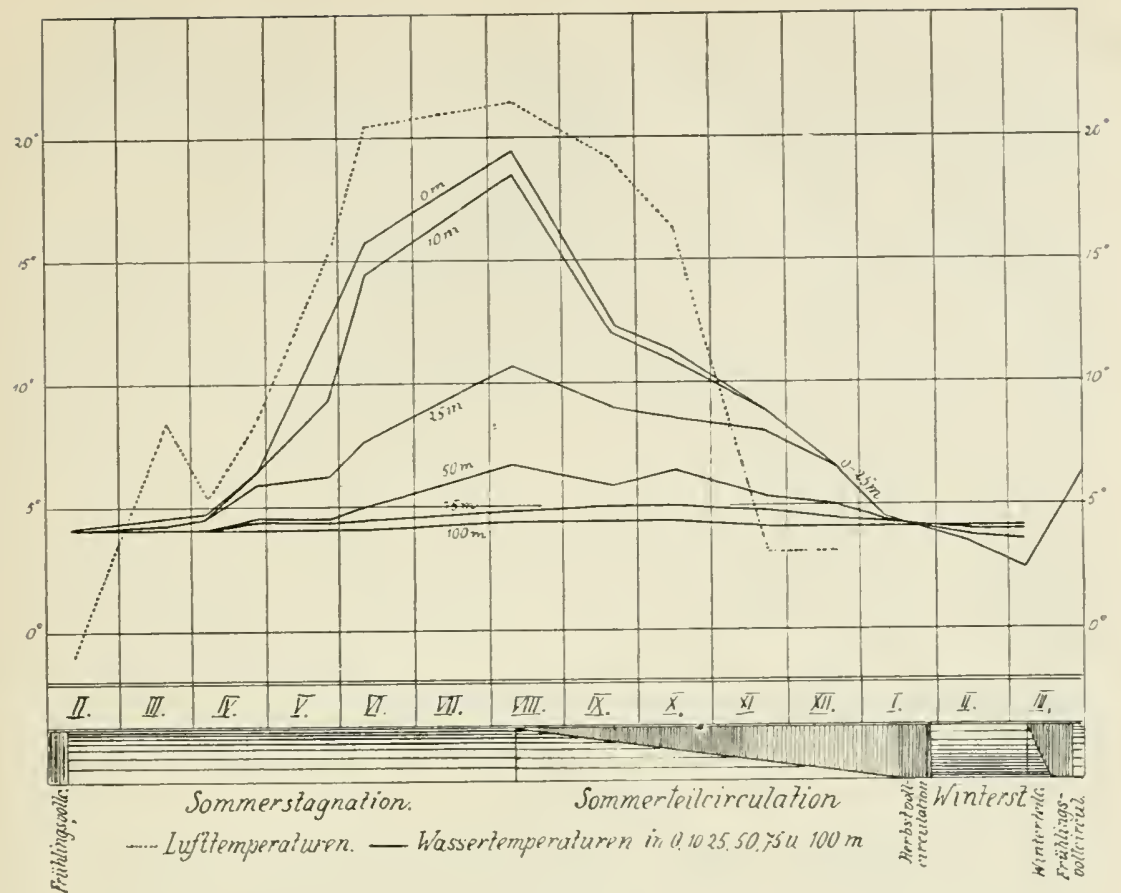

Fig. 4.

Graphische Darstellung der Luft- und Wassertemperaturen. 1908/09.

Die minimale gemessene Temperatur betrug am 12. Februar 1997 1,90. Da nach Richter (Lit. 64) die Seen bei Abkühlung unter $+2^{0}$ gefrieren, hätte sich damals auch der Zugersee in eine Eisdecke hüllen müssen. In der Tat waren auf dem Obersee vereinzelte, im Entstehen begriffene Eisflöße zu bemerken, und bei Zug war der See von einer großen Fläche fast tragfähigen Eises bedeckt. Beinahe hätte also derZugersee das Schicksal einer großen Zahl

Tabelle II.

Temperaturschwankungen in verschiedenen Tiefen.

\begin{tabular}{|c|c|c|c|c|}
\hline & Max. & Min. & Differenz & Mittel \\
\hline Luft & $29,3^{\circ}$ & $-8,3^{\circ}$ & $37,6^{\circ}$ & $\begin{array}{c}\text { Jahresm } \\
9.0^{\circ}\end{array}$ \\
\hline $0 \mathrm{in}$ & $19,5^{\circ}$ & $2.5^{0}$ & $17,0^{\circ}$ & $11,0^{\circ}$ \\
\hline 10, & $18.5^{\circ}$ & $2,5^{0}$ & $16,0^{\circ}$ & $10,5^{0}$ \\
\hline 25, & 10,70 & $2,75^{\circ}$ & $7,95^{\circ}$ & $6,-25^{0}$ \\
\hline 35, & $74^{0}$ & $3,1^{0}$ & $4,3^{\circ}$ & $5.25^{0}$ \\
\hline 50, & $6,6^{\circ}$ & $3,5^{0}$ & $3,1^{0}$ & $5.05^{0}$ \\
\hline 75, & $5,0^{0}$ & $4,0^{\circ}$ & $1,0^{\circ}$ & $t, 5^{0}$ \\
\hline 100. & $4,4^{0}$ & $4,2^{0}$ & $0,2^{\prime \prime}$ & $4,3^{0}$ \\
\hline 150 & $4,4^{0}$ & $4,2^{0}$ & $0,2^{0}$ & $4,3^{0}$ \\
\hline 198 & $4,8^{\circ}$ & $4,2^{0}$ & $0,6^{\circ}$ & $4,5^{0}$ \\
\hline
\end{tabular}


allerdings weniger tiefer Seen geteilt. Wenn das nicht geschehen ist, so ist das seiner großen Tiefe zuzuschreiben, die das Eintreten der Herbstvollzirkulation so lange hinausschiebt, bis in der Luft schon wieder Erwärmung eingetreten ist.

Daß der Zugersee aber trotz seiner Tiefe gegen das Gefrieren nicht völlig gefeit ist, geht aus den Chroniken hervor, die von "Gefrörnen" erzählen aus den Jahren 1623, 1659, 1683, 1691, 1695, 1830 und zuletzt 1891. Merkwürdigerweise begann diese letzte Gefrörne auf dem Obersee und dehnte sich erst 2-3 Tage später auf den Untersee aus.

Die sommerliche Erwärmung geht bis in die Tiefe von $100 \mathrm{~m}$. die ihre maximale Temperatur erst dann erreicht, wenn an der Oberfläche schon längst wieder die Abkühlung eingesetzt hat, nämlich im Oktober. Unter $100 \mathrm{~m}$ Tiefe herrscht die konstante Temperatur von etwas mehr als $4^{0}$ (vergl. Tab. II).

Tabelle III.

Die Sprungschicht. 1906. (Temperaturabnahme per Nieter.)

\begin{tabular}{|c|c|c|c|c|c|c|}
\hline Tiefen & 25. V. & 2'. IT. & 21. VIII. & 17. X. & 18. XI. & 8. I. \\
\hline $0-2$ & $0,85^{\circ}$ & $0,0^{\circ}$ & $0,6^{0}$ & $0,30^{\circ}$ & $-0,01^{\circ}$ & $0^{0}$ \\
\hline $2-5$ & $0,30^{\circ}$ & $0,10^{0}$ & $0,10^{0}$ & $0,10^{\circ}$ & $0^{0}$ & $0^{\circ}$ \\
\hline $5-7$ & $0,10^{\circ}$ & $0,45^{0}$ & $0,10^{\circ}$ & $0^{\circ}$ & $0^{0}$ & $0^{0}$ \\
\hline $7-10$ & $0,30^{\circ}$ & $2,7^{\circ}$ & $0,30^{\circ}$ & $0^{0}$ & $0^{0}$ & $0^{0}$ \\
\hline $10-15$ & $0,28^{\circ}$ & $0,86^{0}$ & $1,62^{0}$ & $0,92^{\circ}$ & $0^{0}$ & $0^{0}$ \\
\hline $15-20$ & $0,26^{0}$ & $0,30^{\circ}$ & $0,68^{\circ}$ & $0,84^{0}$ & $0,02^{\circ}$ & $0^{\circ}$ \\
\hline $20-25$ & $0,14^{0}$ & $0,16^{\circ}$ & $0,20^{\circ}$ & $0,0 \div{ }^{0}$ & $0,72^{0}$ & $0^{0}$ \\
\hline $25-35$ & $0,05^{\circ}$ & $0,08^{0}$ & $0,09^{\circ}$ & $0,0 \div 0$ & $0,03^{0}$ & $0^{0}$ \\
\hline $35-50$ & $0,02^{\circ}$ & $0,01^{0}$ & $0,03^{\circ}$ & $0,03^{0}$ & $0,05^{0}$ & $0^{0}$ \\
\hline
\end{tabular}

Die thermische Stratifikation ist besonders deutlich ausgeprägt zur Zeit intensivster Durchwärmung, also im Hochsommer. In dieser Zeit liegt unter einer warmen Oberflächenschicht eine Schicht, in der die Temperatur rasch, in einem ,Sprung" auf die Temperatur der Tiefe abfällt. Diese "Sprungschicht" ist also eine relativ dünne Schicht mit großen Temperaturdifferenzen. Sie ist schon im Mai zu erkennen und wird immer deutlicher, bis sie im Hochsommer zur Zeit intensivster Durchwärmung am prägnantesten wird. Dann wird sie wieder undeutlicher und schließlich von der 


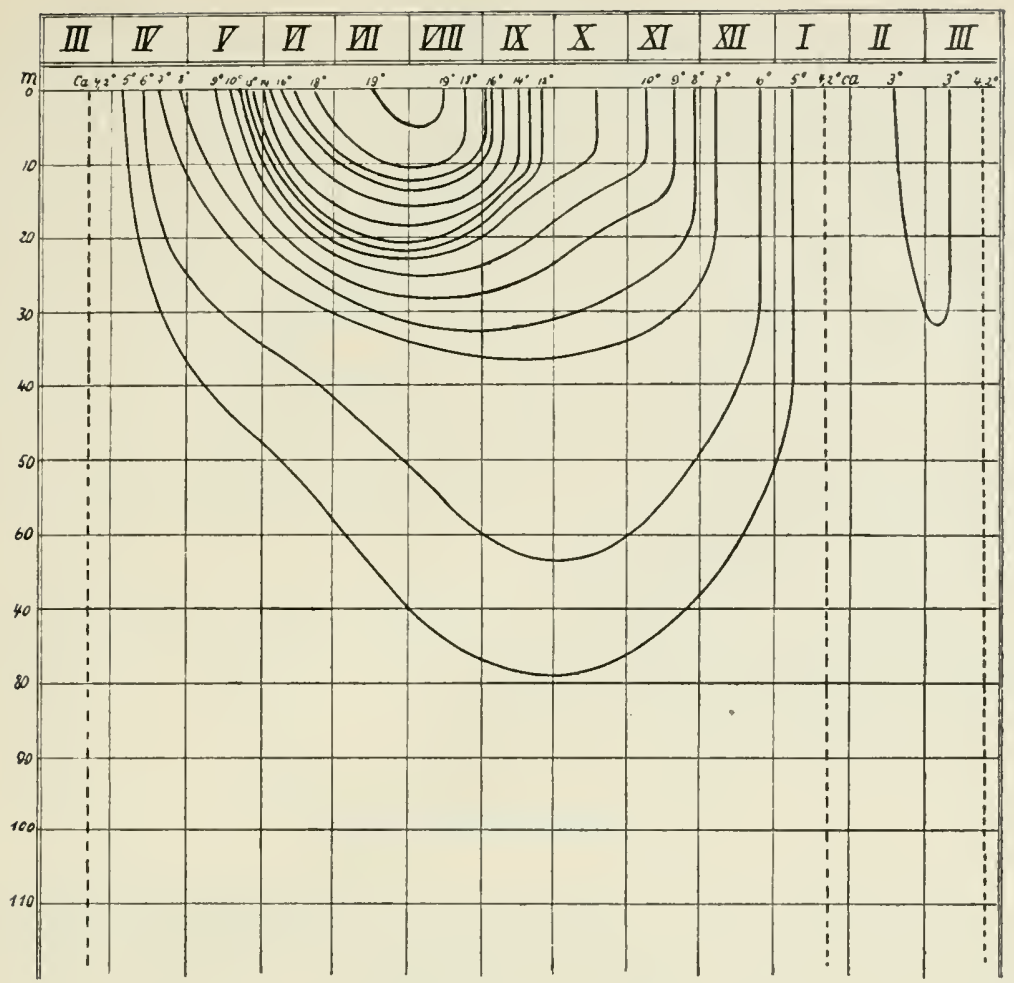

Fig. 5. Temperaturen des Zugersees. 1908/1909. Die Kurven verbinden Ticfen gleicher Temperatur.

herbstlichen Teilzirkulation verwischt. Gleichzeitig sinkt sie von wenigen dm Tiefe im Frühling bis auf ea. $20 \mathrm{~m}$ im Spätherbst. Zur Zeit ihrer größten Deutlichkeit liegt sie zwischen 10 und $20 \mathrm{~m}$.

Über die Ursache der Sprungschicht sind verschiedene Meinungen geäußert worden. Am meisten hat die von Richter für sich, der in der Sprungschicht die Grenze sieht, bis zu der die durch tägliche Erwärmung und darauf folgende Abkühlung in der Nacht entstehenden Konvektionsströmungen wirksam sind. Das Tiefersinken der Sprungschicht ließe sich erklären mit der starken Abkühlung durch Ausstrahlung in den hellen Sommernächten.

Unterhalb der Sprungschicht sind die Temperaturdifferenzen nur klein, und nur langsam nähert sich mit zunehmender Tiefe die Temperatur der Konstante von ca. 4,30. Am Grunde jedoch tritt während der Sommermonate regelmäßig eine Erwärmung um cinige Zehntelgrade ein, eine Erscheinung, die auch in vielen anderen Seen beobachtet worden ist (Lit. 27). 
Da nur die allertiefsten Schichten von dieser Erwärmung betroffen sind, läge es nahe, hier einen Einfluß der Erdwärme, sei es durch direkte Leitung, sei es durch warme Quellen zu vermuten. Dann müßte diese Erscheinung das ganze Jahr konstant andauern. Dasselbe müßte der Fall sein, wenn die höhere Ablesung eine bloße Folge einer Zusammenpressung der Thermometerwand wäre. Tatsächlich aber haben wir es mit Saisondifferenzen zu tun. ForEL hat als Ursache dafür das warme, mit suspendierten und gelösten Mineralstoffen beschwerte Wasser der Zuflüsse erkannt, das infolge seines höheren spezifischen Gewichtes auf den Grund des Beckens fließt und seine Wärme den darüber liegenden Sehichten nur langsam abgibt (Lit. 22).

Infolge seines thermischen Verhaltens muß der Zugersee der Gruppeder t y p is e h e $\mathrm{n}$ te m p e rie r t e $\mathrm{n} \mathrm{S}$ e e $\mathrm{n}$ von Forel (Lit. 22) zugeteit werden.

\section{Optisches Verhalten.}

1. F a rbe des Wassers. Die Eigenfarbe des Wassers wurde durch Vergleichen mit der Foressehen Farbenskala (Lit. 21) festgestellt und entsprach meist den blaugrünen Tönen von No. 6 oder 7. Das Wasser des Obersees war stets etwas blauer als das des Untersees.

Chemisch reines Wasser hat nach Forel tiefblaue Farbe, Nr. 1 der Forelschen Skala. Wenn nun im Zugersee mehr grüne Töne vorherrschen, so ist das 2 Ursachen zuzuschreiben:

1. den im Wasser suspendierten Körperchen,

2. den im Wasser gelösten organischen Stoffen.

Unter letzteren fällt nach Forel namentlich die Humussäure in Betracht, die wohl in großen Mengen mit dem Lotenbach und der Lorze von den Torflagern auf dem Zugerberg und am unteren Ende des Aegerisees dem Zugersee zugeführt werden. Da dieser Gehalt an Humussäure wohl für das ganze Jahr als konstant betrachtet werden darf, so müßte das Wasser auch immer dieselbe Farbe haben.

Dem ist aber nicht so. Im Mai und Juni 1908 stieg die Nummer der Skala auf ea. 8-9; das Wasser zeigte eine Beimengung von gelblichen Tönen; das Gesamtresultat war ein helleres Grün. Diese 
Tabelle IV a.

Protokoll pro 1906.

\begin{tabular}{|c|c|c|c|c|c|}
\hline Datum & Witterung & $\begin{array}{l}\text { Ober- } \\
\text { fläche } \\
\text { Temp. }\end{array}$ & $\begin{array}{l}\text { Trans- } \\
\text { parenz }\end{array}$ & $\begin{array}{l}\text { Plank }- \\
\text { tonvo- } \\
\text { lum }^{1} \text { ) }\end{array}$ & $\begin{array}{l}\text { Dominierende Plankton- } \\
\text { spezies. Bemerkungen }\end{array}$ \\
\hline 19. IV. & schön, windstill & & 12.0 & 8 & \\
\hline 3. V. & klar, windstill & & 3,75 & 8 & Asterionella gracillima \\
\hline 25. V. & Regen & $12,6^{0}$ & 3,75 & 8 & \\
\hline 30/31. Y. & (Nacht) & & & 6 & \\
\hline 12. VI. & bedeckt, Sturm & & 3.5 & 5 & Seeblüte \\
\hline $28 . \mathrm{VI}$ & klar & $19,2^{\circ}$ & 5,5 & 6 & \\
\hline 5. VII. & bedeckt, Bise & & & 4 & Ceratium hirundinella \\
\hline 19. VII. & klar & & 4,3 & $\dot{4}$ & \\
\hline 3. VIII. & , , & & 4,3 & 2 & \\
\hline 1. IX. & ,. & $21,6^{\circ}$ & $4,{ }^{\prime}$ & 2 & \\
\hline 5. X. & . & & 6,2 & 6 & \\
\hline 1. $X$. & bedeckt & $15,3^{0}$ & 7,8 & 6 & \\
\hline 13. XI. & , & & $8,{ }^{\prime}$ & 6 & Cyclotella socialis \\
\hline 19. XI. & Regen ${ }^{\circ}$ & $9.3^{\circ}$ & 9.5 & 6 & getoretia soldets \\
\hline 9. XII. & bedeckt & $7,0^{\circ}$ & 8,6 & 6 & \\
\hline 22. XII. & , & $5,5^{0}$ & 10,5 & 4 & \\
\hline
\end{tabular}

1) $\mathrm{cm}^{3}$ per $\mathrm{m}^{2}$.

Tabelle IV b.

Protokoll pro 1907.

\begin{tabular}{|c|c|c|c|c|c|c|}
\hline Datum & Witterung & $\begin{array}{l}\text { Ober- } \\
\text { fläche } \\
\text { Temp. }\end{array}$ & $\begin{array}{l}\text { Trans- } \\
\text { parenz }\end{array}$ & 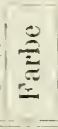 & 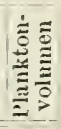 & $\begin{array}{l}\text { Dominierende Piankton- } \\
\text { spezies. Bemerkungen. }\end{array}$ \\
\hline 8. I. & bedeckt & $4,6^{0}$ & 11,8 & & & \\
\hline 28. I. & , & $4,3^{\circ}$ & 16,2 & & & Cyclotella socialis und \\
\hline 12. II. & , & $1,9^{\circ}$ & 16,0 & & & Ceratium hirundinella \\
\hline 26. II. & klar & $2,9^{\circ}$ & 14,8 & & & \\
\hline 21. III. & , & $4,2^{0}$ & 11,8 & 6 & 12 & \\
\hline 29. IV & , & & 8,9 & 7 & 14 & \\
\hline 6. V. & ". & & 11,8 & 7 & 14 & Dinobryon cylindricum \\
\hline 23. V. & .. & $10,0^{\circ}$ & 7,0 & 6 & $1 '$ '́ & \\
\hline 11. VI. & .. & $11,4^{0}$ & 6,15 & 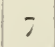 & 14 & \\
\hline 21. VII. & .. & & 4,6 & j & 12 & Fragilaria crotonensis \\
\hline 2. IX. & , & $21,0^{\circ}$ & 4,6 & 7 & 7 & Ceratium hirundinella \\
\hline 3. X. & Regen & $16,1^{\circ}$ & 5,25 & 7 & & ceratum nirunainella \\
\hline 16. XII. & klar & $10,2^{0}$ & 10.9 & 6 & 14 & Cyclotella \\
\hline
\end{tabular}

Farbenveränderung ist dem in diese Zeit fallenden Auftreten einer Seeblüte von Pinus-Pollen zuzuschreiben. Später verlieh die in großen Mengen vorhandene Fragilaria crotonensis dem Wasser 
Tabelle IV c.

Protokoll pro 1908.

\begin{tabular}{|c|c|c|c|c|c|c|c|}
\hline Datım & IVitterung & $\begin{array}{l}\text { Luft- } \\
\text { tempe- } \\
\text { ratur }\end{array}$ & $\begin{array}{l}\text { Ober- } \\
\text { fläche } \\
\text { Temp. }\end{array}$ & 詞离 & 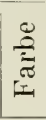 & 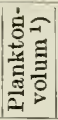 & $\begin{array}{l}\text { Dominierende Plankt.- } \\
\text { spezies. Bemerkungen. }\end{array}$ \\
\hline 6. II. & bedeckt & $1^{0}$ & $4,2^{\circ}$ & 14,5 & 5 & & Cyclotella \\
\hline 22. II. & klar & & & & 6 & 4 & Cyclotella soe \\
\hline 1. III. & , & $0^{\circ}$ & & 16,1 & 6 & 5 & \\
\hline 21. I11. & , & $8,2^{\circ}$ & $4,2^{0}$ & 16,1 & 6 & 12 & Oscillatoria rubescens \\
\hline 5. IV. & Regen & $4,3^{0}$ & & 12,8 & 5 & 12 & \\
\hline 27. IV. & Regen, W'wind & $8,4^{\circ}$ & $6,5^{\circ}$ & 9,9 & 5 & 8 & \\
\hline 20. V. & klar & $25,1^{\circ}$ & & 4,0 & 8 & & Ceratium hirundinella \\
\hline 27. V. & , & $15,4^{\circ}$ & $13,4^{\circ}$ & 3,5 & 8 & 10 & Seeblüte \\
\hline 11. VI. & , & $20,4^{\circ}$ & $15,9^{\circ}$ & 4,8 & 8 & 13 & Asterionella gracillima \\
\hline 31. VII. & , & $25^{0}$ & & 4,6 & 7 & 10 & \\
\hline 10. VIII & , & $21,4^{\circ}$ & $19,5^{\circ}$ & 4,6 & 9 & 6 & \\
\hline 23. IX. & Regen & $19,1^{\circ}$ & $12,2^{\circ}$ & 4,6 & 7 & 11 & \\
\hline 15. X. & klar & $16,1^{\circ}$ & $11,2^{0}$ & 6,3 & 7 & 7 & Ceratium hirundine \\
\hline 1. XI. & bedeckt, IV'wind & $5,3^{\circ}$ & & 9,35 & 7 & 6 & \\
\hline 22. XI. & Regen & $3,1^{\circ}$ & $8,8^{\circ}$ & 9,2 & 7 & 6 & \\
\hline 20. XII. & klar & $3,1^{\circ}$ & $6,5^{0}$ & 11,1 & 6 & 8 & Fragilaria crotonensis \\
\hline
\end{tabular}

1) $\mathrm{cm}^{3}$ per $\mathrm{m}^{2}$.

Tabelle IV d.

Protokoll pro 1909.

\begin{tabular}{|c|c|c|c|c|c|c|c|}
\hline Datum & Witterung & $\begin{array}{l}\text { Luft- } \\
\text { iempe- } \\
\text { ratur }\end{array}$ & $\begin{array}{l}\text { Ober- } \\
\text { lläche } \\
\text { Temp. }\end{array}$ & 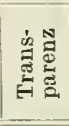 & 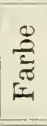 & 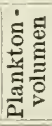 & $\begin{array}{l}\text { Dominierende Plankt.- } \\
\text { spezies. Bemerkungen. }\end{array}$ \\
\hline 10. I. & klar, Bise & 4,70 & $4,7^{0}$ & 12,2 & 6 & 6 & Ceratium hirundinella \\
\hline 14. II. & , & $3,5^{\circ}$ & $3,5^{0}$ & 3,5 & 6 & 12 & Fragilaria crotonensis \\
\hline 6. III. & , & $2,5^{0}$ & $2,5^{\circ}$ & 16,9 & 7 & & $\begin{array}{l}\text { Fragilaria crot. Aste- } \\
\text { rionella gracillima }\end{array}$ \\
\hline 23. IV. & klar & $19,5^{\circ}$ & $10,8^{\circ}$ & 7,4 & 7 & & Asterionella gracillima \\
\hline 21. VI. & , & & & 5,5 & 7 & & Ceratium hirundinella \\
\hline
\end{tabular}

einen bräunlichen Ton, wie dies $U_{\mathbf{L E}}{ }^{\mathbf{1}}$ ) auch in nordischen Seen beim massenhaften Auftreten von Diatomeen beobachtet hat. Der August brachte ein nochmaliges Überhandnehmen der hellgrünen Töne, das aber diesmal seine Ursache in dem durch die Flüsse in den See gebrachten, im Wasser suspendierten Mineralschlamm hatte. forschung.

$\left.{ }^{1}\right)$ Ule, Beitrag zur Instrumentenkunde auf dem Gelbiete der Seen- 


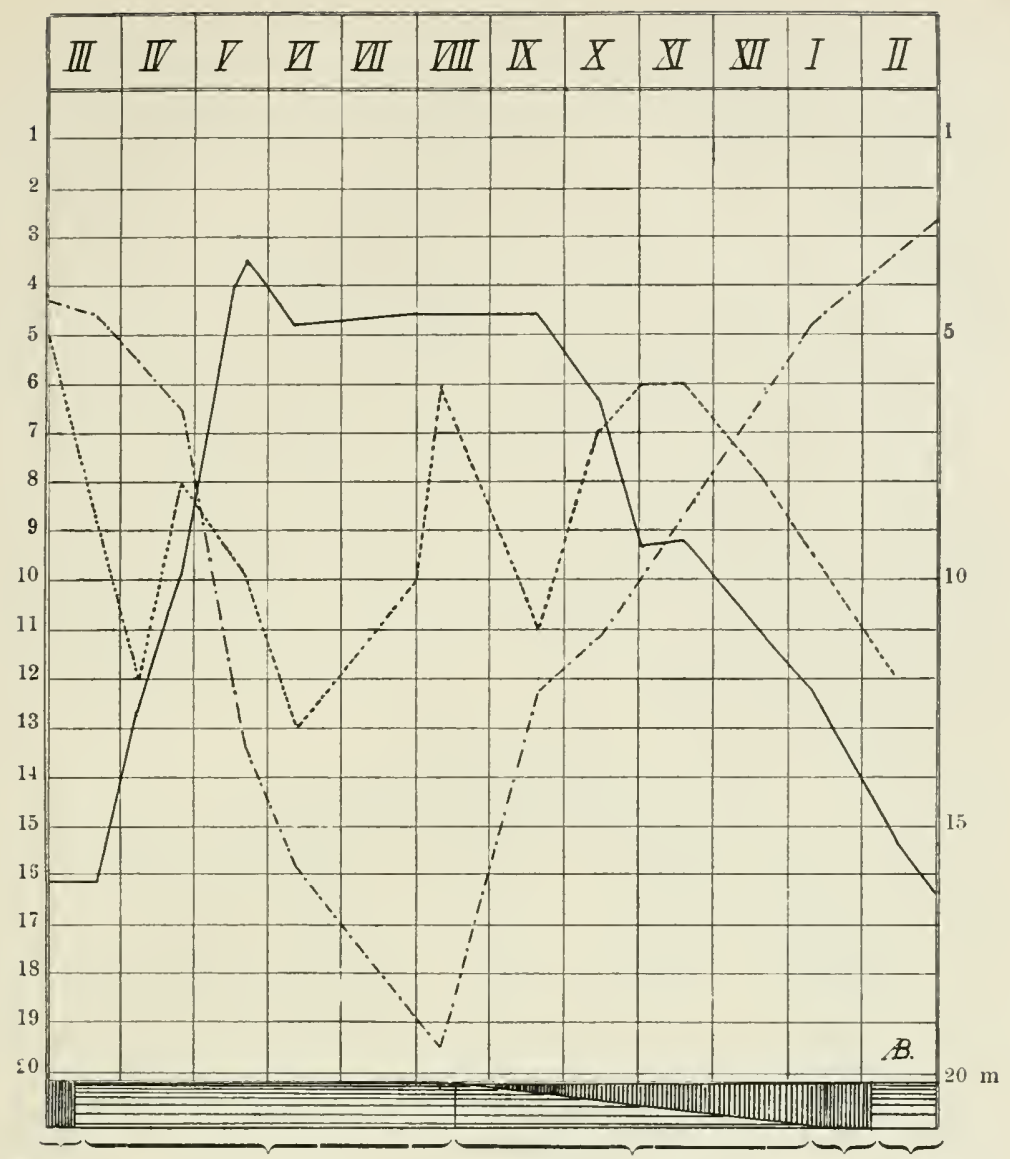

Vollcirc. Sommerstagnation

Herbst teilcirculation

Winterstagn.

Transparenz. $1=1 \mathrm{~m}$.

Herbstrollcirc.

Oberflächentemperatur. $1=1^{0}$.

Planktonmenge unter $1 \mathrm{~m}^{2}$ Oberfläche. $1=1 \mathrm{~cm}^{3}$.

Fig. 6. Transparenzkurve 1908/09.

Am dunkelsten war das Wasser stets in Winter, wenn es weder durch den Mineralschlamm der Flüsse, noch durch sonstige zahlreiche suspendierte Körperchen getrübt war. Doeh war auch dann stets der Einfluß der d unkelgrü $\mathrm{n}$ ä $\mathrm{rbenden}$ H u mu s sä ure bemerkbar.

Die Farbe des Wassers ist also außer der konstant vorhandenen Humussäure abhängig von der Menge der im Wasser suspendierten festen Körperehen und eventuell (Diatomeen!) deren Eigenfarbe.

2. Transparenz. Die Transparenz wurde mit der Secchischen Scheibe nach der bekannten, oft besehriebenen 
Methode regelmäßig bei jedem Besuche des Sees gemessen. Die genauen Resultate sind in den Tabellen am Anfang dieses $\mathrm{Al}$ schnittes eingetragen. Außerdem zeigt die umstehende graphische Darstellung den Verlauf der Transparenzkurve während des Jahres 1908. Zum Vergleich sind die Oberflächentemperaturen und die Planktonvolumina per $\mathrm{m}^{2}$ Wasseroberfläche beigefügt. Die Zeit ist auf der Abscisse, die zugehörigen Werte von Transparenz, Temperatur und Planktonvolumen sind auf der Ordinate, der natürlichen Richtung der Transparenz entsprechend, aufgetragen.

Die Beobachtungen, die sich meist auf das obere Becken beziehen, haben ergeben, daß die Transparenz mit steigender Temperatur abnimmt, mit fallender Temperatur zunimmt. Wie regelmäßig dieser Einfluß der Temperatur wirkt, zeigt die Tabelle V, in der die Jahreszeitenmittel sämtlicher 3 Beobachtungsjahre zusammengestellt sind.

\section{Tabelle V.}

Transparenz 1906/09.

\begin{tabular}{|c|c|c|c|c|}
\hline & $1906 / 07$ & $1907 / 08$ & $1908 / 09$ & $1906 / 09$ \\
\hline Frühling & $5,3 \mathrm{~m}$ & $9,1 \mathrm{~m}$ & $7,0 \mathrm{~m}$ & $7,1 \mathrm{~m}$ \\
\hline Sommer & $4,3 \quad,$. & $4,6 \quad .$. & 4,6 & 4,5, \\
\hline Herbst & $8,1 \quad,$. & $8,1 \quad$, & 8,1, & $8,1 \quad$, \\
\hline Winter & 13,9 & $15,6 \quad$. & 14,6 & 14,7, \\
\hline Mittel & 7,9, & 9,35, & $8,55$. & 8,5, \\
\hline
\end{tabular}

Tabelle VI.

Transparenz in verschiedenen Seen.

\begin{tabular}{|c|c|c|c|c|c|}
\hline & Zugersee & Genfersee & $\begin{array}{l}\text { Vierwald- } \\
\text { stättersee }\end{array}$ & Bodensee & Zürichsee \\
\hline Beobachter & $\begin{array}{l}\text { Brutschy } \\
1906 / 09\end{array}$ & Forel & $\begin{array}{l}\text { Amberg } \\
\text { 1903/04 }\end{array}$ & $\begin{array}{c}\text { Forel } \\
1889 / 91\end{array}$ & $\begin{array}{l}\text { Lozeron } \\
1900 / 01\end{array}$ \\
\hline $\begin{array}{l}\text { Winter } \\
\text { Frühling } \\
\text { Sommer } \\
\text { Herlsst }\end{array}$ & $\begin{array}{r}11,7 \mathrm{~m} \\
7,1 \quad . \\
4,5 \quad, \\
8,1 \quad,\end{array}$ & $\begin{array}{c}15,2 \mathrm{~m} \\
11,7, \\
7,4 \quad, \\
9,7 \quad,\end{array}$ & $\begin{array}{rl}12.93 & \mathrm{~m} \\
9,67 \quad, \\
6,1 \quad, \\
9,03 \quad,\end{array}$ & $\begin{array}{l}6,6 \mathrm{~m} \\
5,2 \quad, \\
4,3 \quad, \\
5,4 \quad,\end{array}$ & $\begin{array}{l}5,5 \mathrm{~m} \\
4,7 \quad, \\
3,3 \quad, \\
6,5 \quad,\end{array}$ \\
\hline \multicolumn{5}{|c|}{ Extreme } & $5,0 \mathrm{~m}$ \\
\hline $\begin{array}{l}\text { Maximum } \\
\text { Minimum } \\
\text { Schwankung. }\end{array}$ & $\begin{array}{r}16,9 \mathrm{~m} \\
3,5 \quad, \\
13,4 \quad,\end{array}$ & $\begin{array}{r}21,5 \mathrm{~m} \\
6,7 \quad, \\
16,8,\end{array}$ & $\begin{array}{r}16,6 \mathrm{~m} \\
4,4, \\
12,2,\end{array}$ & $\begin{array}{c}11,5 \quad \mathrm{~m} \\
1,76 \quad, \\
9,74 \quad,\end{array}$ & $\begin{array}{l}9,4 \mathrm{~m} \\
2,6 \quad, \\
6,8 \quad,\end{array}$ \\
\hline
\end{tabular}


Aus der Tabelle $\mathrm{V}$ geht deutlich hervor, daß das Wasser jeweils im Winter am klarsten und durchsichtigsten war und zur Zeit größter Durchwärmung dem Licht den größten Widerstand entgegensetzte.

Die gewonnenen Resultate stimmen im großen und ganzen mit denen der übrigen subalpinen Seen gut überein, d. h. mit Seen, welche denselben klimatischen und ähnlichen sonstigen Faktoren unterworfen sind. In der Tabelle VI sind die Transparenzwerte verschiedener Schweizerseen miteinander verglichen.

Die Abhängigkeit der Transparenz von der Temperatur ist in allen diesen Seen unverkennbar. Zweifellos sind die Transparenzminima eine Folge der durch die Erwärmung bedingten Stratifikation, wie dies namentlich LozErox dargetan hat.

Die niedrigsten Transparenzwerte wurden jedoch nicht zur Leit intensivster Durchwärmung des Wassers, bezw. prägnantester Temperaturschichtung, welche jeweils im August erreicht wird, sondern im Mai 1906 und 1908 mit je 3,5 m gemessen. Also müssen noch andere Faktoren auf die Transparenz einzuwirken imstande sein. In der Tat ist diese schwache Durchsichtigkeit den großen Mengen von Pollen der Kiefern am nahen Kiemen, vom Winde auf den See hinausgetragen, zuzuschreiben. Der See zeigte zu diesen Zeiten die Erscheinung der, ,Seeblüte", die ilın trübte. Nach dem Verschwinden derselben stieg die Transparenz wieder auf die dem Wasser seinen physikalischen Verhältnissen zufolge zukommenden Werte.

Neben den Transparenzmessungen an der tiefsten Stelle auf der Höhe von Walchwil wurden auch solche jeweils am selben Tage

\section{Tabelle VII.}

Transparenz in verschiedenen Entfernungen von der Lorzemündung.

\begin{tabular}{|c|c|c|c|c|}
\hline & Arth & Walchwil & Risch & Zug \\
\hline 2'. III. 07 & 13,2 & 11,0 & & \\
\hline 25. 111. 07 & & 11.2 & 10,0 & 6,3 \\
\hline 23./2'. V. 07 & 8,1 & 7,0 & & \\
\hline 30./31. VH. 08 & & 4,6 & 3,8 & 3,6 \\
\hline 23. IV. 09 & 8,3 & 8,5 & 8,3 & 7,4 \\
\hline
\end{tabular}


an verschiedenen Orten des Sees vorgenommen. Die Ergebnisse sind in der Tabelle VII verzeichnet.

Aus derselben geht hervor, daß die Transparenz im unteren Becken kleiner ist als im oberen. Die Ursache dafür ist im feinen Geschiebe der Lorze zu suchen, das sich im Wasser in der Nähe der Mündung verteilt und dasselbe trübt. Die Verunreinigung des IVassers mit solchen Mineralteilchen ist um so kleiner, die Transparenz um so größer, je mehr wir uns von der Lorzemündung entfernen.

Da diese Regel nicht nur für die Lorze, sondern in größerem oder kleinerem Maße auch für alle übrigen Zuflüsse gilt, je nach ihrer Stoßkraft, läßt sich die scheinbare Abweichung vom 23. April 1909 leicht erklären. Die Transparenz bei Arth war um diese Zeit geringer als diejenige von Walchwil, weil das Wasser durch den Mineralschlamm der infolge der Schneeschmelze ungewöhnlich starken Rigiaa getrübt war.

Die Beobachtung, daß die Transparenz mit der Entfernung von den Mündungen der Zuflüsse zunimmt, deckt sich mit den an allen bisher in dieser Richtung untersuchten Seen erhaltenen Resultaten. Sie läßt zugleich eine Erklärung der hohen Wintermaxima $z u$, indem die $\mathrm{Zu}$ - und Abflußverhältnisse derart sind, daß die Lorze das Wasser des oberen Beckens nicht zu trüben vermag.

Die hohen Maxima (vergl. Tabelle IV) erlauben, den Zugersee in die Reihe der klarsten Seen der Schweiz zu stellen; er folgt mit 16,9 m (März 1909) gleich nach dem Genfersee, in dem ForEL als größten Wert 21,5 m gemessen hat.

Anderseits fallen die niedrigen Sommerminima auf. Dieselben haben ihre Ursache nicht allein in der Temperaturschichtung, sondern in der Verunreinigung durch die zahlreichen Wildbäche, die zwar bei Trockenheit ganz versiegen, aber nach starken Regengüssen viel Wasser und damit auch viel Geschiebe in den See führen. Sie wirken, wie Amberg (Lit. 3) für den Vierwaldstättersee nachgewiesen hat, bei der Herabsetzung der Transparenz im Sommer wesentlich mit. Ihr Einfluß überdeckt sich mit dem der Wärmeschichtung; die beiden die Transparenz vermindernden Faktoren verstärken sich gegenseitig.

Das Plankton scheint, wie ein Blick auf die graphische Darstellung zeigt, auf die Transparenz keinen Einfluß auszü̈ben. 


\section{Chemisches Verhalten.}

Herr Professor A. Bieler, Kantonschemiker in Zug, hatte die Freundlichkeit, für mich eine Analyse vorzunehmen, wofür ich ihm an dieser Stelle meinen verbindlichsten Dank ausspreche.

Die Proben wurden am 23. April 1909 bei Zug in $700 \mathrm{~m}$ Entfermung vom Ufer geschöpft und enthielten per Liter

\begin{tabular}{|c|}
\hline iekstand \\
\hline Glührückstand \\
\hline lühverlust. \\
\hline sclee Stoffe \\
\hline Chlo \\
\hline niak und Nitrate \\
\hline ilfate und Eisen... \\
\hline . . . \\
\hline lkalinität in Härte \\
\hline
\end{tabular}

Eine andere Probe, $50 \mathrm{~m}$ vom Ufer geschöpft, zeigte nahezu dasselbe Verhalten, enthielt jedoch etwas mehr organische Stoffe, nämlich $30 \mathrm{mg}$ per Liter.

\section{Biologie.}

\section{A. Die Uferregion.}

\section{Allgemeiner Charakter der makrophytischen Uferflora.}

Wie im Abschnitt über die Norphologie und Topographie des Zugersees von einem steilufrigen Obersee und dem flachufrigen Untersee die Rede war, so kann diese Einteilung auch in bezug auf die Besiedlung der Uferregion durch Makrophyten aufrecht erhalten werden.

Der Obersee mit seinen steil abfallenden Felsufern beherbergt nur eine spärliche Flora, deren Hauptbestandteil eine schmale Zone von Phragmites communis ${ }^{1}$ ) bildet. Diese wird begleitet, an einigen Stellen ersetzt durch einen ebenso spärlichen Streifen von Schoenoplectus lacustris. Hier und dort gesellen sich zu ihnen vereinzelte Gürtel von Myriophyllum spicatum, das bis in eine Tiefe von $3 \mathrm{~m}$ vordringt, und Potamogeton perfoliatus, an 2 Stellen auch

1) Nomenklatur nach Schivz u. Keller, Flora der Schweiz. 3. Auft. 1909. 
Potamogeton lucens bis $4 \mathrm{~m}$ Tiefe. Die Böschung ist bis zur Tiefe von $7 \mathrm{~m}$ von Chara ceratophylla, bald ganz spärlich, bald in lockeren Beständen besiedelt. Diese Makrophytengrenze ist zugleich auch die Grenze des biologischen Ufers.

Nur an einer Stelle, bei Immensee, finden sich alle diese Formen in einem Profil vereinigt (vergl. Figur 8, Prof. 1). An den übrigen Standorten fehlen entweder die submersen Formen oder dann das Schilfrohr und die Binse. Das letztere ist namentlich vor den zahlreichen Ufermauern der Fall, wo nur noch die submersen Pflanzen gedeihen können.

Infolge der geringen Niveauschwankungen (vergl. pag. 48) ist die Grenzflora nur schwach entwickelt und auf das Delta der Rigiaa und einige kleine Felsbuchten beschränkt. Sie ist vertreten durch Juncus effusus und Juncus inflexus. Der in der nahen Küßnachterbucht des Vierwaldstättersees vorhandene Cyperus longlls fehlt dem Zugersee heute vollständig, muß früher aber bis hier herübergekommen sein. Einen Anhaltspunkt dafür liefert cin von Schulthess im Juli 1827 bei St. Adrian gesammeltes Exemplar, das im Herbarium helveticum der eidg. techn. Hochschule aufbewahrt wird. Der sehr wahrscheinlich ohnehin nicht große Bestand scheint unterdessen den in jener Gegend vorgenommenen Straßenbauten längs des Ufers zum Opfer gefallen zu sein.

Etwas reichhaltiger ist die Vegetation des Untersees. Namentlich sind es die flachen Uferzonen zwischen dem Kiemen und Risch, Buonas und Cham und am Nordrand, die dem Botaniker ein reiches Feld versprechen, ihn aber stark enttäuschen.

Auch hier sind es hauptsächlich Phragmites communis und Schoenoplectus lacustris, die vorherrschen und längs der genannten Uferstrecken breite Verlandungszonen bilden. Große Dimensionen nimmt das Phragmitetum namentlich bei Zweiern an, wo es eine weite Fläche in der Breite bis zu $100 \mathrm{~m}$ bedeckt. Diese für den Zugersee außerordentliche Breite der Schilfrohrzone ist bedingt durch eine Nagelfluhbank, die nur langsam gegen den See hin abfällt und dann in $1 \mathrm{~m}$ Tiefe plötzlich abbricht. Das Schilfröhricht folgt dieser Bank, ohne sie zu verlassen. Außerhalb stehen noch vereinzelte Exemplare von Schoenoplectus lacustris.

Eine dem Auge angenehme Abwechslung bieten die wenigen Bestände von Nymphaea lutea, der sich im Sumpfgraben auch Castalia alba beigesellt. 
Uferroegetation des Zugersees.

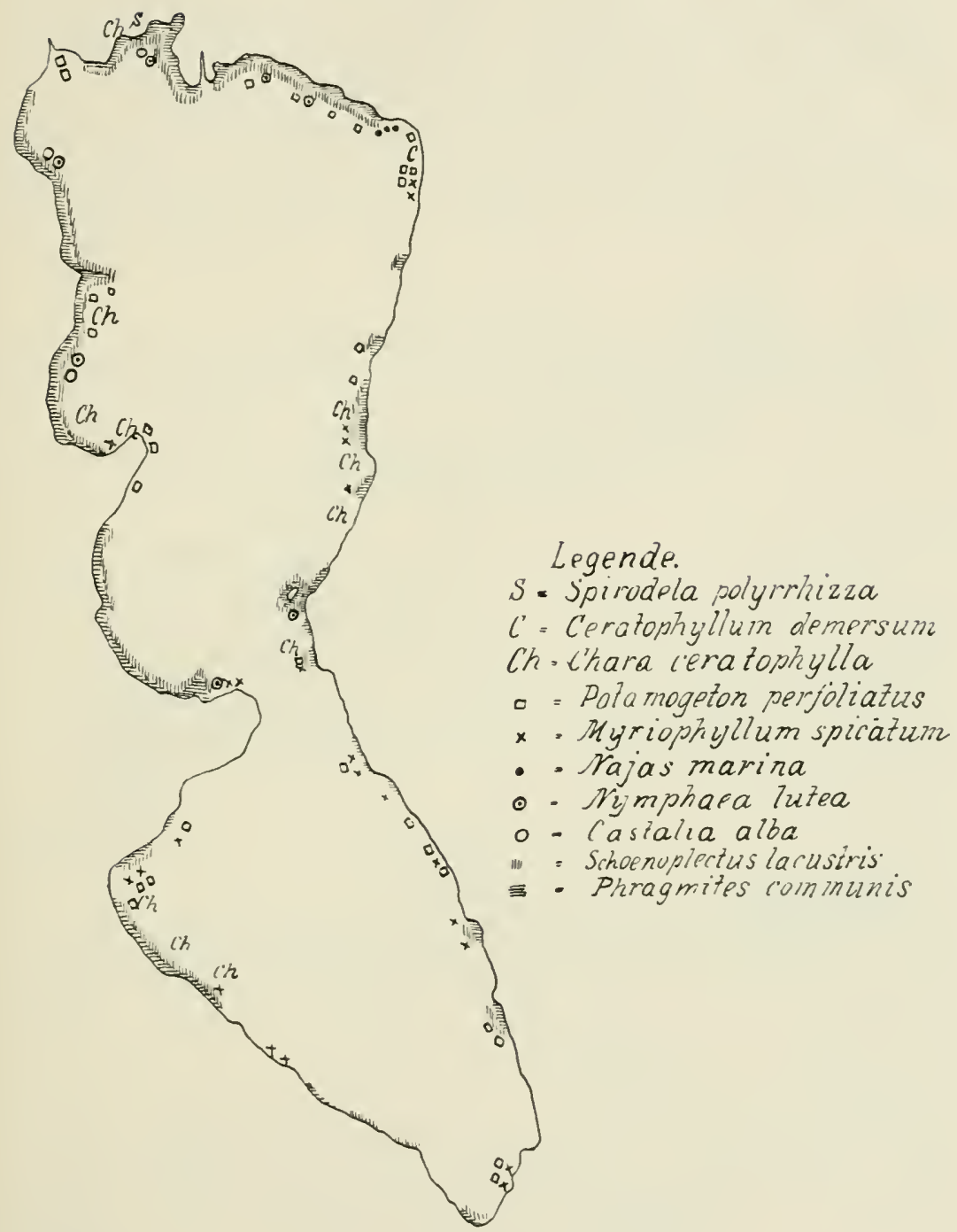

Fig. $\quad \therefore$ 
Der Gürtel der submersen Wasserpflanzen setzt sich zusammen aus Myriophyllum spicatum, Potamogeton perfoliatus, Potamogeton lucens (Zug), Potamogeton crispus (Buonas), Potamogeton pectinatus (Oberwil), Najas marina (Zug) und Chara ceratophylla, die am ganzen Ufer verbreitet ist, aber nur an wenigen Stellen ihre lockeren Bestände entwickelt. Ganz vereinzelt hat sich Ranunculus divaricalus in den Gräben am Nordufer angesiedelt.

An Schwimmpflanzen sind nur Ceratophyllum demersum und Spirodela polyrrhiza zu erwähnen, die beide nur spärlich vertreten sind. Utricularia vulgaris, die in einem Seitenarm des

Tabelle VIII.

Tiefenverteilung der Littoralflora.

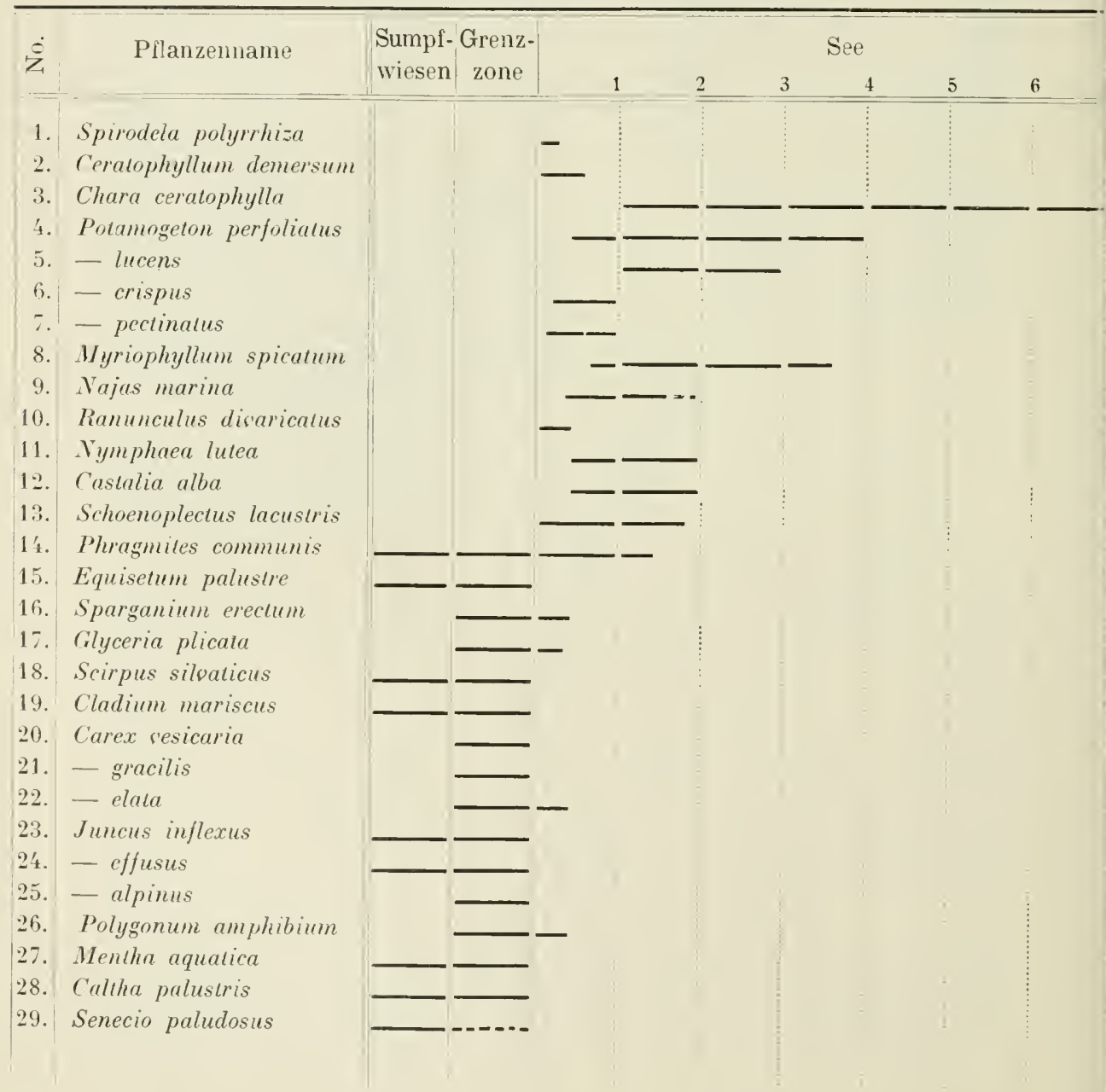


Sumpfgrabens vorkommt, gehört schon nicht mehr zur Flora des Zugersees.

Auch landeinwärts bietet der Untersee nur wenig. Die Grenzzone ist besiedelt von Carex elata, Sparganium erectum, Juncus inflexus, Juncus alpinus, Alisma Plantago aquatica, Polygonum amphibium, Glyceria plicata und einigen anderen, jedoch nur schwach vertretenen Formen (vergl. Florenliste).

Hinter den flachen Uferstrecken liegen überall ausgedehnte Sumpfwiesen, deren Streue von den Anwohnern intensiv ausgebeutet wird.
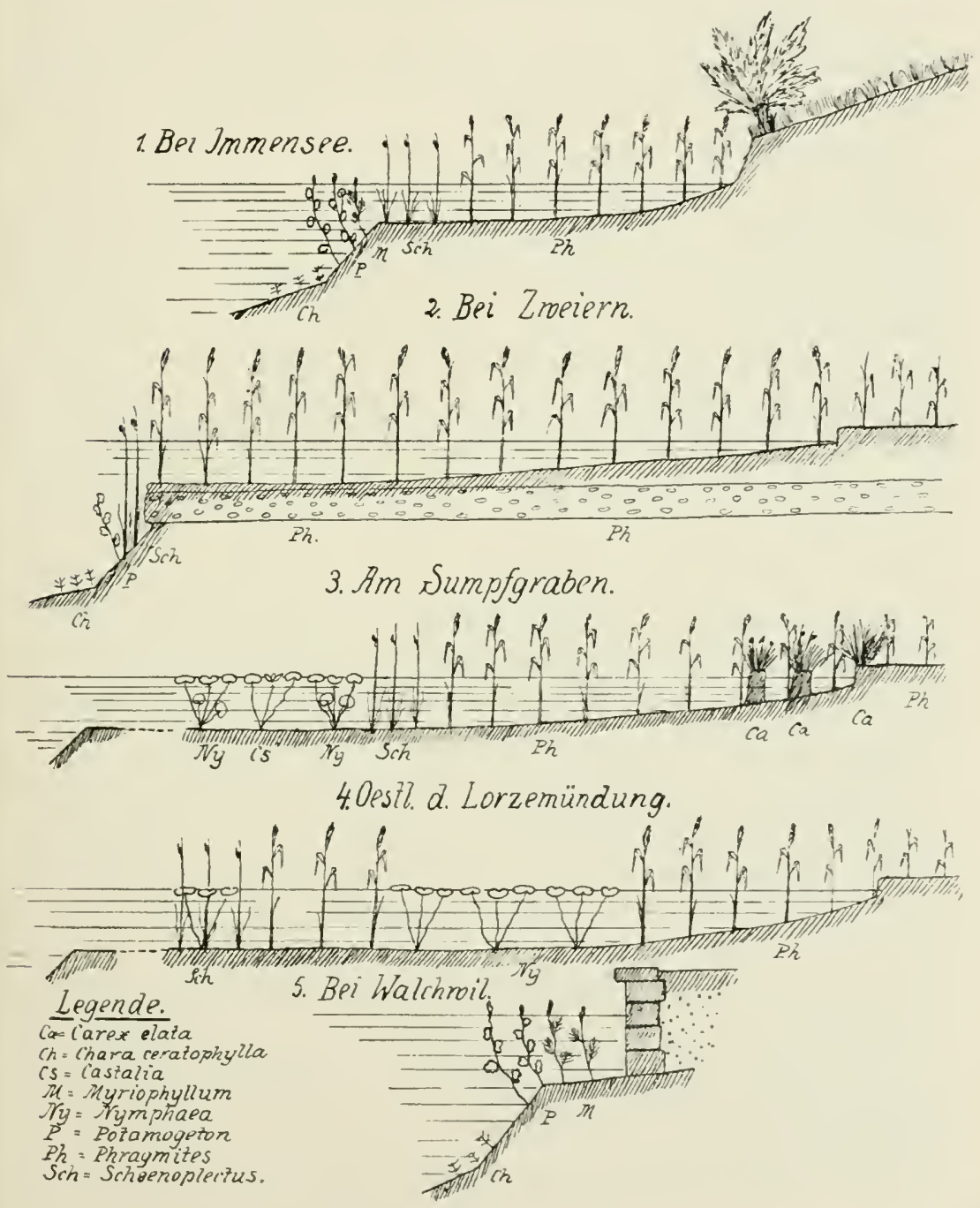

Fig. 8. Vegetationsprofile.

Archiv f. IIydrobiologie. VIII. 


\section{Florenliste.}

\section{a) Die Schwimmflora (Das Pleuston).}

1. Spirodela polyrrhiza (L.) Schleiden findet sich nur sehr spärlich im Schutze des Röhrichts am Nordufer.

2. Ceratophyllum demersum L. liegt in vereinzelten Exemplaren zusammengetrieben im Hafen von Zug.

\section{b) Submerse Wasserpflanzen. ${ }^{1}$ )}

3. Chara ceratophylla WALLRo'TH ist die einzige Vertreterin der in den meisten übrigen Seen mit älınłichen biologischen Bedingungen in mehreren Formen vorhandenen Armleuchtergewächse. Sie ist im Zugersee häufig in einer Tiefe von $1-7 \mathrm{~m}$.

Ieh habe sie im Obersee bestandbildend an der steilen Halde südlich Immensee und vereinzelt längs der ganzen Uferlinie beobachtet, im Untersee zahlreich in der Bucht nördlich dem Schloß Buonas, etwas weniger zahlreich am Ostufer von Oberwil an südwärts bis zur ,Eiele“, im übrigen vereinzelt fast längs des ganzen Ufers. Sie scheint kiesiges und sandiges Ufer zu bevorzugen, sofern dasselbe nicht durch Flußanschwemmungen fortwährend neu überschüttet wird, meidet aber die schlammigen Uferpartien im Norden und Westen fast vollständig.

4. Potamogeton perfoliatus L. ist die im Zugersee bäufigste Form der Gattung. Er ist in den beiden Varietäten, var. densifolius Merer und var. rotundifolius SoxD. vorhanden. Die letztere Varietät herrscht vor, während sich die andere auf schlammigen Giund, namentlich am West- und Nordufer, beschränkt.

$P$. perfoliatus ist beinahe längs der ganzen Uferlinie außerhalł der Schilfzone zu finden, oft vergesellschaftet mit Myriophyllum spicatum, und weicht im Gegensatz zu diesem auch den Deltas der Wildbäche nicht aus. Größere Bestände bildet er bei Immensee, Arth und Walchwil, die jeweils im Spätsommer an den aus dem Masser auftauchenden Blütenständen leicht erkenntlich sind. Er dringt bis in $4 \mathrm{~m}$ Tiefe vor, entfernt sich aber am flachen Ufer des Untersees kaum von der Schilfzone, sodaß dort seine untere Grenze schon bei $1,5 \mathrm{~m}$ liegt.

1) In verdankenswerter Weise revidiert von Herm Dr. E. Baumaxn, Zürich 
5. Potamogeton lucens L. ist im Zugersee nur an wenigen Stellen zu finden, nämlich bei Arth, Walchwil und bei der alten Badeanstalt in Zug, wo er immerhin ansehnliehe Bestände bildet. Es erreicht seine maximale Tiefe bei $3 \mathrm{~m}$.

6. Potamogeton crispus L. konnte ich im Zugersee nur an einer Stelle mit Sicherheit feststellen, nämlich an der Sehifflände von Buonas. Außerdem habe ich dieses Laichkraut in einer stillen Bucht am Nordufer in einem versehwemmten Exemplar gefunden, konnte jedoch dort trotz eifrigen Suchens keinen weiteren Standort konstatieren. Auf alle Fälle ist diese Form im Zugersee sehr selten.

7. Potamogeton pectinatus L. tritt vereinzelt im Zugersee auf und ist bei Oberwil und auf der Südseite des Kiemen spontan zu finden.

Ein fast steter Begleiter von Potamogeton perfoliatus ist

8. Myriophyllum spicatum L. Es tritt zwar weniger bestandbildend auf, ist aber wie jener längs der ganzen Uferlinie bis zur Maximaltiefe von $3,5 \mathrm{~m}$ zu finden. Es scheint die Nähe menschlicher Tohnungen zu bevorzugen, in deren Nähe es nirgends fehlt, während es sonst ebenso günstige Ansiedlungsplätze dieht daneben vermeidet. Ich suche diese Erscheinung dadurch zu erklären, daß durch in den See geworfene Abfälle, Fäkalien usw., die hier langsam verwesen, das Wasser etwas reicher ist an Kohlensäure und sonstigen Nährstoffen.

9. Najas marina L. Das Meernixkraut ist am Nordufer westlich Zug in einigen Buchten ziemlich zahlreich vorhanden. Es bildet auf schlammig-sandigem Grunde in einer Tiefe von 0,5-1,2 m lockere Bestände.

10. Ranunculus divaricatus L. ist nicht sehr zahlreieh, in vereinzelten Exemplaren im schmutzigen Wasser des Letzigrabens und Sumpfgrabens vorhanden. Er gehört jedoch seinem Standort naeh nicht mehr zur eigentlichen Seeflora des Zugersees.

\section{c) Emerse Wasserpflanzen.}

11. Nymphaea lutea L. bildet an vielen Orten entweder dem Sehilfrohr vorgelagerte oder von demselben in verborgenen Buchten eingeschlossene Beständle (vergl. Figur 7, Profil 3/4). Die submersen Blätter gestatten der gelben Seerose noch eine Ansiedlung, wo die weiße infolge der leichten Verletzlichkeit der Schwimmblät ter nicht mehr vegetieren kann. 
Standorte der gelben Seerose im Zugersee sind am Nordufer in fast sämtlichen Buchten, die durch Schilfrohrbestände vor dem Wellenschlag einigermaßen geschützt sind, im Sumpfgraben, bei Cham, beim Hofe Dersbach, in und vor dem Schilf nördlich Buonas, in der Bucht von Böschenrot und endlich am Ostufer im Schutze der „Eiele“. Dem Obersee fehlen die beiden Seerosen ganz (Wellenschlag!).

12. Castalia alba (L.) WooD. tritt nirgends selbständig auf, sondern immer nur vergesellschaftet mit ihrer gelben Verwandten. Ihr vornehmster Standort ist der Sumpfgraben (Profil 3!), wo ihre Schwimmblätter mit denen von Nymphaea lutea eine weite Fläche bedecken und wo die Blütenpracht im Sommer dem Auge ein entzückendes Bild darbietet. Die beiden anderen Standorte, bei Dersbach und Buonas, weisen nur ganz wenige Stöcke auf.

\section{d) Die Sumpfpflanzen.}

a) Bestandteile der eigentlichen Seeflora.

13. Schoenoplectus lacustris (L.) PALLA ist ein getreuer Begleiter des Schilfrohrs. Nur an wenigen Stellen des Obersees tritt er allein in allerdings nur kleinen Beständen auf, um dieses zu ersetzen. Wie das Schilfrohr, ist auch die Seebinse nicht wählerisch, sondern siedelt sich auf jedem Boden an, sofern vom Lande her Raum

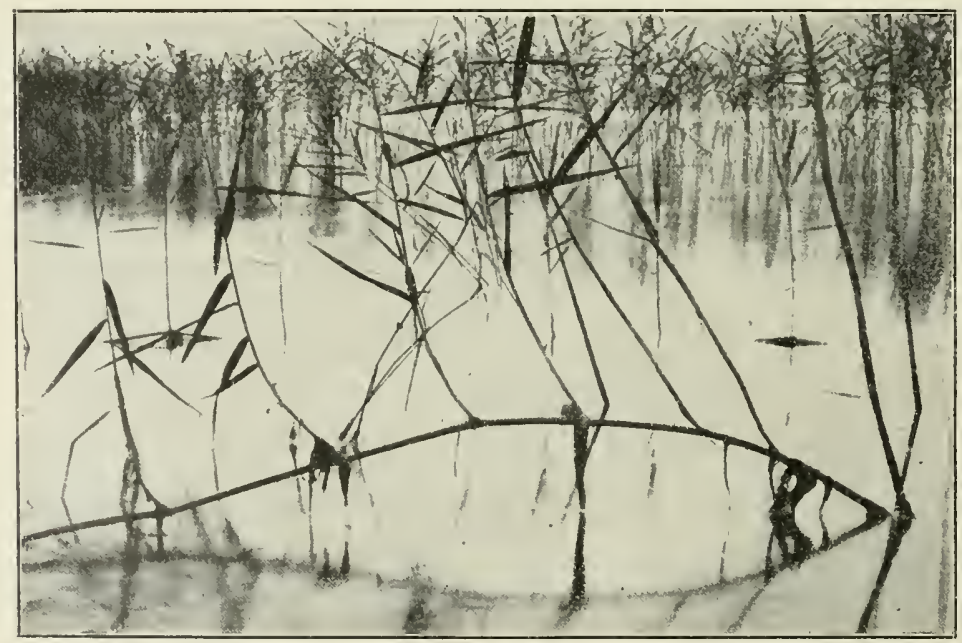

Fig. 9. Legehalme von Schilfrohr bei Risch. 
dazu vorhanden ist. Sie weicht auch kiesigen Orten nicht aus, steht aber in bezug auf Besiedlungsfähigkeit dem Schilfrohr etwas nach. (Vergl. dagegen Bally, der obere Zürichsee.)

Die größte gemessene Tiefe beträgt $1,5 \mathrm{~m}$, die größte Länge $2,9 \mathrm{~m}$.

Südlich des Kiemen und am Nordufer überwintert die Pflanze mit am Grunde stehenden, langen, flutenden Blättern, die jedoch im Frühling nur noch leicht zerreißbare, faserige Bänder bilden. (Vergl. Schröter u. Kirchner, Die Vegetation des Bodensees und BALLY, Der obere Zürichsee.)

14. Phragmites communis L., das gemeine Schilfrohr, bildet einen dichten Kranz um den ganzen See herum, der nur dureh Felspartien im Obersee und am Kiemen und durch Ufermauern (anthropogene Unformung des Ufers!) unterbrochen ist, an einigen Stellen, wie schon erwähnt, ersetzt durch die Binse.

Das Schilfrohr gedeiht auf jedem Boden. Zwar läßt es auf besonders steinigem Boden an einigen Stellen der Binse den Vortritt, hat sich aber anderseits auf den Trümmern des Ufersehlipfes vom Jahre 1887 schon wieder festzusetzen vermocht.

Der Legehalm, in Seen mit großen Niveauschwankungen ein intensiv wirkendes vegetatives Fortpflanzungsmittel, ist im Zugersee eine seltene Erscheinung. Er ist nur einmal gefunden worden (Fig. 9).

Der Verlandungsprozeß durch das Schilfrohr hat am Zugersee eine große Rolle gespielt. Beredte Zeugen davon sind die Pfahlbauten, die am Nord- und Vestufer in den Riedwiesen gefunden und ihrem mehrere Jahrtausende alten Grabe enthoben worden sind.

Wo durch den Wellenschlag die Trümmer abgestorbener Ialme zusammengetragen werden, da entsteht Schwemmtorf. ScuröteR hat diese Erseheinung in der Bucht von Böschenrot beobachtet (vergl. Frü山 u. Sсnвöter, die Moore der Schweiz); doch ist sie am Westufer (Bıse!) ziemlich allgemein, wenn auch nirgends so intensiv, wie gerade hier.

\section{3) Die Grenzflora.}

Diese Formation, die die auf dem überschwemmbaren Hang wachsende Flora umfaßt, ist im Zugersee nur sehwaeh vertreten. Es ist dies einmal dem relativ stabilen Wasserstand, der diese Zone auf ein Minimum beschränkt, und den vielen steilen und 
steinigen Ufern zuzuschreiben. Im Untersee, an dessen flachen Ufern man eine stärkere Entwieklung erwarten könnte, ist sie indessen infolge des alles überwuchernden und beinahe jede Entwicklungsmöglichleit hemmenden Sehilfrohres sowohl qualitativ wie quantitativ nur auf vereinzelte Vorkommnisse beschränkt.

Die auf der Grenzzone wachsenden Formen sind im Gegensatz zu Seen mit großen Niveauschwankungen, z. B. dem Bodensee, samt und sonders Sumpfpflanzen und vordringende Bewohner der Riedwiesen. Angehörige der eigentlichen Seeflora fehlen ganz, weil es eben nie dazu kommt, daß solche trocken gelegt und dadureh gezwungen werden, Landformen zu bilden. Ebenso fehlen die typischen amphibisch lebenden Grenzzonenbewohner, wie Heleocharis acicularis, Littorella lacustris und Ranunculus reptans.

Die auf der Grenzzone rorkommenden Formen sind die folgenden:

15. Equisetum palustre L. kommt als Angehörige der Seeflora nur vereinzelt am Nordufer vor, ist dagegen etwas zahlreicher in den Riedwiesen.

16. Sparganium erectum L. ssp. neglectum BEEBY var. oocarpum Celak. ist etwas häufiger als vorige Art, bildet aber nirgends größere Bestände.

17. Glyceria plicata Fries bildet sowohl längs des flachen Nord- und Westufers, als auch im Letzi- und Sumpfgraben hier und dort kleine Bestände.

18. Scirpus silvaticus L. fand ich auf einer Felsbank bei Böschenrot, die bei Hochwasser nur wenig überschwemmt ist. bei Niederwasser nur wenig vorragt, in Gesellschaft von Phragmites, Cladium mariscus und Mentha aquatica, sowie etwas südlich Risch neben Carex elata und gracilis, Sparganium erectum und Juncus inflexus.

19. Cladium mariscus (L.) R. Br. Obiger Standort; an West- und Nordufer vereinzelt.

20. Carex vesicaria L. und

21. Carex gracilis Cuntis sind nicht sehr häufig an den Sumpfufern und in kleinen Buehten am Kiemen zu finden.

Die wichtigste Stellung unter den Formen der Grenzflori nimmt ein

22. Carex elata All. (= stricta Good), die namentlich am Nordufer in der Nähe des Sumpfgrabens bestandbildend auftritt 
und das Schilfrohr in seiner verlandenden Tätigkeit wirksam unterstützt. Durch das vorgelagerte Röhricht gegen Wellenschlag geschützt, hat sie sich in dichten Horsten angesiedelt und so kleine Inseln gebildet. Zwischen diesen sammelt sich Sehwemmaterial des Röhrichts an und füllt die Zwischenräume aus, während sich gleichzeitig die Horste radial vergrößern und sich zusammenschließen. Eine ähnliche Erscheinung hat auch MAgrix im Lac d'Andert, einem nahezu verlandeten Jurasee. beobachtet. ${ }^{1}$ ) Sehr rasch siedeln sich auf den Horsten andere Pflanzen an (Hentha aquatica und Senecio paludosus). So vermag Carex elata ein vermutlich rasehes Vordringen der Uferlinie zu bewirken.

23. Juncus inflexus L. und

24. Juncus effusus L. sind ziemlich häufige Uferbewohner und ziehen sandigen Boden vor. Bestandbildend tritt J. inflexus am Delta der Lorze und der Rigiaa auf.

25. Juncus alpinus VILL. ist auf die Buchten am Kiemen beschränkt.

26. Polygonum amphibium L. konnte ich nie mit Schwimmblättern finden, sondern stets nur in der Varietät coenosum KocH im Schilf, schlammigen Boden bevorzugend, den es am seichten Nord- und Westrand reichlich findet.

Ähnliches Vorkommen zeigt auch

27. Wentha aquatica L., die immerhin etwas häufiger zu finden ist.

Von den Sumpfwiesen her dringen hin und wieder bis in die Grenzzone vor

28. Caltha palustris L., die immerhin den eigentlichen See vermeidet und sich an der Lorze- und Letzigraben-NIündung aufhält, und

29. Senecio paludosus L., welche Form gelegentlich hart an den Uferrand und auf die Carex-Horste hinaustritt.

\section{B. Das Plankton.}

\section{Fangmethoden.}

Über den Fang des Planktons mit dem Netz ist schon so viel geschrieben worden, daß wohl darüber hinweggegangen werden

1) Maginas, Les lacs du Jura. 
darf (Lit. 76). Dagegen mögen einige Worte der Fangmethode von Lohmaxi (Lit. 51) gewidmet werden.

LoHмaxy schöpfte zuerst im Hafen von Syrakus und später in deutsehen Neeren Wasser, um dasselbe in ganz bestimmten Quantitäten zu filtrieren. Als Filter verwendete er mit bestem Erfolge Seidentaffet, der infolge seiner engen Maschen auch die allerkleinsten Organismen mit Ausnahme der Bakterien zurückhẳlt. Das Filtrat wird mit Hilfe eines weichen Pinsels abgewaschen und mikroskopisch untersucht. Es enthält alle z. B. in einem Liter enthaltenen Organismen.

Lohmaxn zählte dieselben und berechnete daraus die im Kubikmeter enthaltene Individuenzahl einer jeden Spezies. Mit Hilfe einer Pumpe dehnte er diese Zählungsmethode auch auf die Tiefe aus.

Meine Versuche ergaben die Anwendbarkeit dieser Filtrationsmethode auch auf das Süßwasser. Doch haben die Zählungsresultate trotz peinlichster Sorgfalt so viele Fehlerquellen, daß ich mich niclit dazu verstehen konnte, aus dem Resultat der Filtration einer so geringen Menge Schlüsse zu ziehen auf die im See überhaupt anwesende Planktonquantität. Vor allem darf nicht als absolut fest angenommen werden, daß das Plankton unter denselben Bedingungen vollständig homogen verteilt sei. Das beweisen schon die Inhalte von zwei nebeneinander gewonnenen Filtraten, die einander zwar ähnlich sind, aber eben doch nicht völlig miteinander übereinstimmen.

Anderseits aber hat mir die Lonmaxsche Filtrationsmethode sehr wertvolle Dienste in den qualitativen Planktonuntersuchungen geleistet. Die Pumpe habe ich ersetzt durch einen Wasserschöpfapparat, mit dessen Hilfe ich beliebigen Tiefen Wasser entheben konnte. Das Filtrat des Seidentaffets lieferte mir Formen, die infolge ihrer Kleinheit dem Planktonnetz noch entschlüpfen. So konnte ich zu gewissen Zeiten große Mengen einer kleinen Synedra und kleine Cyclotellen (vergl. pag. 92) nachweisen, die in den Fängen mit dem Netz nur spärlieh vorhanden waren. Andere kleine Formen, wie Oocystis lacustris und Bumilleria exilis konnte ich überhaupt nur auf diesem Wege feststellen.

Die Filtrate ermöglichen also Schlüsse über die Qualität, annähernd allerdings auch über die Quantität des in verschiedenen Tiefen vorhandenen Planktons. 


\section{Allgemeines. - Vertikale und horizontale Verbreitung des Planktons. Das Plankton der Zuflüsse.}

Das Plankton des Zugersees besteht aus einer Anzahl perennierender und aus nur während eines begrenzten Teils des Jahres anwesenden Formen. Im Sommer dominierte stets Ceratium hirundinella, dessen maximale Entwicklung in den meisten bisher untersuchten Seen in die warme Jahreszeit fällt. Sobald sich im Herbst eine starke Abkühlung des Wassers einstellt, beginnen andere Arten sich zu vermehren, um Ceratium hirundinella zu verdrängen. Im Herbst 1906 nahm Cyclotella so zahireich überhand, daß sie dem Wasser bräunliche Töne zu geben vermochte. Gegen den Frühling 1907 hin, zur Zeit der ungefähren thermischen Ausgleichung, traten an ihre Stelle die Formen von Dinobryon, um endlich der Fragilaria crotonensis Raum zu geben. Nachdem sich den Sommer über Ceratium behauptet hatte, wurde es im Herbst 1907 zunächst wieder durch Cyclotellen verdrängt; diese mußten der plötzlich massenhaft auftretenden Oscillatoria rubescens weichen. Das Ende der Winterorganismen machten die zierlichen Sterne von Asterionella gracillima. Etwas einförmiger verlief der Winter 1908/09: Fragilaria-Asterionella-Fragilaria, das war die Reihenfolge der herrschenden Formen.

Da sämtliche der im Verlaufe der Beobachtungsperiode zur Vorherrschaft gelangten Arten perennierend sind, mutet einen der immerwährende Wechsel der Formen an, wie ein nie endgültig entschiedener Kampf - der Kampf ums Dasein.

Gleichzeitig mit dem Wechsel der Arten gehen auch Temporalvariationen der perennierenden Formen vor sich, die zum Teil zyklisch dem Wechsel der Jahreszeiten folgen.

Unverkennbar sind es vorzugsweise die jährlichen Temperaturschwankungen, die die Gesellschaft des Planktons gestalten und die auch die Variationen der Arten beeinflussen.

Nach Ostwald (Lit. 59) ist die innere Reibung oder Viscosität des Wassers in hohem Maße abhängig von der Temperatur. In 25grädigem Wasser ist die Sinkgeschwindigkeit eines Planktonten doppelt so groß als bei $0^{\circ}$, oder umgekehrt bei $0^{0}$ die Tragfähigkeit des Wassers doppelt so groß als bei $25^{\circ}$. Dem Sinken suchen sich die Organismen durch den ,Formwiderstand" zu widersetzen, der bedingt wird durch die spezifische Oberfläche und durch be- 
Tabelle IX a.

Periodicität der wichtigsten Phytoplanktonten. 1906/07.

\begin{tabular}{l}
\hline \hline \multicolumn{1}{c}{ Species } \\
\hline \hline Dinobryon cylındricum \\
- divergens \\
- sociale \\
Cryptomonas ovata \\
Ceratium hirundinella \\
Peridinium tabulatum
\end{tabular}

- cinctum

Glenodinium pusillum Chroococcus minutus

Comphosphaeria lacustris

Anabaena flos aquae

Clathrocystis aeruginosa

Coelosphaerium Kuetzingian.

Oscillatoria mubescens

Cyclotella socialis

- Schroeteri

- glomerata

- melosiroides

Asterionella gracillima Fragilaria crotonensis

Tabellaria fenestrata

Synedra delicatissima

Oocystis lacustris

Nephrocytium Aghardianum Botryococcus Braunii

Sphaerocystis Schroeteri Cosmarium scenedesmus

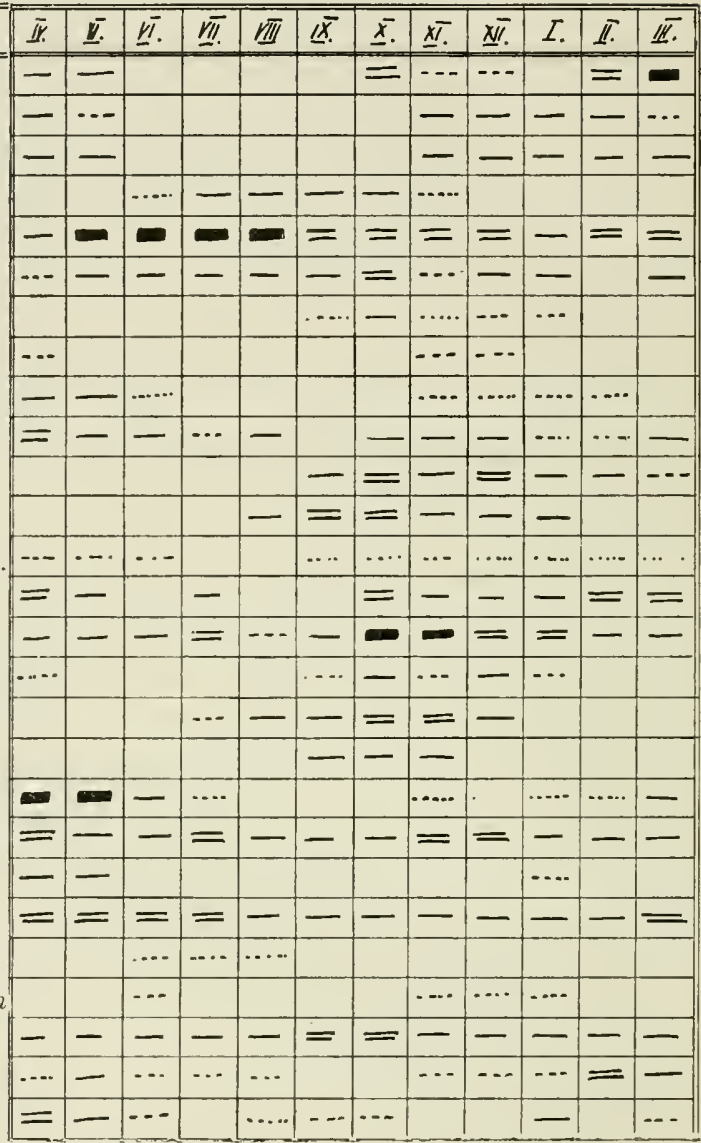

m dominierend; = sehr häufig; - nicht selten; .... selten, vereinzelt.

sonders dazu geeignete Organe und Organelle, wie Fortsätze, Dornen, Stacheln, Cilien usw.

Im Sommer dominieren Formen, die der geringeren Tragfähigkeit des warmen IVassers am besten angepaßt sind. Hierher gehört vor allem Ceratium hirundinella, das infolge seiner sparrigen Körpergestalt und wohl auch durch seine Eigenbewegung dem Schweben sehr gut angepaßt ist. Außerdem ist es sehr variabel und stellt seine Variabilität zum Teil in den Dienst der Anpassung an die verminderte Tragfähigkeit des Wassers. Ihm gesellen sich Formen bei, die, wie Mallomonas und Notholca longispina, sich infolge ihres großen Formwiderstandes mit Erfolg der Sinkbe- 


\section{Tabelle IX b.}

Periodicität der wichtigsten Phytoplanktonten. 1907/08.

$\frac{\text { Species }}{\overline{\text { Dinobryon cylindricum }}}$

- divergens

-.. sociale

Cryptomonas ovata Ceratium hirundirella Peridinium tabulatum

\section{- cinctum}

Glenodinium pusillum Chroococcus minutus Gomphosphaeria lacustris Anabaena flos aquae Clathrocystis aeruginosa Coelosphaerium Kuetzingian. Oscillatoria rubescens Cyclotella socialis

- Schroeteri

- glomerata

- melosiroides

Asterionella gracillima Fragilaria crotonensis Tabellaria fenestrata Synedra delicatissima Oncystis lacustris Vephrocytium Aghardianum Botryococcus Braunii Sphacrocystis Schroeteri Cosmarim scenedesmus

\begin{tabular}{|c|c|c|c|c|c|c|c|c|c|c|c|}
\hline $\bar{r}$ & $\underline{r}$ & $\bar{n}$ & ni & nIII. & $\underline{x}$ & $\underline{x}$ & \pm & $\underline{v^{\prime}}$ & $I$. & II. & III. \\
\hline 0 & $=$ & $\cdots$ & & & & & & & & $\cdots$ & - \\
\hline- & $=$ & $\cdots$ & & & - & $=$ & & $=$ & & $\ldots$ & - \\
\hline \multirow[t]{2}{*}{$=$} & ca. & - & $\ldots$ & - & - & $\ldots$ & & $\cdots$ & & ... & $\cdots$ \\
\hline & $\cdots$ & - & - & - & $\cdots$ & $\cdots \cdots$ & & & & & \\
\hline$=$ & - & $=$ & $=$ & 0 & $=$ & $=$ & & $=$ & & - & - \\
\hline- & $\ldots$ & $\cdots$ & - & $=$ & $=$ & $=$ & & $=$ & & - & - \\
\hline$\cdots$ & & & & & $\cdots$ & $\cdots$ & & $\cdots$ & & - & \\
\hline \multirow[t]{5}{*}{$\cdots$} & $\cdots$ & $\cdots$ & $\cdots$ & $\ldots$. & $\cdots$ & & & & & & $\cdots$ \\
\hline & & & & & & $\cdots \cdots$ & & & & $\cdots$ & \\
\hline & $\cdots$ & & $\ldots$ & $\cdots$ & $\cdots$ & $\cdots$ & & - & & - & - \\
\hline & & & - & & - & - & & & & - & - \\
\hline & & & - & & - & $=$ & & & & 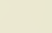 & -.. \\
\hline$\cdots \cdots$ & $\ldots$ & $\cdots$ & $\cdots$ & $\ldots$ & $\cdots$ & $\ldots$ & & - & & - & - \\
\hline$=$ & - & & 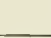 & & & & & $\cdots$ & & - & $=$ \\
\hline \multirow[t]{3}{*}{-} & - & - & - & & - & $\cdots$ & & $\cdots$ & & $=$ & $=$ \\
\hline & & - & 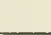 & & & & & & & & \\
\hline & . & & - & $\ldots$ & $\cdots$ & & & 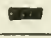 & & $\cdots$ & $\cdots$ \\
\hline- & - & . & $\longrightarrow$ & & $\cdots$ & & & & & $=$ & -- \\
\hline$\cdots$ & $=$ & $=$ & $\cdots$ & & & & & & & 一 & - \\
\hline \multirow[t]{2}{*}{-} & $=$ & $\infty$ & $=$ & & & - & & $=$ & & - & - \\
\hline & $\cdots$ & & & & & & & & & & $\cdots$ \\
\hline \multirow[t]{3}{*}{$=$} & $=$ & $\ldots$ & .... & & & & & & & - & $\cdots$ \\
\hline & $\cdots$ & & & & & & & & & & \\
\hline & & & & & $\cdots$ & & & & & $\cdots$ & $\cdots$ \\
\hline- & - & - & - & - & - & - & & - & & - & - \\
\hline \multirow[t]{2}{*}{-} & - & - & $\cdots$ & $\cdots$ & - & - & & - & & $=$ & $=$ \\
\hline & $\cdots$ & $\cdots$ & - & - & - & - & $\cdots$ & - & & & - \\
\hline
\end{tabular}

wegung widersetzen, sowie solche, die sich durch Eigenbewegung schwebend erhalten können.

In der kalten Jahreszeit werden diese Sommerorganismen von den im allgemeinen liälteliebenden Diatomeen verdrängt. ${ }^{1}$ ) In stets gleicher Menge ist Botryococcus vertreten. Diese Alge ist mit cinem vortrefflichen hydrostatischen Apparat, mit Öltröpfehen und von Gallerte umschlossenen Hohlräumen versehen,

1) Daß an dem Zurücktreten von Diatomeen im Sommer ihr geringeres Schwebevermögen schuld sei, wird durch die neuedings von H. STEIxER im Luganersee konstatierte Tatsache pines Maximums ron Asterionella zur Zeit des Temperaturmaximums unwahrscheinlich gemacht. (Anm. während des Druckes nach mündl. Mitteil.) 
Tabelle IX c.

Periodicität der wichtigsten Phytoplanktonten. 1908/09.

\begin{tabular}{c}
\hline \multicolumn{1}{c}{ Species } \\
\hline \hline Dinobryon cylindricum \\
$-\quad$ divergens \\
- sociale
\end{tabular}

Cryptomonas ovata

Ceratium hirundinella

Peridinium tabulatum

- cinctum

Glenodinium pusillum

Chroococcus minutus

Gomphosphaeria lacustris

Anabaena flos aquae

Clathrocystis aeruginosa

Coelosphaerium Kuetzingian.

Oscillatoria rubescens

Cyclotella socialis

-- Schroeteri

- glomerata

-- melosiroides

Asterionella gracillima

Fragilaria crotonensis

Tabellaria fenestrata

Synedra delicatissina

Oocystis lacustris

Nephrocytium Aghardianum

Botryococcus Braunii

Sphaerocystis Schroeteri

Cosmarium scenedesmus

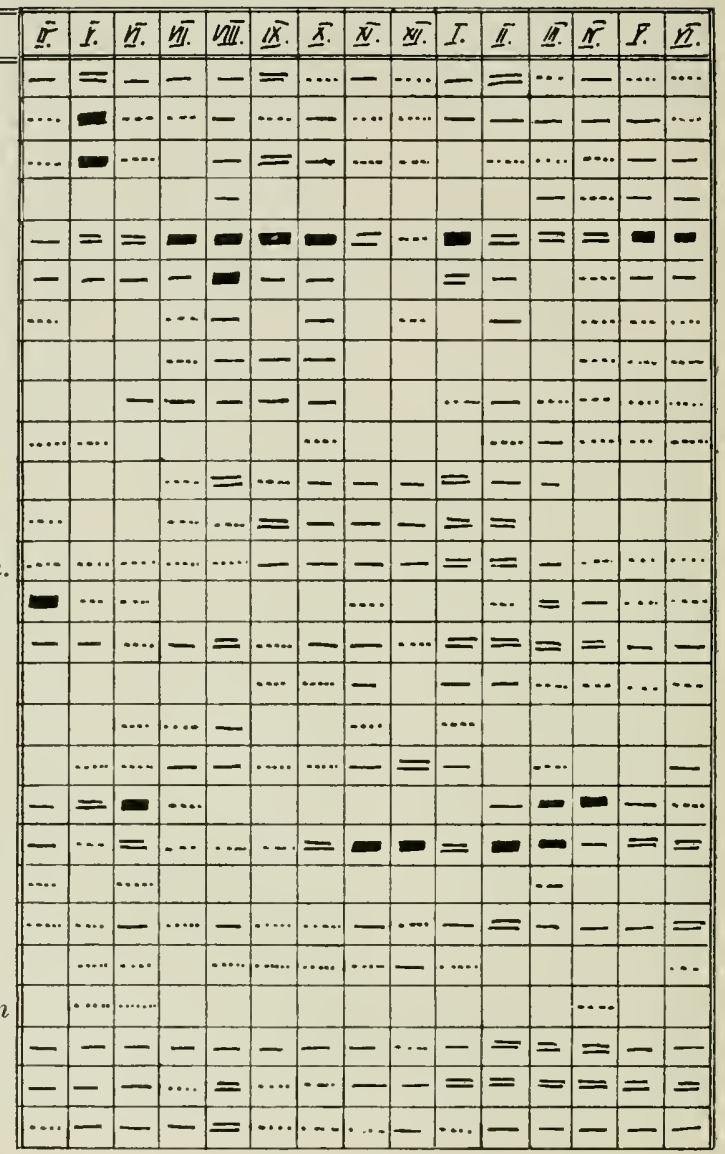

der sie nicht nur schwebend, sondern sogar schwimmend erhält, so daß sie gegenüber der Tragfähigkeit des Wassers völlig indifferent ist.

Oberflächenzüge warmer Tage sind relativ arm an Arten und Individuen. Reicheres Planktonleben herrseht dagegen in der Tiefe, indem dort diejenigen Formen vegetieren und sich tummeln, die infolge der geringeren Tragfähigkeit der Oberflächenschichten an die zähern Tiefenwasser gebunden sind. An der Oberfläche finden sich Sommer-, bezw. Warmwasserformen, in der Tiefe auch Winter- bezw. Kaltwasserorganismen. So hielt sich Dinobryon im Sommer gelegentlich in großer Individuenzahl in $10-25 \mathrm{~m}$ Tiefe auf, wähırend es an der Oberfläche nur spärlich oder gar nicht vertreten war. Ein ähnliches Verhalten zeigten auch die Diato- 
meen, z. B. Cyclotella socialis und melosiroides, sowie auch Synedra delicatissima. (Vergl. Tab. X.)

Die Temperaturschichtung allein genügt jedoch nicht, um die Tiefenverteilung des Planktons zu regulieren. Als weiterer wichtiger hier wirkender Faktor muß das Licht angesehen werden. Die obersten Wasserschichten absorbieren dasselbe sehr stark (Lit. 76). Wenn auch die chemisch wirksamen Strahlen tiefer gehen als es mit dem Auge direkt beobachtet werden kann, so verlieren sie doch schon in relativ geringer Tiefe die den assimilierenden Organismen nutzbringende Intensität.

Lichtbedürftige Algen sind deshalb meist auf die Oberfläche beschränkt. Am lichthungrigsten scheint Botryococcus Braunii zu sein, der sich als Schwimmer energisch an der Oberfläche behauptet. Auch die übrigen Chlorophyceen und die Schizophyceen erreichen ihre untere Grenze zwischen 25 und $35 \mathrm{~m}$. Die größte Tiefe erreichen die Diatomeen, die namentlich im Winter (maximale Transparenz!) in $50 \mathrm{~m}$ Tiefe noch recht zahlreich zu finden sind. (Vergl. Tab. X.)

Vermutlich auf chemische Einflüsse zurückzuführen ist die starke Entwicklung von Clathrocystis aeruginosa und Anabaena flos aquae jeweils im Spätsommer und Herbst. Es ist dies die Zeit, in der die Zuflüsse den See mit organischen Substanzen bereichert haben. Vergleichende chemische Analysen stehen mir leider nicht zur Verfügung. Doch wird diese Annahme bestätigt durch die horizontale Verteilung des Planktons. Der Untersee war namentlich im Sommer 1908 reicher an genannten Planktonarten als der Obersee. Die Untersuchungen ron Nussbaumer (Lit. 57) haben aber ergeben, daß die Anzahl der Keime mit der Entfernung von der Stadt Zug abnimmt. Ebenso hat die Vergleichung der Planktonquantitäten im Untersee (Tab. XI) stets größere Mengen ergeben, was nach Pfexilger (Lit. 63) ebenfalls auf eine größere Menge organischer Stoffe im Untersee schließen läßt.

Im übrigen konnten in der örtlichen Entwicklung des Planktons wohl Unterschiede festgestellt werden (vergl. Tab. XI). Doch scheint es sich dabei um ,Schwarmbildung" zu handeln. Der Zugersee, der topographisch in 2 Teile zerfällt, ist biologisch ein einheitliches Becken.

Die Planktonmenge an der tiefsten Stelle per $\mathrm{m}^{2}$ schwankte zwischen 2 und $14,5 \mathrm{~cm}^{3}$. Einzig der Bodensee hat ein ähnlich kleines Planktonvolumen aufzuweisen, nämlich $14,0 \mathrm{~cm}^{3}$. Der 
Tabelle XI.

Lokale Differenzen in der Zusammensetzung des Phytoplanktons.

\begin{tabular}{|c|c|c|c|c|c|c|c|c|c|c|c|c|c|c|}
\hline \multirow[b]{2}{*}{ Species } & \multicolumn{4}{|c|}{ 24:/25 mang 17} & \multicolumn{3}{|c|}{$23 / 25$ main of. } & \multicolumn{3}{|c|}{ 31. Inh 08 . } & \multicolumn{4}{|c|}{ 22. 14mil 19y. } \\
\hline & $\frac{5}{5}$ & בै & $\begin{array}{l}3 \\
3 \\
\beta \\
\end{array}$ & रे & $\frac{5}{\xi}$ & रु & से & है & $\begin{array}{l}\xi \\
\vdots \\
\vdots\end{array}$ & ई & $\frac{3}{3}$ & 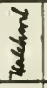 & $\begin{array}{l}\checkmark \\
j \\
\vdots\end{array}$ & है \\
\hline Dinobryon cylindricum & $\infty$ & - & - & - & - & 一 & - & & & & - & - & $\cdots$ & $\cdots$ \\
\hline — dic'ergens & $\cdots$ & $\cdots$ & $\cdots$ & $\cdots$ & - & $=$ & 一 & $\cdots$ & $\cdots$ & $\cdots$ & - & - & - & $\cdots$ \\
\hline - sociale & $\cdots$ & & & & - & - & - & & $\cdots$ & $\because$ & $\cdots$ & - & 一 & - \\
\hline Cryptomonas ovata & & & & & & & & - & - & - & & $\cdots$ & & \\
\hline Ceratium hirundinella & 一 & $=$ & $=$ & $=$ & $\cdots$ & 一 & $=$ & $\infty$ & $\rightarrow$ & $=$ & $=$ & $=$ & $=$ & - \\
\hline Peridinium tabulatum & - & $\cdots$ & $\cdots$ & $\cdots$ & & & $\cdots$ & $\cdots$ & - & & & $\cdots$ & & \\
\hline - cinctum & & & & & & & & - & $=$ & - & & $\cdots$ & $\cdots$ & \\
\hline Glenodinium pusillum & & & & & $\cdots$ & & & $\cdots$ & $\cdots$ & 一 & & $\cdots$ & & \\
\hline Chroococcus minutus & & & & & & & & - & - & $\cdots$ & & $\cdots \cdot$ & & \\
\hline Gomphosphaeria lacustris & $\cdots$ & $\cdots$ & $\cdots$ & $\cdots$ & & & & & & & $-\cdots$ & $=$ & 一 & - \\
\hline Anabaena flos aquae & $\cdots$ & $\cdots$ & $\cdots$ & $\cdots$ & $\cdots$ & & & $\cdots$ & $\cdots$ & - & & & & \\
\hline Clathrocystis aeruginosa & & & & & & & & $\cdots$ & $\cdots$ & - & & & & \\
\hline Coelosphaerium iuetzingian. & $\cdots$ & $\cdots$ & $\cdots$ & $\cdots \cdots$ & & & & $\cdots$ & & $\cdots$ & $\cdots$ & $\cdots$ & & \\
\hline Oscillatoria rubescens & $=$ & $=$ & $=$ & $=$ & - & - & 一 & & & & - & 一 & - & 一 \\
\hline Cyclotella socialis & - & 一 & $\cdots$ & - & - & - & - & - & - & & - & $=$ & - & 一 \\
\hline - Schroeteri & $\cdots$ & & & & & & $\cdots$ & & & & & $\cdots$ & & \\
\hline - glmerata & & & & & & & $+9+s$ & $\cdots$ & - & & & & & \\
\hline - melosiroides & & & & & & & $\cdots$ & $\cdots$ & $\cdots$ & $\cdots$ & & & & \\
\hline Asterionella gracillima & - & - & $\cdots \cdot$ & - & $=$ & $=$ & $\infty$ & $\cdots$ & & $\ldots$ & - & - & - & - \\
\hline Fragilaria crotonensis & - & - & - & - & $=$ & $=$ & $=$ & $\cdots$ & & & - & - & $=$ & - \\
\hline Tabellaria fenestrata & & & & & - & $\cdots$ & & & & & & & & \\
\hline Synedra delicatissima & $=$ & $=$ & $=$ & $=$ & - & $\cdots$ & - & & $\cdots$ & $\cdots$ & - & - & - & $\cdots$ \\
\hline Oocystis lacustris & & & & & & & & & & & & & & \\
\hline Nephrocytium Aghardianum & & & & & & & & & & & & $\cdots$ & & \\
\hline Botryococcus Braunii & - & - & - & - & - & - & 一 & 一 & - & - & $=$ & $=$ & - & 一 \\
\hline Sphaerocystis Schroeteri & $=$ & - & $\cdots$ & $\cdots$ & - & - & - & $\cdots$ & $\cdots$ & - & $=$ & $=$ & $=$ & $=$ \\
\hline Cosmarizm scenedesmus & $\cdots$ & $\cdots$ & $\cdots$ & $\cdots$ & $\cdots$ & $\cdots$ & $\cdots$ & - & - & $=$ & - & - & & - \\
\hline Planktonvol. $\mathrm{cm}^{3}$ unter $1 \mathrm{~m}^{2}$ Oberil. & 12 & 12 & 11 & 16 & 13 & 14 & 14 & 10 & 12 & 19 & 13 & 13 & 15 & 16 \\
\hline
\end{tabular}

Genfersee hat $126 \mathrm{~cm}^{3}$, der Zürehersee 260-1006 $\mathrm{cm}^{3}$ unter $1 \mathrm{~m}^{2}$ Oberfläche. Diese wenigen Vergleichsziffern beweisen, daß der Zugersee an Plankton relativ arm ist. Das Gesetz von STrod tusx. nach dem ein See umso ärmer an Plankton ist, je steiler seine Ufer abfallen (vergl. pag.44) und je geringer deswegen seine Oberfläche im Verhältnis zum Gesantrolumen ist, findet hier seine Bestätigung.

Die Maxima der Planktonvolumina wurlen stets durch die maximale Entwicklung der Dinobryon-Arten und der Diatomeen bedingt. Mit der Abnahme dieser Arten wurde stets auch das 
Planktonvolumen wieder kleiner. Die Maxima fallen mit der Periode der Vollzirkulation zusammen, wie das anderwärts besonders Whipple für die Diatomeenmaxima in den seichten, als Wasserreservoire dienenden Seen bei Boston konstatiert hat. Ob auch in dem tiefen Zugersee die erleichterte Nahrungszirkulation vom Boden aus hierfür verantwortlich gemacht werden kann, ist fraglich. Vielleicht bedingen andere Momente gerade zu dieser Zeit das Maximum der betreffenden Arten.

Um eine allfällige Zufuhr von Plankton durch die Zuflüsse festzustellen, habe ich zu verschiedenen Jahreszeiten Wasser aus dem Lotenbach, der Rigiaa, dem Hüri- und dem Ghürschbach durch das Planktonnetz filtriert. Wie zu erwarten, war der Erfolg absolut negativ, weil keiner dieser Bäche in seinem Sammelgebiet stagnierende Gewässer hat. Die ganze Ausbeute beschränkte sich auf einige Arten von Diatomeen, die für das Plankton nicht die geringste Bedeutung haben.

Anders liegen die Verhältnisse bei der Lorze. In ihrem Einzugsgebiet liegt der Aegerisee. Vergleichende Fänge vom 25./26. Mai 1907 ergaben folgendes:

Im Aegerisee fand ich 17 Formen, unter denen Ceratium hirundinclla dominierte. In der Lorze, unmittelbar bei ihrem Einfluß in den Zugersee, waren noch 4 Arten vorhanden. Die übrigen sind durch den Transport zerstört worden. In einer Entfernung von $70 \mathrm{~m}$ von der Lorzemündung konnte von einer Beeinflussung des Zugerseeplanktons durch dasjenige des Aegerisees nichts mehr bemerkt werden. Es dominierte Asterionella gracillima, und Ceratium hirundinella war nicht zahlreicher als in größerer Entfernung vom Ufer. Die Zuflüsse vermögen also das Plankton des Zugersees in keiner Weise zu beeinflussen.

\section{Das Phytoplankton.}

$$
\begin{aligned}
& \text { Planktonliste. } \\
& \text { Schizomyceles. }
\end{aligned}
$$

Vergl. Nussbaumer, Über Verunreinigung von Seen durch Einleitung städt. Al)wässes mit spezieller Berücksichtigung des Zugersees. 1909.

$$
\text { Schizophyceae. }
$$

* Chroococcus minutus var. carneus CHoD. 
* Gomphosphaeria lacustris Chod.

†† Merismopedium glancum (Енвg.) NAEG.

* Anabaena flos aquae (Lyxgr.) BréB.

* Clathrocystis aeruginosa (Kuetz.) Hexfr.

* Coelosphaerium Kuetzingianum NAEG. Microcystis punctiformis Kincis.

* Oscillatoria rubescens DC. †† Lyngbya bipnnctata LEMr.

$$
\text { Flagellatae. }
$$

Diplosiga frequentissima $\mathrm{Z}_{\mathrm{ACH}}$.

Dinobryon cylindricum Імно $\mathrm{F}$

* - divergens Iмн.

* - sociale EнRBg.

* Mallamonas producta (ZACH.) Iwaxoff

* Cryptomonas ovata EHrBg. Uroglena volvox Enrba.

$$
\text { Peridinea. }
$$

* Ceratium hirundinella O. F. IIÜLler

* Peridinium tabulatum (Ehrbg.) Clap. et Lachm.

* - cinctum Ehrbg.

* Glenodinium pusillum PÉxARD

$$
\text { Diatomaceae. }
$$

* Cyclotella comta (Enrbg.) Kuetz. var. tenuis Friche

* - bodanica Eulensteix rar. lemanensis Lens.

* - socialis Sснӥтt.

* - Schroeteri Lemi.

* - glomerata Bachuaxx

* - melosiroides LeMu.

* Asterionella gracillima (Haxtzsch.) Heis.

* Fragilaria crotonensis Kiтt.

$\dagger$ - capucina Desu.

* Tabellaria fenestrata (Lyхgв.) Kuetz.

$\dagger$ - flocculosa (Rotis) Grunow

† Cymatoplenra elliptica Kuetz.

$\dagger-$ solea (BRе́в.) II. Sir.

* Synedra delicatissima IV. Sir.

$\dagger$ - splendens KuETz.

Archiv f. Hydrobiologie, VIIII. 
Synedra radians IV. Sis.

* †† Campylodiscus hibernicus EнRBg.

$\dagger \dagger$ Pleurosigma attenuatum (Kuetz.) W. Sm.

$\dagger \dagger$ Nitzschia linearis var. tenuis W. Sм.

$\dagger \dagger$ Navicula viridis Kuetz.

$*_{\dagger}$ Diatoma elongatum AG. var. tenue (AG.) V. H.

† Diatoma valgare BoRY var. producta GRun.

†† Encyonema caespitosum KuETz.

$$
\text { Conjug a ta e. }
$$

* Cosmarinm scenedesmus Delp.

- Botrytis Menegh.

Stanrastrum gracile RaLfs

$$
\text { Chlorophyceae. }
$$

Bumilleria exilis Borzr.

Oocystis lacustris CHoD.

Nephrocytium Aghardianum NAEg.

*广 Raphidium Bralnii NAEG.

Pandorina morum (M̈̈́Ler) BoRY

* Botryococcus Braunii Kuetz.

* Sphaerocystis Schroeteri Cнор.

$* \uparrow$ Dictyosphaerium pulchellum Wood.

Pediastrum Boryanum (Turp.) Mexegh.

Scenedesmus quadricanda (Turp.) Brér.

Obiges Verzeichnis enthält meine eigenen Funde. Nach Васнилхм (Beitrag zur Kenntnis der Schwebeflora der Schweizerseen. Biol. Zentralbl. Bd. XXI., 1901) sind für den Zugersee noch die folgenden beizufügen:

Stichogloea olivacea var. sphaerica CHoD.

Eudorina elegans EHrbG.

Wahrscheinlich handelt es sich hier nur um ganz vereinzelt aufgetretene Exemplare.

Die von Bachmaxx und CHODAT schon früher gefundenen Arten (verg], oben zitierte Publikation) sind mit * bezeichnet. Die mit $\dagger$ bezeichneten Arten sind nur in einzelnen Exemplaren gefunden worden, die mit $\dagger \dagger$ bezeichneten als Tycholimneten zu betrachten. Beide Kategorien werden bei Anlaß der Besprechung der einzelnen Arten keine Berücksichtigung finden. 
Bemerkungen über die einzelnen Planktonten.

$$
\text { Schisomycetes. }
$$

Über die Bakterien des Zugersees hat sich Nussbaumer ausgesprochen. Er hat seine Untersuchungen auf die Verunreinigungen des Sees in unmittelbarer Nähe der Stadt Zug beschränkt und nimmt spezielle Rücksicht auf die hygienischen Verhältnisse.

Er kommt zum Schlusse, daß das Wasser des Zugersees als sehr rein zu betrachten sei, da schon in $700 \mathrm{~m}$ Entfernung vom Ufer die Zahl der Keime pro $\mathrm{cm}^{3} 100$ selten übersteigt.

Doch ist auch das offene Wasser nicht keimfrei. In $1950 \mathrm{~m}$ Entfernung rom Ufer geschöpfte Wasserproben enthielten an der Oberfläche zwar keine Keime, dagegen in $20 \mathrm{~m}$ Tiefe 16 , in $30 \mathrm{~m}$ Tiefe noch 12 pro $\mathrm{cm}^{3}$.

In den LoHMdxischen Filtraten fand ich recht häufig die rosenkranzartigen Fäden eines Streptococcus von $2 \mu$ Zellendurchmesser. In Fragilaria-reichem Plankton habe ich stets einen Mikroorganismus beobachtet, der sich längs der Bänder sehr' lebhaft bewegte. Seine Länge beträgt ca. 5 \%., seine Dicke ca. 1 ... Eine auffallende Randzone läßt vermuten, daß ein Pelz von Cilien als Bewegungsorganell dient. Es handelt sich vermutlich um eine Form von Bacillus. Vïtale Färbung ist nicht gelungen; in konserviertem Naterial war nichts mehr zu sehen.

$$
\text { Schizophyceae. }
$$

Die Schizophyceen sind im allgemeinen im Zugersee sowohl an Zahl der Arten wie der Individuen nur schwach vertreten. Das an organischen Stoffen arme Wasser sagt ihnen offenbar nicht zu. Wenn auch der Untersee gelegentlich etwas reicher an Blaualgen ist (vergl. pag. 78), so kann noch lange nicht ron einem Reichtum gesprochen werden.

Chroococcus minutus var. carneus CHoD. ist mit Unterbrechungen, jedoch zu den verschiedensten Jahreszeiter aufgetreten, nimmt aber keinen wesentlichen Anteil an der Bildung des Gesamtplanktons.

Gomphosphaeria lacustris CHOD. und Coelosphaerium Kuetzingianum NAEG. werden sehr oft miteinander verwechselt und sind deshalb von Bachмaxx in seinen, Vergleichenden Studien über das Plankton von Seen Schottlands und der Schweiz" einer gewis 
willkommenen vergleichenden Besprechung unterzogen worden. Coelosphaerium Kuetzingianum fehlt den Planktonfängen nur selten. Nur schwach ausgeprägte Maxima der Entwicklung fallen auf die Wintermonate (vergl. Tab. IX, Dez. 1907 bis März 08, Sept. 1908 bis März 09). Etwas seltener und nur einmal, im April 1906, in größerer Menge aufgetreten ist Gomphosphaeria lacastris. Anabaena flos aquae (Lyngr.) Bréв. und Clathrocystis aernginosa. (KuETz.) Henfr. sind Herbstformen, die sich bis in den Vinter hinein behaupten, ihn auch gelegentlich überdauern, im Sommer aber fast spurlos wieder verschwinden. Im August 1908 brachte es allerdings Anabaena flos aquae zu einer schon starken Mengenentwicklung. Im allgemeinen scheinen diese beiden Formen an ähnliche Lebensbedingungen gebunden zu sein. Sie schwimmen zur Zeit ihrer maximalen Entwicklung (1906 September bis Oktober, 1907 Oktober, 1908 August bis Oktober) an der Oberfläche, vergesellschaftet mit dem perennierenden Botryococcus Brannii, so dicht, daß man in einer fast beliebig kleinen geschöpften Wassermenge stets vereinzelte Kolonien beobachten kann. Schon mit einer guten Lupe kann man dann auf den knäuclig aufgewundenen Fäden von Anabaena flos aquae einen dichten Pelz eines passiven Planktonten, der zierlichen Vorticella convallaria (vergl. pag. 100) wahmehmen. Zur Bildung einer eigentlichen Seeblüte, wie dies durch Clathrocystis aernginosa auf dem Zürichsee geschehen ist (vergl. Schröter, Die Schwebeflora unserer Seen), liam es nie.

Dieselbe Periodizität dieser beiden Formen - Herbstmaxima - ist ganz allgemein beobachtet worden. Es liegt die Tendenz nahe, diese Erscheinung mit der Nenge organischer Stoffe zu begründen, die im Laufe eines Sommers dem See durch seine Zuflüsse zugeführt werden (vergl. pag. 78).

Microcystis punctiformis KırснN. ist eine kleine, koloniebildende Cyanophycee, deren ca. $1 \mu$ große kugelige, bläuliche Zellen in einem $10-20 \mu$ großen gallertigen Lager eingebettet sind. Die Chromatophoren erscheinen ihrer Kleinheit wegen fast farblos, und deshalb wird diese Alge woh] vielfach übersehen, um so mehr, als sie auch dem Netze leicht entschlüpft, während man sie durch Filtration nach LoHmañ leicht feststellen kann. Sie ist ein Sommerorganismus und immer nus vereinzelt vorhanden.

Die interessanteste Cyanophycee des Zugersees ist Oscillatoria rubescens DC., die sich öfters rasch epidemieartig ver- 
mehrt, um nachher ebenso rasch wieder zurückzugehen oder ganz zu verschwinden. Sie dominierte im Dezember 1904 (nach BAcHMAxN Lit. 7) und im April 1908. In ihrer Periodizität ist sie sehr unregelmäBig. Ihre maximale Frequenz erreicht sie jeweils im Winter. Im Sommer hält sie sich mit Vorliebe in der Tiefe auf und geht bis $50 \mathrm{~m}$. Diese Beobachtung deckt sich mit der von LozERox im Zürichsee gewonnenen, wo Oscillatoria rubescens vom Jahre 1898 an derart dominierte, daß sie beinahe alles übrige Plankton unterdrückte. Im Juli 1901 war sie an der Oberfäche gar nicht vertreten, hatte dagegen in $13 \mathrm{~m}$ Tiefr alles andere beinahe überwuchert.

$$
\text { Flagellatae. }
$$

Die Gattung Dinobryon ist im Zugersee vertreten durch

Dinobryon cylindricum Імн.

Dinobryon divergens Iин.

Dinobryon sociale EнввG.

Es sind lauter ausgesprochene Winterorganismen, deren maximale Entwicklung in der Regel auf die Zeit der totalen Ausgleichung fällt (vergl. Tab. IX). Doch sind sie nicht unbedingt an diese Bedingung gebunden, wie HuBer (Lit. 39) aus dem Verhalten in den Montiggler Seen schließen z: können glaubt. Im Oktober 1908 nahm Dinobryon divergens eine dominierende Stellung ein. Dem massenhaften Auftreten der Kolonien ging stets eine Periode voran, in der das Plankton reich an Einzelindividuen war. Es bestätigt sich also hier die Annahme von Huber (Lit. 39), daß sich die Dinobryon-Arten durch Zerfallteilung vermehren. Seine Vermutung jedoch, daß diese Art vegetativer Vermehrung ein Merkmal verschiedener Arten und Varietäten sein könnte, bestätigt sich nicht, da sich alle 3 Formen gleich verhalten, auch Dinobryon sociale, bei dem HuBER diese Erscheinung nicht beobachtet hat.

Die Tiefenverteilung ist abhängig von der Tragfähigkeit des Wassers, was im Sommer jeweils dadurch zum Ausdruck kommt, daß die maximale Entwicklung sich anf die Tiefen von $10-25 \mathrm{~m}$ beschränkt (vergl. pag. 76 und Tab. X). Dabei sind die Kolonien mehr in den lıöheren Schichten, während die Einzelindividuen auf die tieferen Regionen beschränkt sind. Vermutlich sind die Kolonien besser befähigt, sich im wärmeren Wasser schwebend zu 
erhalten als die mit nur geringem Formwiderstand ausgestatteten Einzelindividuen.

Cryptomonas ovata Enrba. ist eine Sommerform, welehe, obwohl zur Zeit maximaler Entwicklung nicht selten, doch keinen wesentlichen Anteil an der Bildung des Gesamtplanktons bildet.

Mallamonas producta (ZAcir.) Jwaxoff ist ein Sommerorganismus und dem warmen, weniger tragfähigen Wasser durch die langen Stacheln trefflich angepaßt (vergl. pag. 73). Auch diese Form war nie zahlreich vertreten.

Uroglena volvox EHRBg. zeigte ein sehr eigenartiges Verhalten. Diese Alge ist ein einziges Mal, im Juni 1906 plötzlich in großen Mengen aufgetreten und vermochte in $5 \mathrm{~m}$ Tiefe fast alle übrigen Formen zu verdrängen. Nachher ist sie wieder ebenso rasch beinahe spurlos verschwunden, und nur ganz vereinzelt versprengt vorkommende Exemplare bilden Relikte jener „Epidemie“.

Diplosiga frequentissima $\mathrm{Z}_{\mathrm{ACH}}$. ist als passiver Planktont an Asterionella gebunden.

$$
\text { Peridineae. }
$$

Für die norddeutsehen Seen (vergl. Berichte der biolog. Station Plön u. a.), sowie für die Alpenseen (vergl. Huber, Montigglerseen) werden die Peridineen stets als aussehließliche Sommerformen bezeichnet. In den tiefen Schweizerseen (Boden-, Züricher-, Vierwaldstätter-, Genfersee usw.) sind sie dagegen perennierend. Der Grund für dieses Verhalten der Peridineen scheint in den versehiedenen thermischen Verhältnissen zu liegen. In Seen, die im Winter regelmäßig gefrieren, also in seichten Becken, sind sie auf die warme Jahreszeit beschränkt und fehlen im Winter entweder ganz oder sind nur sehr spärlich vertreten, so im Katzensee und Greifensee (Lit. 3 und 95). In tiefen Seen mit geringeren Temperaturschwankungen sind sie perennierend. Immerhin ziehen sie auch hier warmes Wasser vor. Im Sommer erreichen sie stets ihre maximale Entwicklung und erweisen sich dadurch als echte Sommerorganismen.

Nach Wesenberg-Lund sind die Peridineen auf Cyanophyceen-arme Gewässer beschränkt. Da in der Tat der Zugersee nur wenig Blaualgen enthält, anderseits aber reich an Peridineen ist, bestätigt sich diese Beobachtung auch hier.

Ceratium hirundinella O. F. MüLLER ist eine für den Zugersee 
charakteristische Planktonform, charakteristisch sowohl deswegen, weil es nie, auch im Winter nicht, verschwindet, als auch wegen seiner von der anderer Seen abweichenden, gedrungenen, beinahe plump zu nennenden Gestalt.

Ceratium kennzeichnet sich für den Zugersee als Sommerform dadurch, daß es sein Entwicklungsmaximum und eine zugleich numerisch über alle übrigen Planktonformen dominierende Stellung regelınäßig in den Sommermonaten im Juli und August erreicht. Im Winter läßt es sich durch die Kaltwasserformen zurüekdrängen. jedoch nie so weit, daß es nicht noch immer einen beträchtlichen Anteil an der Bildung des Planktons nähme. Wintercysten sind im offenen Wasser höchst selten. Sowohl am Grunde wie am Ufer habe ich rergebens darnach gesucht. Rasch rermag es im Frühling wieder die Oberhand zu gewinnen.

Wie in allen bisher untersuchten Gewässern zeichnet sich Ceratium hirundinella auch im Zugersee durch seine auffallende Variabilität auf. Es tritt uns in 2 deutlich voneinander versehiedenen Formentypen entgegen, die durch Übergänge (Fig. 11) nur lose miteinander verbunden sind.

Der im Zugersee gewöhnliche Typus zeichnet sich durch seinen plumpen Körper aus, der mit stark vorspringenden Leisten versehen ist. Die Hörner sind relativ kurz und gehen unvermittelt aus dem Rumpf hervor. Die Zahl der Hinterhörner beträgt 2-3. Die Länge schwankt zwischen 97 und 190 p., die Breite zwischen 48 und $79 \mu . \quad$ Morphologisch stimmt diese Form recht gut mit dem Typus curtum ${ }^{1}$ ) von Guyer (Lit. 95) überein. Während dieser Typus nach den Beobachtungen GuYers der Saisonvariation nur schwach unterworfen ist, gilt für den Zugersee gerade das Gegenteil.

In Plankton der kältesten Periode war dieser Typus beinahe ausschließlich durch 3hörnige Formen vertreten. Höchstens $3 \%$ aller Individuen haben 3 Antapicalhörner aufzuweisen. lın Frühling erscheinen zuerst wenige, dann immer mehr 4hörnige Formen, deren maximale Entwieklung mit der wärmsten Periode zusammenfällt.

Wir haben es also, um mich eines Ausdruckes von Huber zu bedienen, mit einer Additionsreihe zu tun. Die Entwicklung des dritten Antapicalhornes erfolgt mit steigender Temperatur.

Mit fortschreitender Abkühlung nimmt im Herbst die Zahl

1) Nach Bachuax (Lit. 96) synonym mit carinthiacum Zederbater und pumilum ZacH. 
Tabelle XII.

Statistik über die Variation des Winkels zwischen den Hinterhörnern von Ceratium hirundinella.

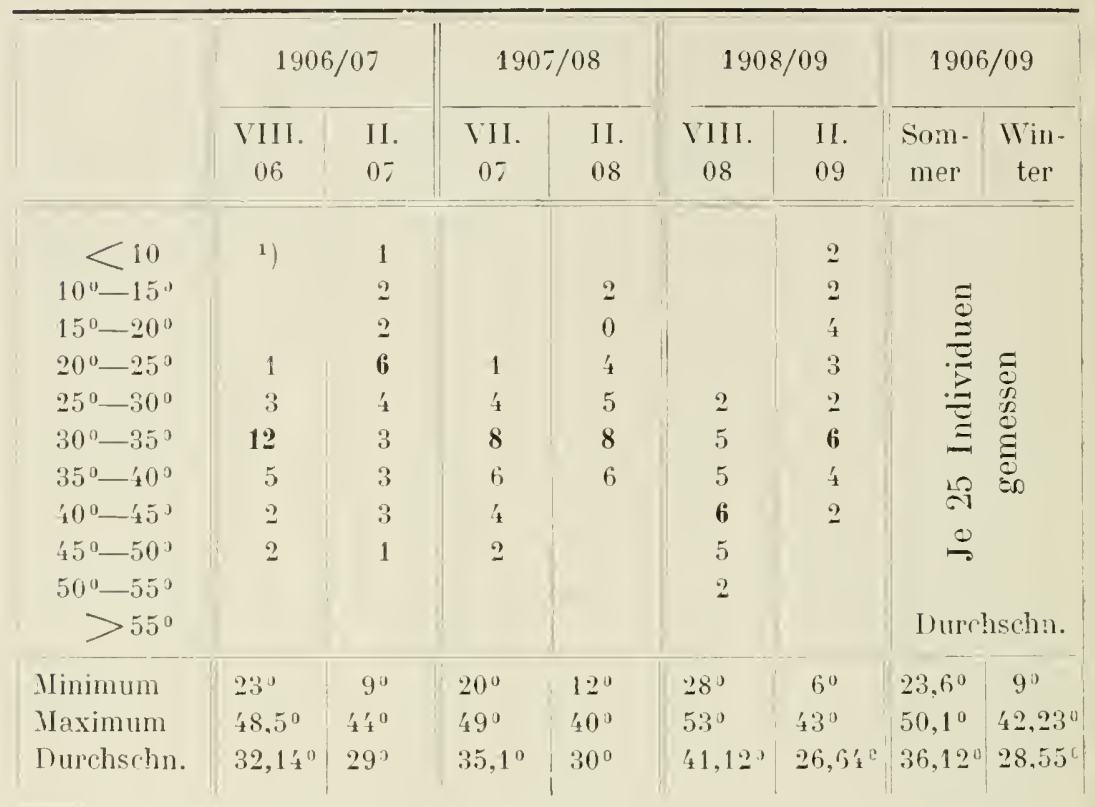

1) Anzahl der Individuen.

der 4hörnigen Indıviduen wieder ab, und ist schon im November wieder stark reduziert.

Schon wiederholt (Lit. 39) ist darauf aufmerksam gemacht worden, daß der Winkel zwischen den Antapicalhörnern im Sommer größer sei als im Winter. Durch exakte variationsstatistische Messungen (vergl. obenstehende Tabelle) habe ich diese Beobachtungen bestätigen können. Der durchschnittliche Spreizungswinkel zwischen den beiden Antapicalhörnern von 3 hörnigen Ceratien mißt im Sommer $36^{\circ}$, im Winter 28․ Auch hier haben wir es offenbar mit einer Vergrößerung des Formwiderstandes zu tun.

Wesenberg-Lund und Huber haben die Länge von Ceratien aus den dänischen und den Montigglerseen variationsstatistischen Untersuchungen unterworfen und gefunden, daß die Sommerformen immer kleiner sind als die Winterformen. Meine Messungen (vergl. Fig. 10) haben zu einer Bestätigung dieses Resultates geführt. Diese Cyclomorphose ist in Beziehung gebracht worden mit der Schwebetheorie und aufgefaßt worden als Anpassung an 
Qünge.

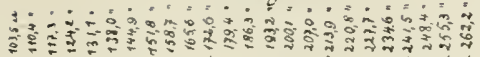
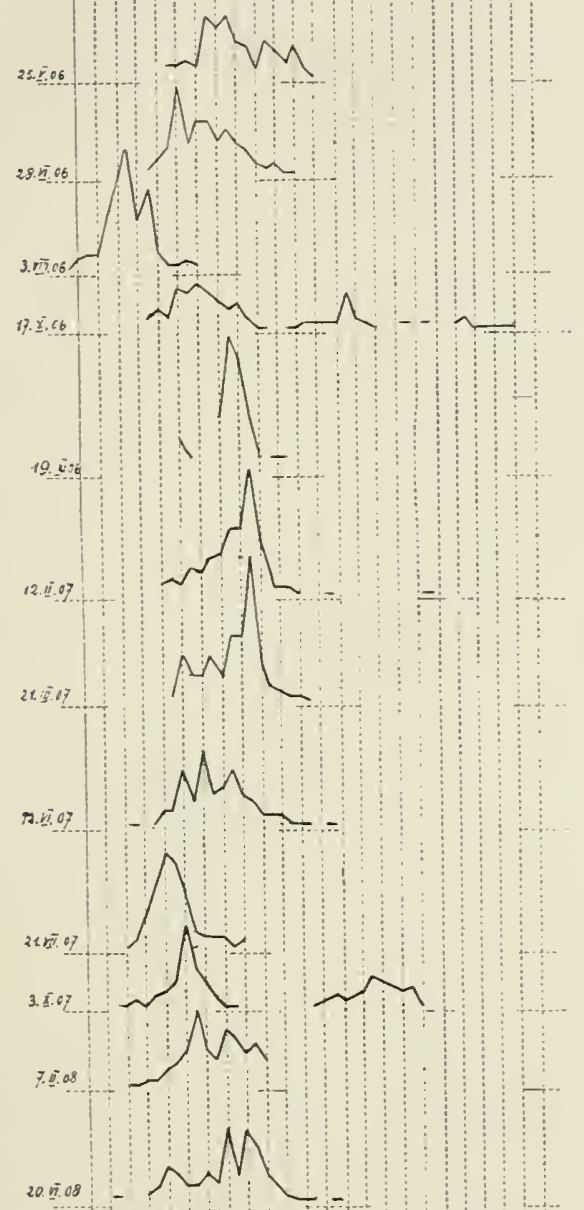

20. nies
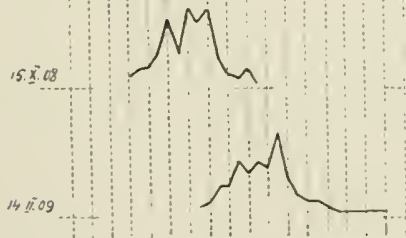

Brcite.

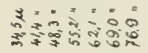
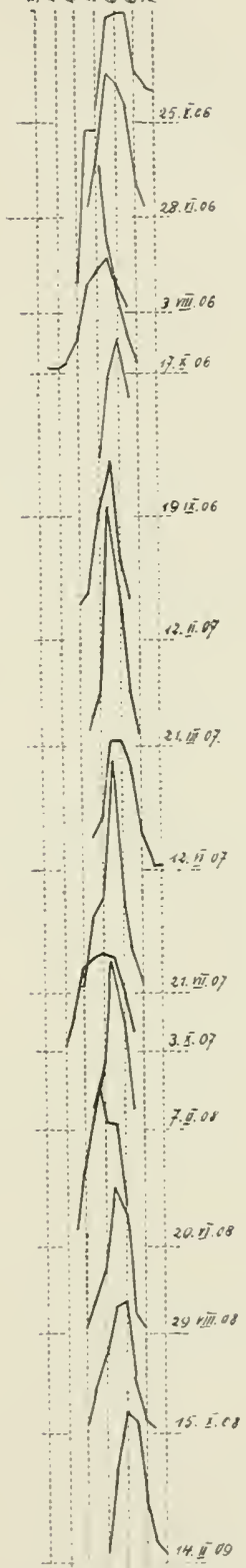

F:g. 10. Größenvariation von Ceratium hirundinella im Zugersee. 1906-1909. 
die verringerte Tragfähigkeit des warmen Wassers, dem sich Ceratium durch Verḳleinerung der spez. Oberfläche akkommodiert.

Aber welche Folge hätte die Verkleinerung von Ceratium? Vor allem verkürzen sich die Hörner. Und sind nicht gerade sie es, die den Formwiderstand in günstigem Sinne beeinflussen? Bei Notholca longispina und anderen Formen wird mit Recht die Verlängerung der Stacheln als Verstärkung. des hydrostatischen Apparates angesprochen (Lit. 84). Wenn dureh die Verkleinerung von Ceratium auch die spez. Oberfläche verkleinert wird, so hat die Verkürzung der Hörner doch gleichzeitig eine ganz wesentliche Schwächung des hydrostatischen Apparates zur Folge. Die Erklärung und Begründung der Größenvariation mit Hilfe der Schwebetheorie kann hier also nicht genügen. Gelegentliche Widersprüche zwingen förmlich, sich noch nach anderen Faktoren umzusehen. So z. B. beobachtete ich die maximale Größe des Jahres 1908 im Juni. Kurz zuvor, im Mai, war dem See durch eine „Seeblüte“ aus Pinuspollen eine Menge von organischen Stoffen zugetragen worden. Da nach KoLKwitz und MArsson Ceratium oligosaprob ist, ist es nicht ausgeschlossen, daß diese spontan in den See getragenen organischen Stoffe das Wachstum gefördert hätten. In der Tat hat Guyer im Greifensee nachgewiesen, daß die Größe von Ceratium hirundinella nicht nur mit der Temperatur variiert, sondern auch mit dem Gehalt an organischen Stoffen zunimmt.

Bemerkenswert ist das Verhalten von Ceratium in Väringen (Schweden), wo es nach Lemuermaxy gegen den Hochsommer hin eine Tendenz zum Wachstum hat. Alle diese Tatsachen beweisen, wie sehr STEUER recht hat, wenn er ausdrücklich betont, dafs zur Erklärung der Cyclomorphose neben der inneren Reibung des Wassers auch alle übrigen biologischen Faktoren in Betracht zu ziehen sind.

Im Gegensatz zu Ceratium curtum GuYer (ich bediene mich dieses Ausdruckes lediglich zur Bezeichnung des morphologischen Typus) ist die zweite Form des Zugersees schlank und zierlich. Der Körper verjüngt sich und geht so nur allmählich in die Hörner über, deren Zahl stets 4 beträgt. Die Leisten sind bedeutend schwächer entwickelt als bei curtum. Die Länge schwankt

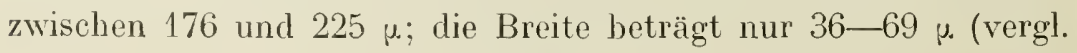
Fig. $11 \mathrm{~m} / \mathrm{o}$ ). Diese Form tritt jeweils im Spätsommer spontan auf 


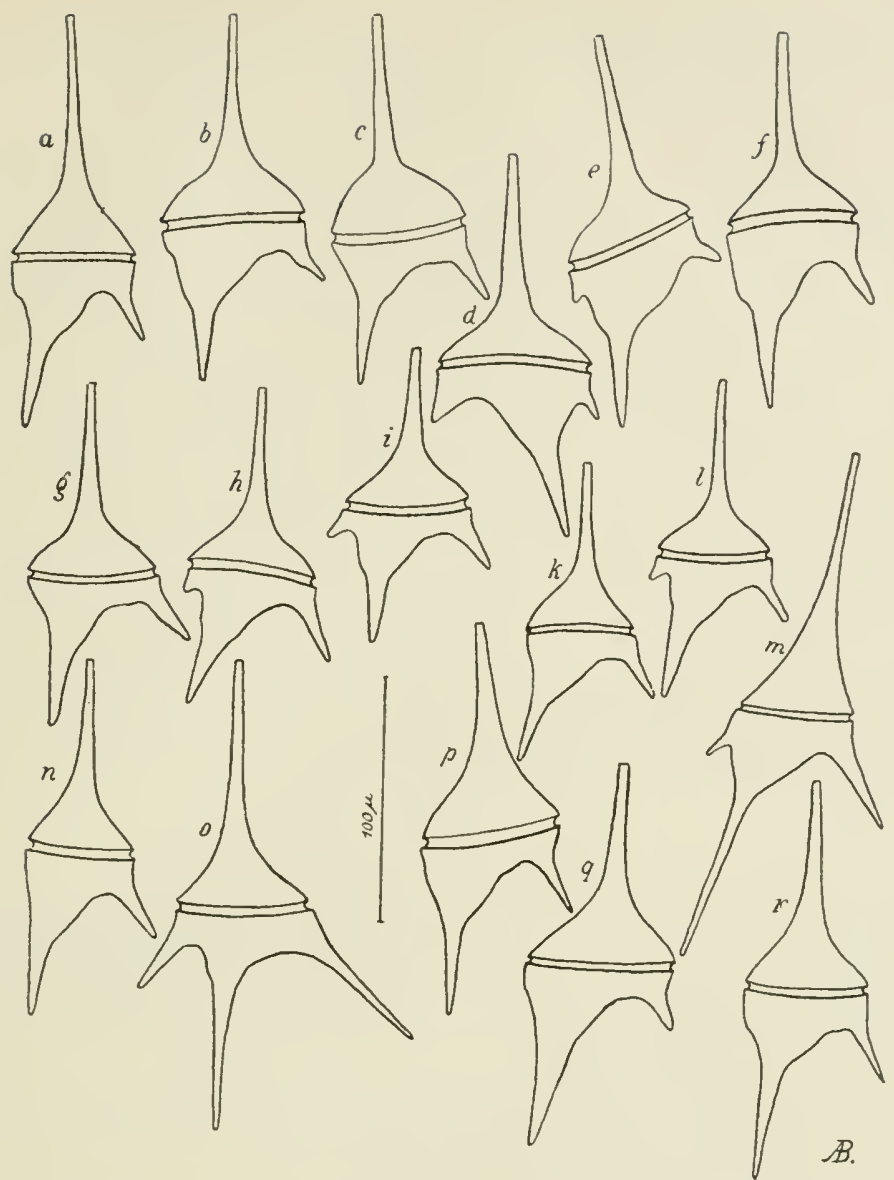

Fig. 11. Ceratium hirindinelta. Formentyp sn (1908/09.)

a) 7. Febr. 1908 . b) 1. März 1908. c, d, e) 20. Mai 1908. f) 11. Juni 1908. g, h, i) 31 . Juli 1908. k, l m) 24. Sept. 1908. n, o) 15. Okt. 1908. p) 22. Nov. 1908. q) 10. Jan. 1909. r) 14. Febr. 1909.

und erreicht ihr Entwicklungsmaximum im Oktober. Gleichzeitig mit den vierhörnigen Formen von curtum wird sie nachher seltener und ist schon im Dezember wieder vollständig verschwunden. Nur vereinzelte Cysten (vergl. Fig. 12) erinnern nachher noch an sie. Ihres zeitlich so begrenzten Auftretens wegen konnte kieine Cyclomorphose beobachtet werden.

Diese Form mit ihren schlanken Hörnern wäre augenscheinlich dem warmen Wasser vortrefflich angepaßt. Um so überraschender ist es, wenn sie erst mit eintretender Abkühlung erseheint. Gleichzeitig mit ihr erscheinen auch Clathrocystis aeruginosa und Anabaena flos aquae. Es wäre möglich, daß sie an ähnliche chemische Ver- 
hältnisse gebunden wäre wie diese, nämlich an die Gegenwart einer größeren Menge von organischen Stoffen (vergl. pag. 78).

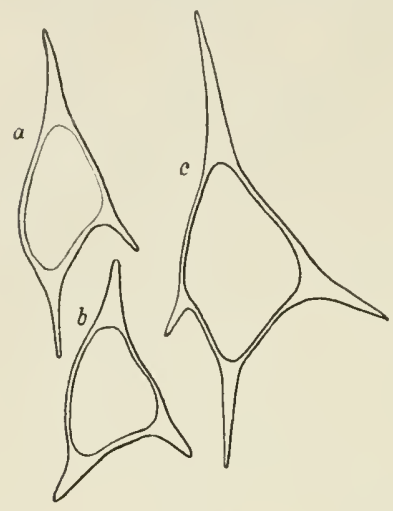

Fig. 12.

Ceratium hirundinella.

Cysten a) u. b) des perennierenden Typus, c) der Herbstform.

Peridinium tabulatum (EnrbG.) Clap. et Lachuann und Peridinium cinctum ЕнвG. erweisen sich insofern als Sommerorganismen, als sie in der warmen Jahreszeit das Maximum ihrer Entwicklung erlangen, treten jedoch nur selten in größerer Zahl auf. Doch sind sie nicht auf den Sommer beschränkt, sondern waren im Januar 1909 ebenso zahlreich wie im Sommer.

Glenodinium pusillum PÉNARD, diese kleine, zierliche Peridinee, erlangt. nie eine wesentliche Bedeutung und ist nur intermittierend, im Sommer aber stets vorhanden.

$$
\text { D i a to ma ce a } \epsilon^{\mathbf{1}} \text { ) }
$$

Die Diatomeen liefern die für den Zugersee charakteristischsten Formen. Jhr Entwicklungsmaximum fällt auf die kalte Jahreszeit, in der sie, abwechselnd mit den Dinobryonarten, über die übrigen Planktonformen dominieren.

Von Interesse ist zunächst die formenreiche Gattung Cyclotella, die wie folgt vertreten ist:

1. Nicht koloniebildend: Cyclotella comta und Cyclotella bodanica.

II. Kolonicbildend.

A. Ring- oder schraubenförmige Kolonien: Cy clotella socialis.

B. Kolonien \pm geradlinig.

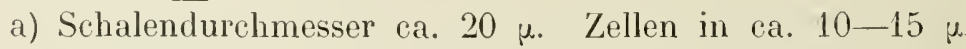
Abstand. Cyclotella Schroeteri.

b) Schalendurchmesser $4-7 \mu$; Zellen eng aneinander liegend.

1. Schalenrand stark abgerundet. Nur wenige Zellen in einer Kolonie. Chromatophoren hell.

$$
\text { Cyclotella melosiroides. }
$$

1) Revidiert durch Herra F. Meister, Horgen. 
2. Schalenrand nur wenig abgerundet. Zahlreiche Zellen in einer kettenförmigen Kolonie. Chromatophoren dunkelbraun. Cyclotella glomerata.

Cyclotella comta KTzG. var. tenuis Fricke hat einen Durchmesser von $5-32 \mu$; die Schalenseite ist konvex ausgewölbt und radial gerippt; je die zweite Rippe ist peripher verstärkt.

Diese schmucke Diatomee war zu Anfang der Untersuchungsperiode recht häufig, ist aber schon im zweiten Jahre stark zurückgegangen, war jedoch bis zuletzt noch immer zu finden. Doch sind namentlich große Exemplare selten geworden, und nur durch genaue Beobachtung war es schließlich möglich, diese Art ron cinzelnen Individuen ron der folgenden zu unterscheiden.

Cyclotella bodanica Eulenstern rar. lemanica Lemm. ist im Zugersee vereinzelt und nur selten. Sie tritt gegenüber der vorigen Form vollständig zurück. Ihre Größe schwankt zwischen 15 und $32 \mu$, läßt sich also nicht im entferntesten vergleichen mit den großen Formen des Boden- oder Genfersees.

Cyclotella socialis ScI Ütт bildet kettenförmige Kolonien, die spiralig aufgewunden sind. Im Bodensee fand Sciütт flache, scheibenförmige Kolonien; vermutlich sind dort die Schraubengänge so niedrig, daß sie in der Aufsicht als Scheiben erscheinen. Die Kolonien kommen dadurch zustande, daß von den einzelnen Zellen aus nach dem Zentrum und zu den Nachbarzellen Nadeln ausstrahlen und wahrscheinlich miteinander verwachsen. Diese Nadeln können durch Färbung von ganz frischem Material gesehen werden, wobei sich die Ungebung, nicht aber die Nadeln färben. Die Untersuchungen von Sснӥтт über den Chemismus dieser Nadeln sind resultatlos geblieben (Lit. 73).

Cyclotella socialis ist eine Winterform. Ihre höchsten Frequenzziffern erreichte sie stets zwischen den Monaten Oktober und März. Im Oktober und November 1906 nahm sie eine dominierende Stellung ein, blieb dagegen in ihrer Entwicklung während des Jahres 1907/08 stark zurück.

Cyclotella Schroeteri Lem m. bildet langgestreckte Kolonien ron 4-16 Individuen, die durch Fäden miteinander verbunden sind. Die einzelnen Zellen sind bis $20 \mu$ groß. Die Schalenseite ist nach außen gewölbt und am Rande radial gerippt.

Sie erweist sich als Ilerbstform. Doch ist sie nie zahlreich und nur zeitweise vorhanden. 
Cyclotella melosiroides LEM ist die kleinste Cyclotelle des Zugersees. Sie mißt bis $5 \mu$ Durchmesser und erhält ihren Charakter dadurch, daß ihre Schalenseiten aneinanderhaften und so starre, kettenförmige Kolonien zustande kommen.

Diese Form gehört zu den permanent vorhandenen Planktonten, entgeht jedoch ihrer Kleinheit wegen dem Planktonnetz sehr leicht. In den LoHMANsehen Filtraten ist sie stets sehr zahlreich bis in große Tiefen vorhanden. Bei $50 \mathrm{~m}$ konnte noch keine wesentliche Abnahme, namentlich der Einzelindividuen konstatiert werden. Ihre untere Grenze liegt erst bei ca. $80 \mathrm{~m}$.

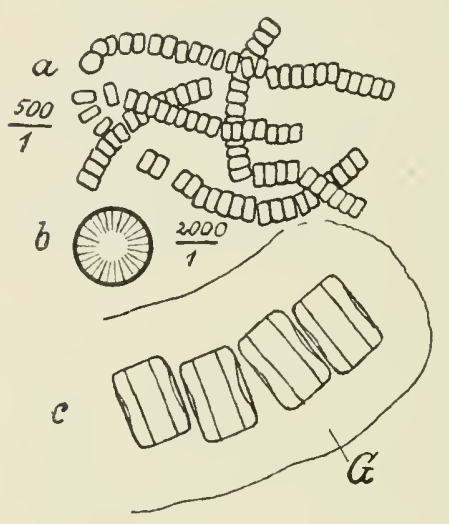

Fig. 13.

Cyclotella glomerata Bacinanx scheint im Zugersee endemisch zu sein. BACHMANN, ein ausgezeichneter Kenner des Plankton sämtlicher Schweizersowie zahlreicher ausländischer Seen, fand diese Form schon im Oktober 1898 und beschreibt sie in seinel neuesten Publikation (Lit. 96). Sie weicht sowohl in ihrer Morphologie als auch in ihrem Habitus derart von allen andern Cyclotellenarten ab, daß ich es für gerechtfertigt halte, wenn Cyclotell glomerata Bacнuлмx. sie als neue Spezies beschrieben wird.

a) Habitusbild. b) Schalenseite.

c) Gürtelbandseite. G) Gallerthülle.

Die Zellen haben einen Schalendurchmesser von $4-7 \%$ (meistens $5 \mu$ ) und sind 2,5-4 $\mu$ dick. Die Schalenseite ist schwach konkav und trägt äußerst schwache Rippen, die nur sehr schwer zu erkennen sind. Ihre Darstellung in Figur 13 ist übertrieben stark, da es schlechtweg unmöglich ist, sie zeichnerisch richtig zu Papier zu bringen.

Die einzelnen Zellen sind in einem Gallertfaden kettenartig eingebettet. Die Gallerthülle kann durch Tusche sichtbar gemacht werden, aus der sie hell herausleuchtet. Die Fäden sind zu lockeren Knäueln ineinander verwickelt.

Übergänge zu andern Arten fehlen. Am nächsten steht die fragliche Art der Cyclotella melosiroides Lemm., von der sie aber durch die Art und Weise der Koloniebildung immer noch wesentlich abweicht.

Cyclotella glomerata wurde, wie oben bemerkt, von Prof. 
Bachuax schon im Jahre 1898 gefunden. Ich beobachtete sie zuerst im Juli 1906; ron da an nahm ihre Zahl bis zum November kontinuierlich zu; in Dezember war sie wieder seltener und bald darauf vollständig versehwunden. Im Juli 1907 erschien sie wiederum und dominierte im Januar 1908. Ton 1908 auf 1909 war sie weit seltener, am zahlreichsten im August 1908. BAcнxגхx hat sie im Dezember 1904 als ,,sehr häufig" notiert. Ihre Periodizität scheint also insofern geregelt $\mathrm{zu}$ sein, daß sie frühestens im Juli erscheint, in der Zeit zwischen August und Januar ihre maximale Entwicklung erreicht, nachher wieder abnimmt und spätestens zur Zeit der Frühlingsvollzirkulation wieder versehwunden ist.

Die Cyelotellen sind also samt und sonders Herbstorganismen. Bemerkenswert mag noch sein, daß ihre leeren Schalen, zum Teil noch vollständig erhalten, zum Teil durch die Auflösung der Kieselsäure im Wasser schon angegriffen, am Grunde $(197 \mathrm{~m})$ die einzigen Zeugen organischen Lebens im See sind. Der feine Schlamm enthält zahlreiche dieser Schalen, die das Urmaterial wären zu einem späteren ,Cyclotellenton" oder einer ,Cyclotellenkreide".

Asterionella gracillima (HАхтzsch) НЕıв. Die zierlichen Sterne dieser Diatomee wechseln stark in ihrer Frequenz. Sie sind zahlreich im Frühling und erreichen ihr Entwicklungsmaximum in der Zeit unmittelbar nach der Frühlingsvollzirkulation. Im April und Nai 1906, im Juni 1908 und im März und April 1909 dominierten sic. In den Sommermonaten, meist bis tief in den Herbst hinein, fehlte Asterionella gracillima vollständig. Sie trägt als passiven Planktonten sehr häufig die Flagellate Diplosiga frequentissima.

Fragilaria crotonensis Kiтt. ist speziell im Zürichersee zum Gegenstand einer variationsstatistischen Untersuchung gemaeht. Sowohl die konstant bleibenden Größenunterschiede, wie biologische Eigenheiten veranlaßten Schröter und Vogler, ${ }^{1}$ ) vier Varietäten von Fragilaria crotonensis zu unterscheiden. Die im Zürichersee gemachten Bcobachtungen bestätigten sich in einer Reihe anderer Schweizerseen.

Da Fragilaria crotonensis im Zugersee zwar perennierend, aber in stark wechselnder Frequenz vertreten ist, mußten die variations-

1) Scuröter und Vogler, Variationsstatislische Untel'suchungen über Fragilaria crotonensis (EDw.) Kiтt. im Plankton des Zürichsees in den Jahren 1896-1901. Vierteljahrsschr. der nat. Ges. Zürich. 1901. 
statistischen Untersuchungen auf die Zeiten beschränkt werden, in denen die Bänder zahlreich genug vorhanden waren.

Fragilaria crotonensis scheint im Zugersee in 2 Formen vorzuliegen.

1. Bänder meist gedreht. Individuen alle in der Ebene der

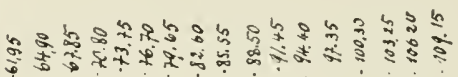

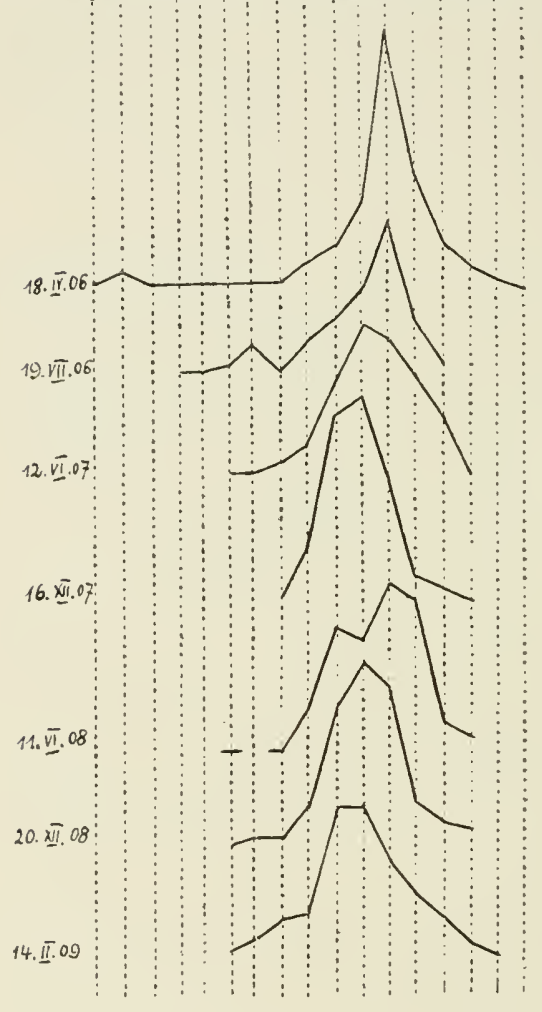

Fig. 14 .

Größenvariation von Fragilaria crolonensis. Bänder liegend, beinahe eine geschlossene Fläche bildend. Breite der einzelnen Individuen $4-6 \%$ (breitere Individuen vorwiegend) und Bandbreite

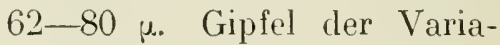
tionskurven (nur einmal beobachtet) bei $77 \mu$.

Diese Diagnose stimmt in allen Punkten überein mit derjenigen, die Schröter von der var. curta im Zürichsee gibt.

2. Bänder flach. Individuen in der Bandebene gedreht. Breite dereinzelnen Individuen $3,75-5,2$ \%. Bandbreite 80 bis $103 \mu$. Gipfel der Variationskurven zwischen 91 und 94 ..

Diese Form stimmt am besten mit der var. $s u b$ prolong a $t$ a Sch вӧтеR und Vogler überein. Zwar sind im Zürichersee die Individuen B. nur ,oft" gedreht, hier immer. Doch verbietet diese kleine morphologische Differenz nicht, die große Form von

Fragilaria crotonensis des Zugersees als var. $s u b p$ ro lo $n$ g a t a Schroeter und Vogler zu bezeichnen.

Das biologische Merkmal derselben jedoch, die auf ihr schmarotzende Chytridiacee, konnte im Zugersee nicht beobachtet werden.

Meine Beobachtungen bestätigen die Richtigkeit der ScinöterVogLERschen Auffassung der Variationskurven als Rassenmischkurven rerschiedener Varietäten, von denen 2 im Zugersee vorkommen. 
Var. curta ist weitaus seltener. Nur im Juli 1906 vermochte sie sich in der Kurve durch einen Gipfel besonders bemerkbar zu machen. (Vergl. nebenstehende Figur.) Doch ist sie durch ihren Habitus von der andern Form deutlich differenziert und neben dieser stets zu beobachten.

Var. subprolongat a war immer weitaus häufiger. Sie erreichte ihre maximale Entwicklung jeweils im Winter, war jedoch auch im Sommer nicht selten. Sie dominierte im April 1907 und während des ganzen Winters 1908/09.

Teilweise bestätigt sich auch hier die Beobachtung von Schröter und Vogler, nach der die Bandbreite während gewisser Perioden kontinuierlich abnimmt. Diese Abnahme erklärt sich durch den Teilungsmodus der Diatomeen.

Zu Anfang der Untersuchungsperiode, im April 1906, lag der

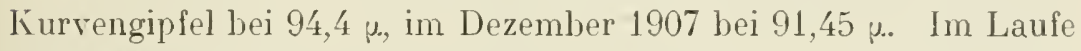
von 20 Monaten hatte sich also der Gipfel um 3 s. verschoben (vergl. auch graphische Darstellung!), oder per Jahr um 1,8 \%. Im Juni 1908 betrug die durchschnittliche Bandbreite 92,69 «, im Februar 1909 nur noch 91,45 w, was wiederum einer jährlichen Abnahme von ca. 1,8 jentspricht. Die Verschmälerung der Bänder ist also größer als im Zürichsee, wo sie nur ca. 1 \% per Jahr beträgt.

Über die Ursache der Größenzunahme vom Dezember 1907 zum Juni 1908 sind nur Vermutungen möglich. Schröter und Vogler vermuten, daß entweder Auxosporenbildung, wie bei den Cyclotellen stattfinde, oder daß Fragilaria crotonensis sich spontan wieder vergrößern könne. Die Form der Variationskurven scheint sehr für letztere Möglichkeit zu sprechen.

Tabellaria fenestrata (LYхGв.) Ku EтZG. zählt zu den seltensten Planktonformen des Zugersees. Sic wurde nur ganz vereinzelt im April und Nai 1906, im Januar und Nai 1907, im März, April und Juni 1908 und endlich im März 1909 gefunden. Sie beschränkt also ihre Anwesenheit auf die kalte Jahreszeit. Die Kolonien waren immer kettenförınig.

Synedra delicatissima W. S.r. ist in stark wechselnder Quantität im Zugersee nahezu immer vorhanden, fehlte aber im Sommer 1907 vollständig. Das Optimum der Entwicklung lag jeweils im Frühling.

Eine ganz kleine Form, var. breo is W. Sm, von bloß $15 \%$, im Maximum $25 \mu$ Länge, ließ sich stets in großer Menge in den LoHмaxschen Filtraten nachweisen (vergl. Tab. X). Sie hält sich

Archiv f. Hydrobiologie. VIII. 
im Sommer mit Vorliebe in Tiefen zwischen 10 und $20 \mathrm{~m}$ auf, wo sie dann recht häufig über die anderen Formen dominiert.

$$
\text { Conjug at a e. }
$$

Die Conjugaten bevorzugen im allgemeinen seichte Gewässer und sind deshalb im Zugersee nur von untergeordneter Bedeutung. Zwar sind die Ufer reich an ihren Vertretern; allein das offene Wasser beherbergt deren nur 2.

Cosmarium scenedesmus Delp. hat dem Zugersee fast nie gefehlt, war jedoch in der Regel nie in großer Menge vertreten. Nur einmal hat es bezeichnenderweise im seichten Untersee dominiert. Gegenüber dem Licht verhält es sich wie Sphaerocystis Schroeteri. Unter $20 \mathrm{~m}$ Tiefe ist es nur noch selten.

$$
\text { Chlorophyceae. }
$$

Bumilleria exilis KLebs ist eine nur schwer sichtbare Form. Sie besteht aus bis $15 \mu$. langen Reihen cylindrischer Zellen von ca. $2 \mu$ Dicke. (Lit. 97, pag. 389 ff. Taf. II, Fig. 17.)

Ich verdanke ihre Kenntnis den Lommansschen Filtraten. Ihrer Zartheit wegen wird sie wohl meist übersehen. Sie hält sich mit Vorliebe in der Tiefe auf und ist auf den Sommer beschränkt. ${ }^{1}$ )

Oocystis lacustris Снор. ist eine sehr kleine und wohl deshalb sehr oft übersehene Planktonchlorophycee. Die kleinen Zellen mit den lebhaft grün gefärbten Chromatophoren waren nur im Sommer und nur ganz vereinzelt vorhanden.

Nephrocytium Aghardianum NAEG. ist zeitlich und an Zahl in verschiedenen Jahreszeiten vereinzelt aufgetreten. Es macht nur einen unwesentlichen Bestandteil des Zugerseeplanktons aus, ist aber gerade wegen seiner Seltenheit bemerkenswert.

Pandorina morum (Müller) Bory erwies sich nicht als ständige Zugerseebewohnerin. Sie fand sich nur im Sommer 1908 in ganz vereinzelten Exemplaren.

Botryococcus Brannii KuEtz. fehlt im Zugersee nie. Ihre großen Kolonien schwimmen stets in großer Zahl an der Ober-

1) Im Piankton ist Bumilleria bisher nie konstatiert worden. „Beide Arten von Bumilleria (sicula und exilis) sind Bewohner feuchten Bodens, haben also ursprünglich mit dem Plankton nichts zu tun. S:e wachsen aber beide sehr fut in Nährlösungen, könnten daher auch an überschwemmten Orten sehr wohl sich entwickeln und such in Teiche oder Szen hineinkomm॰n." (Anm. w. d. Druckes nach frdl. Mitt. von Herrn Prof. KíbBs.) 
fläche. In Übereinstimmung mit zahlreichen andern Autoren beobachtete ich beständig rote und grüne Kolonien. Die roten scheinen die älteren zu sein, in deren Gallerte sich ein Farbstoff entwickelt.

Besonders stark war Botryococcus Braunii im Herbst 1906 (in Gesellschaft mit Clathrocystis aeruginosa und Anabaena flos aquae) und im Frühling 1909 entwickelt.

Sphaerocystis Schroeteri CiıOD. Die sehr schön grün gefärbten Kolonien dieser Alge sind im Zugersee fast immer, doch in stark wechsehnder Menge vertreten. Sie waren zahlreich im Februar 1907, im Februar und März 1908 und während des ganzen ersten Halbjahres 1909.

Für das Licht ist Sphaerocystis Schroeteri sehr empfindlich. Sie ist am zahlreichsten an der Oberfläche und gedeiht bis auf $20 \mathrm{~m}$ Tiefe. Darunter noch gefischte vereinzelte Exemplare haben gebleichte Chromatophoren und scheinen dem Absterben nahe zu sein.

\section{Das Zooplankton.}

$$
\text { Protozo } a \text {. }
$$

Difflugia hydrostatica ZAcH.

Acanthocystis turfacea CARTER

Coleps hirtus Еиввя.

Vorticella convallaria EnRBG.

$$
\text { Rotatoria. }
$$

Conochilus unicornis Rouss.

Floscularia mutabilis BoLtox

Asplanchne priodonta EHRBG.

Synchacta pectinata EиввG.

Hudsonella pygmaea Calmax

Mastigocerca capucina Wierz. et ZicH.

Brachionus angularis Gosse

$$
\text { var. rotunda Rouss. }
$$

Anuraea cochlearis Gosse

- aculeaia Enrig.

Anapus testudo LaUterborx

Notholca longispina Kellicot

Polyarthra platyptera Eнвв.

Triarthra longiseta Eıв

Pedalion mirum Hudsox. 
Entomostraca.

Daphnia hyalina LEYDIG

Sida crystallina LEYDIG

Leptodora hyalina LILLJEBORG

Bytotrephes longimanus LEYDIG

Bosmina longirostris O. F. M.

Cyclops strenuus Fischer

- Leuckarti Claus

Diaptomus gracilis G. O. SARS

- graciloides LILLJEBoRG

- laciniatus LILlJEBORG.

Der geringen Menge des Phytoplanktons entsprechend herrscht. Im Zugersee im Vergleich zu andern Seen auch kein reiches Tierleben, wenigstens nicht an Quantität. Qualitativ finden wir dieselben Formen wieder, wie sie aus anderen größeren präalpinen Seen bekannt sind. Interessieren mag die Tatsache, daß die von Heuscher (Lit. 35) im Aegerisee gefundenen Zooplanktonten, 22 an der Zahl, im Zugersee samt und sonders wieder vertreten sind, daß allerdings der Zugersee an Arten etwas reicher ist.

Die Beobachtung der einzelnen Spezies hat nur zur Bestätigung von Wahrnehmungen anderer Autoren an anderen Gewässern geführt. Deshalb wird es kaum als Lücke empfunden werden, wenn die Wiedergabe derselben gruppenweise und summarisch geschieht.

$$
\text { Protozoa. }
$$

Die Protozoa erweisen sich im Zugersee als perennierend. Einzig Difflugia hydrostatica bevorzugt die warme Jahreszeit.

Vorticel la conoallar $i$ a läßt sich von verschiedenen Organismen, namentlich aber von Fragilaria crotonensis und Anabaena flos aquae tragen und wohl auch ernähren (Lit. 3). Daß dieser passive Planktont an seine Träger gebunden ist, ist selbstverständlich.

Die Protozoa treten gegenüber den meisten anderen Zooplanktonten stark zurück.

Rotatoria.

Es sind nur wenige Formen dieser Gruppe, welche bei der Bildung der gesamten Planktonmenge lebhaften Anteil nehmen. 
Die ïbrigen treten entweder zeitweise stark zurück oder vermögen sich überhaupt nie zur Geltung zu bringen.

Perennierend sind Hudsonella pygmaea. Anuraea cochlearis, Notholca longispina, Polyarthra platyptera.

So $\mathrm{mm}$ e r for m e $\mathrm{n}$ : Anapus testudo, Hastigocerca capucina.

Frühlings- und H e rbst formen: Synchaeta pectinata, Asplanchne priodonta, Triarthra longiseta.

Die übrigen Formen waren so selten und nur rereinzelt vorhanden, so daß für sie keine bestimmte Periode festgestellt werden konnte. Es betrifft dies allerdings z. T. tycholymnetische Formen, wie Brachionus angularis var. rotunda und Anuraea aculeata, die als zufällig verschwemmte Uferbewohner anzusehen sind.

Die wichtigste Form unter den Rotatorien des Zugersees ist A n uraea cochlearis, die das ganze Jahr stets in großer Zahl vorhanden und eine getreue Begleiterin von Ceratium hirundinella ist, deren Existenzbedingungen sie vollständig teilt. Variationsstatistische Stichproben ergaben eine völlige Übereinstimmung mit den Resultaten von Lauterbors (Lit. 42), KRÄtzschuAr (Lit. 43) und andern: Verkürzung des Caudalstachels gegen den Sommer hin. Die morphologischen Variationen waren aber im übrigen gering. Es waren nie bemerkenswerte Abweichungen ron der typischen Form zu sehen.

Neben Anuraea cochlearis waren immer Polyarthra platyptera und die zierliche Notholca longispina recht zahlreich, während Hudsonella pygmaea zwar nie fehlte, aber doch im Sommer ihre maximale Entwicklung zeigte.

\section{Entomostraca.}

Die Entomostraken sind unter den Zooplanktonformen quantitativ am stärksten vertreten. Sie sind mit auffallender Regelmäßigkeit immer nahezu gleich zahlreich, höchstens mit der Abweichung, daß das eine Mal die Copepoden, das andere Mal die Daphniden in den Vordergrund treten.

Die wichtigste Form unter den Daphniden ist $D$ a $p$ h i a hy a li $n$ a, die nur einmal, im Dezember 1906 verschwunden, sonst aber immer vorhanden war. Sie erreicht jeweils im Sommer ihre maximale Entwicklung.

$B$ osm $i$ a lo $\log$ irostris hielt sich während des ganzen Jahres, war aber nie besonders zahlreich. Sie bevorzugt auch hier 
die kalte Jahreszeit, wie dies nach BuriardT, BALLy und andern Forschern auch anderwärts der Fall ist.

Leptodora hyalina ist ein Sommerorganismus, während Bytotrephes longimanus sich das ganze Jahr über hält. Beide Formen sind sehr selten.

Die Copepoden sind vertreten durch die Gattungen Cyclops und Diaptomus.

Die Diaptomus-Arten waren einmal, im Dezember 1906, in ganz erstaunlich großer Menge vorhanden. Die geschlechtsreifen Tiere dieser Gattung drängten Cyclops stark in den Hintergrund. Larven beider Gattungen fehlten vollständig. Ebenso war die sonst immer vorhandene Daphnia hyalin a vollständig verschwunden.

Dieses Maximum der Entwicklung, verbunden mit Geschlechtsreife, kehrte immer zur selben Zeit, zwischen Dezember und Januar wieder. Aber nie wieder ließ es sich in solchem Maße beobachten wie im Winter 1906/07.

Die Cyclops-Arten sind im allgemeinen weniger zahlreich vertreten als die vorige Gattung. Cyclops strenun $n$ überdauert den Winter neben den Diaptomiden, während $C$ y $c l$ op $\mathrm{s}$ $L$ e u $c k$ art $i$, wie überall, gegen den Winter hin verschwindet.

Eigenartig ist die Erscheinung, daß sich die Entomostraken im Winter stets deutlich rot färben. Diese Beobachtung deckt sich mit der Tatsache, daß ihre Verwandten in den Alpenseen immer rot gefärbt sind.

\section{Résumé der limnologischen Daten.}

1. G e o graph is e h e L a g e: Mitte der Längsachse des Sees $47^{\circ} 04^{\prime}$ nördl. Breite, $8^{\circ} 29^{\prime}$ östl. Länge von Greenwich.

2. Ḧ̈h en lagge: $416,7 \mathrm{~m}$ ü. М.

3. H y drographis ch e Dat e $n$ : Länge $13,5 \mathrm{~km}$; größte Breite 4,5 km; Flächeninhalt 38,236 $\mathrm{km}^{2}$; Volumen $3,21 \mathrm{~km}^{3}$. Mittlere Tiefe $84 \mathrm{~m}$; maximale Tiefe $198 \mathrm{~m}$. Mittlere Pegelschwankungen $16 \mathrm{~cm}$. Flußgebiet der Reuß.

4. Geologische Entstehung: Toter Talboden der Reuß quer zu der den Alpen vorgelagerten Molasse-Antiklinalen.

5. Thermische Daten: Temperierter See. Sprungschicht 
in 10-20 m Tiefe. Untere Grenze der jährl. Erwärmung in $100 \mathrm{~m}$ Tiefe.

6. Optisches Verhalten: Farbe No. 6-7 der Forelschen Skala. Transp a ren z: Mlaximum 16,2 m (Febr.). Minimum 3,5 m (Mai, Seeblüte). 4,2 m (Juli-August, Wärmeschichtung).

7. Biologie: Makrophytische Uferflora. Besteht aus

$\begin{array}{lrc}\text { Pleuston } & 2 \text { Spezies } \\ \text { Submerse Wasserpflanzen } & 8 & , \\ \text { Emerse Wasserpflanzen } & 2 & , \\ \text { Sumpfpflanzen der Seeflora } & 2 & , \\ \text { Sumpfpflanzen d. Grenzzone } 15 & ,\end{array}$

$$
\text { Total: } 29 \text { Spezies }
$$

Quantitativ am stärksten vertreten sind Phragmites communis und Schoenoplectus lacustris. Die übrigen Spezies treten stark zurück. Im ganzen sehr einförmige Vegetation.

\section{Plankton.}

Phytoplankton.

\begin{tabular}{lrc} 
Schizophyceae & 7 & Spezies \\
Flagellatae & 7 &, \\
Peridineae & 4 & $"$ \\
Diatomaceae & 18 & $"$ \\
Conjugatae & 2 &, \\
Chlorophyceae & 10 & $"$ \\
Tycholimnetisches Pl. & 9 & \\
\hline
\end{tabular}

Phytoplankton total $\overline{57 \text { Spezies }}$ Zooplankton.

\begin{tabular}{lr} 
Protozoa & \multicolumn{1}{c}{ 4 Spezies } \\
Rotatoria & $14 \quad "$, \\
Entomostraca & $10 \quad "$, \\
\cline { 2 - 2 } Zooplankton total & 28 Spezies \\
\cline { 2 - 2 } &
\end{tabular}

Planktonische Organismen total 8j Spezies

Phytoplanktonische Charakteristik: Typischer See. Starkes Hervortreten von Dinobryon, Ceratium und Cyclotella, zeitweise auch Fragilaria crotonensis. Starkes Zurücktreten der Schizophyceen und Conjugaten. Unter den Diatomeen fehlt ILelosira. 


\section{Durchgesehene Literatur.}

1. Aeppli, A. Beiträge zur geolog. Karte der Schweiz. Lieferg. XXXIT, 189'.

2. Ayberg, B. Limnologische Untersuchungen des Vierwaldstättersees. Festschrift der nat. Ges. Luzern. 1905.

3. Amberg, O. Beiträge zur Biologie des liatzensees. In.-Diss., Vierteljahrsschr. der nat. Ges. Zürich. 1900.

4. Apsteix, G. Das Süwasserplankton. Methoden und Resultate der quantitat. Untersuchung. Kiel und Leipzig 1896.

5. Aufsess, O. Die physikalischen Eigenschaften der Seen. Die Wissenschaft, Heft 4. Braunschweig 1905.

6. Bacuyax, H. Cyclotella bodanica und ihre Auxosporenbildung. Jahrb. f. wiss. Botanik, Bd. XXXIV. 1903.

7. - - Beitrag z. Kenntnis der Schwebeflora der Schweizerseen. Biolog. Centralblatt, Bd. XY1. 1901.

8. - - Der Speciesbegriff. Verhandl. d. schweiz. nat. Gesellschaft. Luzern 1906.

9. - - Vergleichende Studien über das Phytoplankton von Seen Schottlands und der Schweiz. Archir f. Hydrobiologie II. Planktonkunde, Bd. IIl. 190\%.

10 Bally, W. Der Obere Zürichsee. Beiträge zn einer Monographie. In.Diss. Zürich. Archiv f. Hydrobiologie und Planktonkunde, Bd. III. 190 \%

11. Branc, H. Note sur le Ceratium hirundinella O. F. M., sa variabilité et son mode de réproduction. Bull. de la soc. vaud. des sc. nat. Tol. XX. Lausanne. 188'.

12. Brumptaler, J., Die kolonieenbildenden Dinobryonarten. Verh. d. k. k. zool.-bot. Ges. in Wien. 1901.

13. Burkirdt, G., Faunist:sche und systematische Studien über das Zooplankton der größ. Seen d. Schweiz und ihrer Grenzgebiete. Revue suisse de Zoologie, T. VII. 1899.

1'́. - - Quantitative Studien über das Zooplankton des Vierwaldstättersees. Mitt. d. nat. Ges. Luzern. 1900.

15. Сиорат. Algues vertes de la Suisse. Bern 1902.

16. DüGgeLI, II. Pflanzengeographische und wirtschaftliche Monographie des Sihltales bei Einsiedeln. In.-Diss. Zürich. Vierteljahrsschr. der nat. Ges. Zürich 1903.

17. Exgler und Praxtl. Die natürlichen Pflanzenfamilien. Leipzig 1900.

18. Eyferth, B. Einfachste Lebensformen. 4. Aufl. Braunschweig 1909. 
19. Flemer. Das Lnglück in Zug. Zürich 188 \%.

20. Forel, F. A. Die Temperaturverhältnisse des Bodensees. Bodenseeforschungen. Lindau 1893.

21. - - LE Lemax. Monographie limnologique. I-III., Lausanne 1892 bis 1902 .

22. - - Handbuch der Seenkunde. Allgemeine Limnologie. Stuttgart 1901. 23. FrEY, O. Talbildung und glaciale Ablagerungen zwischen Emme und Reuß. Veue Denkschr. d. schweiz. nat. Ges. Bd. XLI. 1907.

2壬. Früh u. Schröter. Die Torfnoore der Schweiz. Bern 190'.

25. Funruxx. Beiträge zur Biologie des Neuenburgersees. Biolog. Centralblatt. Bd. XX. 1900.

26. HAECKEL, E. Planktonstudien. Jena 1890.

27. Halbfass, W. Ergebnisse neuerer simultaner Temperaturmessungen in einigen tiefen Seen Europas. Petermanns Mittlg. II. 1910.

28. Haxsgirrg, A. Prodromus der Algenflora von Böhmen. I und II. Prag 1886 und 1892.

29. Heru, A. Die Entstehung der alpinen Randseen. Vierteljahrsschr. d. nat. Ges. Zürich 189'.

30. - - Zur Katastrophe von Zug. Zürich 1887.

31. Ilecscher, J. Der Sempachersee und seine Fischereiverhältnisse. Schweiz. Fischereizeitung. 1895.

32. - - Untersuchungen über die Fischereiverhältnisse des Sarnersees. Pfäffikon 1900.

33. - - Thuner- und Brienzersee, ihre biolog. und Fischereiverhältnisse. Pfäffikon 1901.

3'. - - Untersuchungen über die biolog. und Fischereiverhältnisse des Kilöntalersees. 1903.

35. - - Beiträge zu einer Monographie des Aegerisees etc. Pfäffikon 1906.

36. Hofer, Br. Die Verbreitung der Tierwelt im Bodensee. Bodenseeforschungen. Lindau 1896.

37. Hudsox und Gosse. The Rotifera. 2 Bde. und Suppl. 1886-1889.

38. Johirssex, W. Elemente der exakten Erblichkeitslehre. Jena 1909.

39. Huber, G. Monographische Studien im Gebiete der Montigglerseen (Südtirol) etc. In.-Diss. Zürich. Archiv für Hydrobiologie. 1905.

40. - - Der Kalterersee (Südtirol). Archiv für Hỹdrobiologie 190\%.

41. Kauruaxx. Beiträge zur geolog. Karte der Schweiz. Lieferung XI, 18:2.

千2. Kirchier, O. Cryptogamenflora von Schlesien. Breslau 1878 .

43. Iі́ӓтzschiar, H. Über den Polymorphismus von Anuraea aculeata. Internat. Revue für Hydrobiologie etc. 1908.

‘'. Keissler, K. Beiträge zur Kenntnis des Phytoplanktons des Zellersees in Salzburg. Archiv für Hydrobiologie, 1910.

45. LAupert, C. Das Leben der Binnengewässer. Leipzig 1908.

46. Lauterborx, R. Der Formenkreis von Anuraea cochlearis. Verhandl. des nat.-med. Vereins Heidelberg. 1901 und 1903.

47. Lemuermux, E. Beiträge zur Kenntnis der Planktonalgen in den Ber. der biolog. Station Plön I-XI, 1893-1903.

48. - - Die Gattung Dinobryon Ehbg. Ber. der deutsch. bot. Ges. 1900.

49. Linder, Ch. Etude de la faune pélagique du lac de Bret. Rerue suisse de Zoologie. Grenève 190'.

50. Lozerox, II. La répartition verticale du Plancton dans le lac de Zürich 
de décbr. 1900 à décbr. 1901. In.-Diss. Zürich. Vierteljahrsschr. d. nat. Ges. Zürich 1902.

51. Lonuann, H. Neue Untersuchungen über den Reichtum des Neeres an Plankton und über die Brauchbarkeit der versch. Fangmethoden. Wissenschaftliche Wasseruntersuchungen. Kiel 1902.

52. Magnin, A. Les lacs du Jura. No. 1, Généralités sur la limnologie jurassienne. Lyon-Paris 1895.

53. Migula, W. Kryptogamenflora von Deutschland, Deutsch-Österreich und der Schweiz. Bd. II, Algen. Gera 1907.

54. Mühlberg, Fr. Beiträge zur Kenntnis des Zugerlandes. Jahresbericht der kant. Industrieschule Zug. 1863.

55. NäGeli, Einzellige Algen. Zürich 1849.

57. Nussbaumer, Тн. Über die Verunreinigung von Seen durch Einleitung städtischer Abwässer mit spezieller Berücksichtigung des Zugersees. Vierteljahrsschr. der nat. Ges. Zürich 1909.

58. Oltmanns, Fr. Morphologie und Biologie der Algen. 2 Bde. Jena 1904 und 1905.

59. Ostwald, W. Zur Theorie des Planktons. Biolog. Centralblatt. Bd. XX11. 1902.

60. - - Über eine neue theoretische Betrachtungsweise in der Planktonologie, insbesondere über die Bedeutung des Begriffs der ,,inneren Reibung “* des Wassers für dieselbe. Ber. der Stat. Plön. Bd. 10. 1903.

61. Pénard, Les Péridinées du Léman. Bull. de la soc. bot. de Genève. 1891.

62. Penck und Brücкner. Die Alpen im Eiszeitalter. Leipzig 1909.

63. Pfenniger, A. Beiträge zur Biologie des Zürichsees. 1n.-Diss. Zürich. 1902.

64. Ricuter, E. Die Temperaturverhältnisse der Alpenseen. Verh. des 9. deutsch. geogr. Tages zu Wien. Berlin 1891.

65. Roux, MArc. Le. Notes biologiques sur le lac d'Annecy. 1904.

66. Schilling, A. Die Süßwasserperidineen. In.-Diss. Basel. Marburg 1891. 67. Schinz und Kíeller. Flora der Schweiz, 3. Aufl. Zürich 1909.

68. Sснӧnfeldt, H. v. Diatomaceae Germaniae. Berlin 1907.

69. Sснвӧтеr und Kirchner. Die Vegetation des Bodensees. Bodenseeforschungen. Lindau 1896--1902.

70. Sснвӧтев, C. Die Schwebeflora unserer Seen. Neujahrsblatt der nat. Ges. Zürich 1897.

71. Sснröter u. Vogler. Variationsstatistische Untersuchungen über Fragilaria crotonensis etc. Vierteljahrsschr. der nat. Ges. Zürich 1901.

72. Schröter und Wilczeck, Notice sur la flore littorale de Locarno. Boll. della soc. tic. di sc. nat. Locarno 1904.

73. Хснӥтт, A. Ein neues Mittel der Koloniebildung bei Diatomaceen etc. Pringsheims Jahrb. Bd. 33. 1902.

74. Seligo, A. Hydrobiologische Untersuchungen. Danzig 1907.

75. — - Tiere und Pflanzen des Seeplanktons. Mikrolog. Bibliothek. Stuttgart 1908.

76. Steuer, A. Planktonkunde, Leipzig 1910.

77. Ule, W. Beitrag zur Instrumentenkunde auf dem Gebiete der Seenforschung. Petermanns Mittlg. Bd. 40. 1894.

78. Van Heurck, H. Synopsis des Diatomées de Belgique. Anvers 1880-1885.

79. Vogler, P. Die Anwendung der Variationsstatistik zur Untersuchung von Planktondiatomeen. Flora od. allgem. botan. Zeitung. 1902. 
80. Waldvogel, E. Der Lützelsee und das Lautiker-Ried. Ein Beitrag z Landeskunde. Vierteljahrsschr. d. nat. Ges. Zürich 1900.

81. Waruing, E. Oekologische Pflanzengeographie. Berlin 1902.

82. Weissuann, A. Das Tierleben im Bodensee. Bodenseeforschungen. Lindau 1877.

83. Wesenberg-Lund. Studier over de Danske Soers Plancton. Kopenh. 1904. S'́. - - Von der Abhängigkeit zwischen dem Bau der Planktonorganismen und dem spez. Gewicht des süßen Wassers. Biol. Centralbl. 1900.

85. - - Plancton investigations of the Danish Lakes. Kopenhagen 1908.

86. - - Grundzüge der Biologie und Geographie des Süßwasserplanktons etc. Intern. Revue der ges. Hydrobiologie und Hydrogeographie. Leipzig 1910.

87. Woltereck, R. Internationale Revue der gesamten Hydrobiologie und Hydrogeographie. Bd. 1-3, Leipzig, 1907-1910.

88. - - Weitere experimentelle Untersuchungen über Artveränderungen, speziell über das Wesen quantitativer Artunterschiede bei Daphniden. Verh. der deutsch. zool. Ges. Leipzig 1909.

89. Zacharias, O. Forschungsberichte der biologischen Station Plön. Bd. $1-11,1893-1903$.

90. - - Archir für Hydrobiologie und Planktonkunde. Bd. 1 ff. 1904. 91. - - Das Tier- und Pflanzenleben des süßen Wassers. 2 Bde. Leipzig 1891. 92. - - Das Süßwasserplankton. Leipzig 1907.

93. Zederbauer, E. Geschlechtliche und ungeschlechtliche Fortpflanzung von Ceratium hirundinella. Ber. d. deutsch. bot. Ges. Bd. 22, 1904.

94. Zsснокке, Fr. Beziehungen zwischen der Tiefenfauna subalpiner Seen und der Tierwelt von Kileingewässern des Hochgebirges. Internationale Revue, Bd. 1, 1908.

95. Guyer, O. Beiträge zur Biologie des Greifensees. Archiv für Hydrobiologie. 1910.

96. Васнмann, H. Das Phytoplankton des Süßwassers mit besonderer Berücksichtigung des Vierwaldstättersees. Mitt. der nat. Ges. Luzern, Heft VI. 1911.

97. Krebs, G. Die Bedingungen der Fortpflanzung bei einigen Algen und Pilzen. Jena 1896. 


\section{Inhalt.}

1. Physische Verhältnisse

1. Das Seebecken. . . . . . . . . . . . . . 43

A. Lage und morphologische Verhältnisse . . . . . . . . 43

B. Entstehung. . . . . . . . . . . . . . 4 4́

2. Das Wasser . . . . . . . . . . . . . 47

A. Hydrometrische Verhältnisse . . . . . . . . . . 47

B. Thermisches Verhalten . . . . . . . . . 48

C. Optisches Verhalten . . . . . . . . . . . . 5 '

D. Chemisches Verhalten ............. 61

II. Biologie . . . . . . . . . . . . . . 61

A. Die Uferregion ............... . . . 61

Allgemeiner Charakter der makrophytischen Uferflora. . . . . 61

Florenliste . . . . . . . . . . . . 66

B. Das Plankton . . . . . . . . . . . . 71

1. Fangmethoden . . . . . . . . . . 71

2. Allgemeines. - Vertikale und horizontale Verbreitung des Planktons. - Das Plankton der Zuflüsse . . . . . 73

3. Das Phytoplankton . . . . . . . . . . . . . 80

4. Das Zooplankton . . . . . . . . . . . . . . 99

III. Résumé der limnologischen Daten. . . . . . . . . . 102

Anhang: Durchgesehene Literatur . . . . . . . . . . . . . 104 


\section{Curriculum vitae.}

Am 17. Oktober 1885 in Peilau (preuß. Schlesien) geboren, kam ich im Jahre 1890 mit meinen Eltern nach deren Heimatstadt Rheinfelden, wo ich die Schulen besuchte. Im Frühling 1901 trat ich in die technische Abteilung der aarg. Kantonsschule zu Aarau ein und verließ diese Anstalt, ausgestattet mit dem Reifezeugnis, im Herbst 190'.

Hierauf besuchte ich als regulärer Studierender die damalige Abteilung VI B der eidg. technischen Hochschule in Zürich und erwarb im Sommer 1907 das Diplom eines Fachlehrers der Naturwissenschaften.

Seit Neujahr 1908 amte ich als Hauptlehrer der naturwisserschaftlich-mathematischen Fächer an der Bezirksschule Seon. In den Ferien und während meiner sonstigen freien Zeit setzte ich meine im Jahre 1906 begonnenen Studien am Zugersee fort und habe die Resultate derselben in vorliegender Dissertation zusammengefaßt, die mit Ende Fehruar 1911 abgeschlossen wurde. 



\section{Crartenskizze des Engersces.}
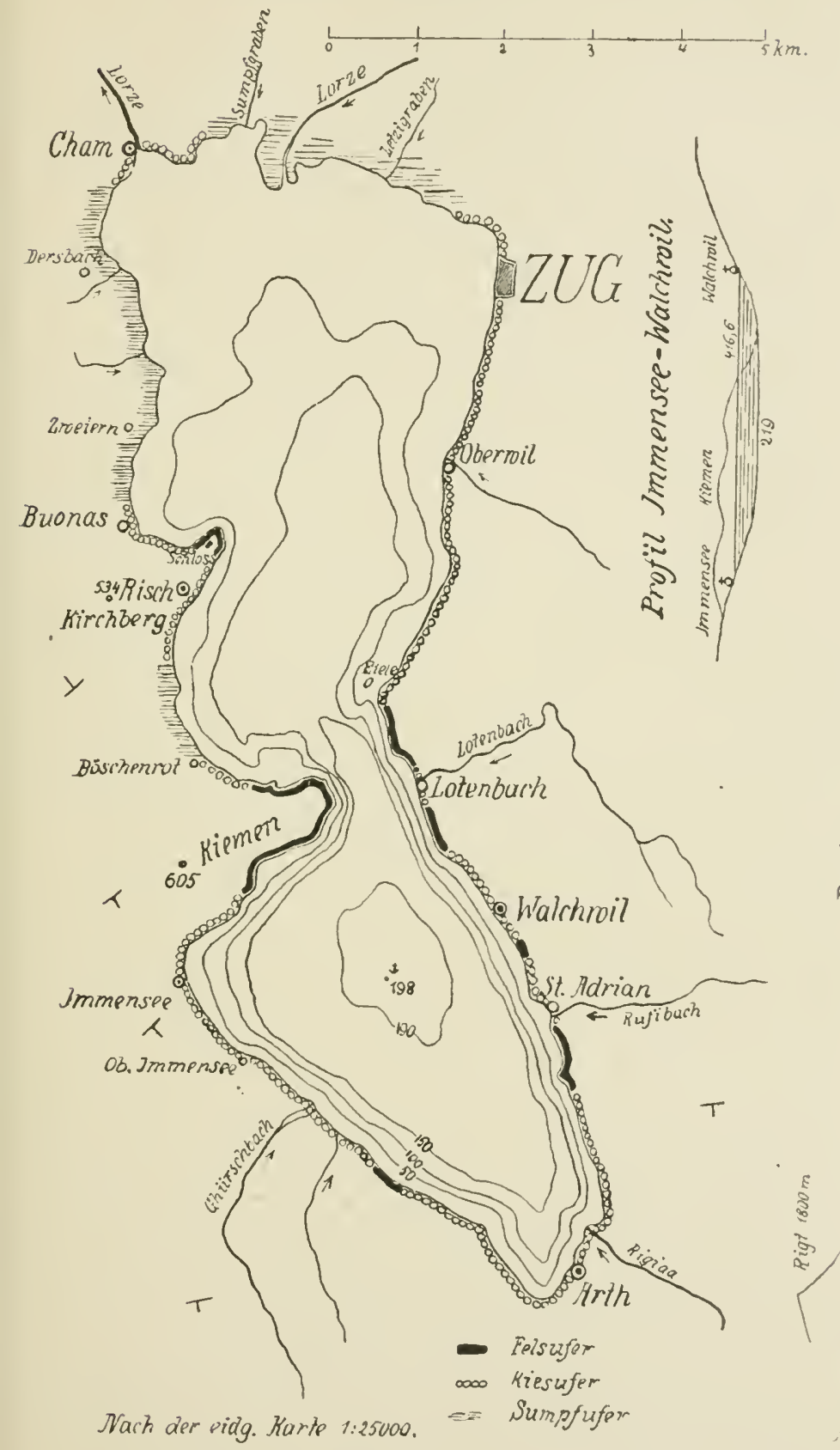

$\stackrel{5}{5}$

$\frac{2}{2}$

Fig. 1. 

ath

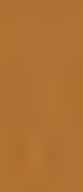

I

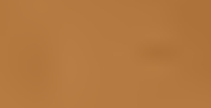

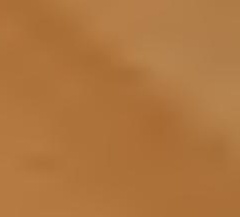

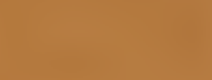

$=$

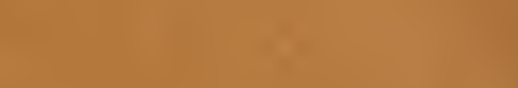

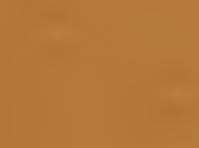

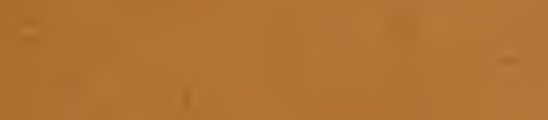

$$
\begin{aligned}
& \text { - }
\end{aligned}
$$

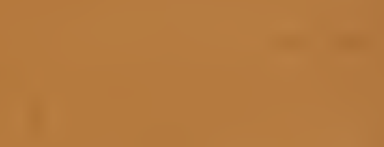

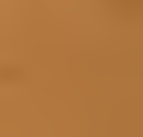

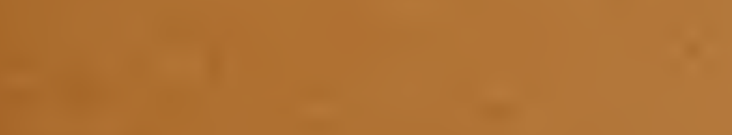

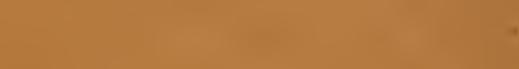

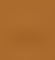

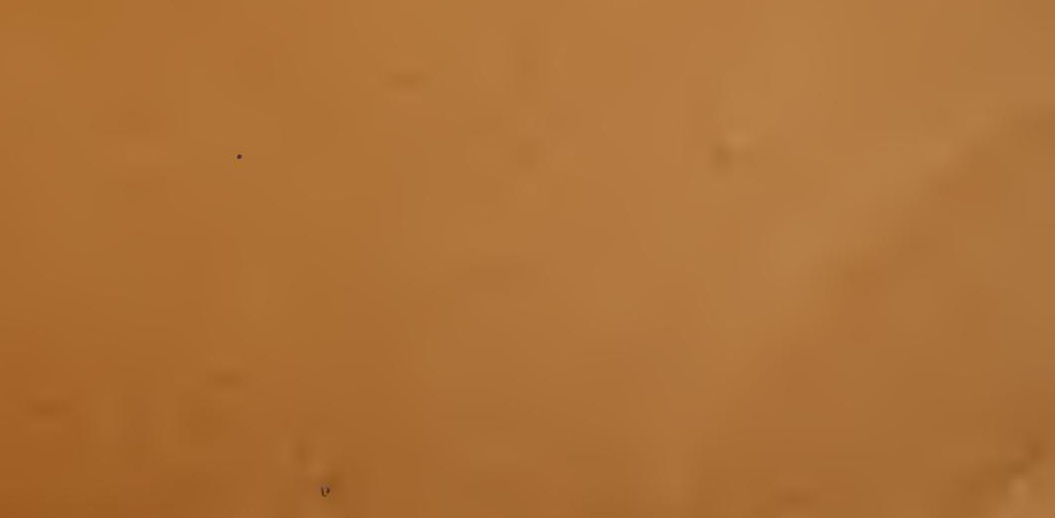


THE LIBRARY

UNIVERSITY OF CALIFORNIA

Santa Barbara

THIS BOOK IS DUE ON THE LAST DATE STAMPED BELOW. 